\title{
Common Inflammatory Mechanisms in COVID-19 and Parkinson's Diseases: The Role of Microbiome, Pharmabiotics and Postbiotics in Their Prevention
}

\author{
Valery Danilenko (D) \\ Andrey Devyatkin (D) ${ }^{2}$ \\ Mariya Marsova (D) \\ Madina Shibilova (iD ${ }^{3}$ \\ Rustem Ilyasov (D) \\ Vladimir Shmyrev ${ }^{4}$ \\ 'Vavilov Institute of General Genetics, \\ Russian Academy of Sciences, Moscow, \\ Russia; ${ }^{2}$ Central Clinical Hospital with \\ a Polyclinic CMP RF, Moscow, Russia; \\ ${ }^{3}$ Polyclinic No. I CMP RF, Moscow, \\ Russia; ${ }^{4}$ Central State Medical Academy \\ CMP RF, Moscow, Russia
}

\begin{abstract}
In the last decade, metagenomic studies have shown the key role of the gut microbiome in maintaining immune and neuroendocrine systems. Malfunction of the gut microbiome can induce inflammatory processes, oxidative stress, and cytokine storm. Dysfunction of the gut microbiome can be caused by short-term (virus infection and other infectious diseases) or long-term (environment, nutrition, and stress) factors. Here, we reviewed the inflammation and oxidative stress in neurodegenerative diseases and coronavirus infection (COVID-19). Here, we reviewed the renin-angiotensin-aldosterone system (RAAS) involved in the processes of formation of oxidative stress and inflammation in viral and neurodegenerative diseases. Moreover, the coronavirus uses ACE2 receptors of the RAAS to penetrate human cells. The coronavirus infection can be the trigger for neurodegenerative diseases by dysfunction of the RAAS. Pharmabiotics, postbiotics, and nextgeneration probiotics, are considered as a means to prevent oxidative stress, inflammatory processes, neurodegenerative and viral diseases through gut microbiome regulation.

Keywords: renin-angiotensin-aldosterone system, gut microbiome, coronavirus infection, COVID-19, neurodegenerative diseases, inflammatory processes, oxidative stress, pharmabiotics, probiotics, postbiotics, symbiotics, Lactobacillus
\end{abstract}

\section{Introduction}

Inflammation and oxidative stress are common symptoms of neurodegenerative diseases and viral infections such as Parkinson's disease and COVID-19. The immuno pathogenesis induced by SARS-CoV-2 disrupts the immune system, leading to inflammatory responses. It is reported that COVID-19 enters the cell by interacting with the angiotensin-converting enzyme II receptor ACE2 and transmembrane serine protease-2 TMPRSS2 ${ }^{1-3}$ Therefore, serum angiotensin 2 AngII levels increase as a result of its reduced degradation by ACE2. Accumulated AngII has been shown to activate inflammatory cytokines, including interferon-gamma, followed by interferon gene stimulation, resulting in increased cytokine storm and associated acute respiratory distress syndrome, as seen in severe disease. ${ }^{1,4-6}$ Moreover, activation of cytokines leads to hyperactivation of downstream signaling cascades, including nuclear transcription factor kappa B NF- $\mathrm{kB}$, which is usually activated by SARS-CoV-2 itself via pattern recognition receptors. ${ }^{1,5,7}$
Correspondence: Rustem Ilyasov Email apismell@hotmail.com 
Elevated levels of reactive oxygen species by SARS-CoV -2 can cause redox imbalances, increase the amount of lipid peroxidation products, and open the transition pores of mitochondrial permeability. Factors such as procaspase, apoptosis initiation factor, and cytochrome $\mathrm{C}$ are activated as a result of an electron imbalance in mitochondria. ${ }^{1,8-10}$ These factors contribute to further cell damage, promoting apoptotic cell death. ${ }^{1,11-13}$ Evidence is also accumulating that oxidative stress caused by increased reactive oxygen species production after hypoxia promotes the death of dopamine-containing neurons through apoptosis, which leads to the development of Parkinson's disease, a progressive neurodegenerative disorder. ${ }^{1,14-16}$

Patients diagnosed with Parkinson's disease do not have dopamine-containing neurons in the substantia nigra compacta and striatum. 6-hydroxydopamine is a well-known neurotoxin that induces neurotoxicity in the nigrostriatal dopaminergic system by inhibiting mitochondrial electronic circuit complexes I and IV and contributing to dopamine-containing neurons' degeneration. ${ }^{1,15,17-19}$ Hence, this leads to a dopamine deficiency and has a strong effect on dopaminergic receptors. Surprisingly, the neurotransmitter dopamine and its receptors have been implicated in the regulation of respiration. ${ }^{1,20-22}$ Moreover, it has been reported that 6-hydroxydopamine is produced endogenously in Parkinson's disease patients. ${ }^{1}$ The actual cause of the development and progression of Parkinson's disease is not yet known. ${ }^{1}$ Several pieces of evidence suggest that dopamine-containing neurons' death may result from elevated reactive oxygen species levels, ${ }^{1,23-25}$ mitochondrial respiratory failure, ${ }^{1,26-28}$ and activation of the NF-kB and caspase pathways. ${ }^{1,27,29,30}$

The development of inflammation and oxidative stress is often accompanied by dysbiosis or dysfunction of the gut microbiome. ${ }^{31,32}$ The gut microbiome plays a vital role in human health and disease and is, therefore, a popular area of research. $^{32,33}$ Lactobacteria $^{32,34}$ are the most important probiotic bacteria in the gut microbiome. Their positive functions include antagonism and competition with opportunistic microorganisms, improving digestion, participating in the maturation of the immune system at an early age and maintaining immunological homeostasis throughout life, neuromodulation, and the production of vitamins and other useful compounds, including antioxidant. ${ }^{32,35,36}$ These bacteria can exhibit significant antioxidant activity in the intestine of the host and promote the production of enzymes and antioxidant compounds that neutralize reactive oxygen species and prevent oxidative damage. . $^{32,37,38}$
However, most of their functions are specific for strains and are not common to several genera or species. ${ }^{32,37-39}$

The neuromodulatory potential of the human gut microbiome has been studied since the introduction of the gut-brain axis concept. Potential biomarkers that explain the neuromodulatory potential of the gut microbiome have been identified. ${ }^{32,40-42}$ Correction of the intestinal microbiome of patients with inflammatory diseases and oxidative stress characterized by an unbalanced antioxidant system should be carried out using strains of probiotic bacteria with selected antioxidant properties. The gut microbiome of people resistant to oxidative stress can be extracted to find unique strains that can be used to treat patients with chronic inflammatory diseases using a gut microbiome-based approach. ${ }^{32}$

The microbiome-gut-brain axis explains the mutual regulation of the nervous system and the gut microbiome through immunological, neurological, and neuroendocrine systems. ${ }^{43,44}$ Imbalance the microbiome-gut-brain axis under adverse factors, such as antibiotics, stress, food quality $^{45-47}$ weakens the intestinal barrier and cause the formation of pathological processes such as chronic inflammation of the gastrointestinal tract, Alzheimer's disease and neurodegenerative diseases. ${ }^{47-49}$ It has been shown that inflammation in the gastrointestinal tract increases neuroinflammatory processes, ${ }^{50,51}$ which can be a consequence of the malfunction of the renin-aldosteroneangiotensin system (RAAS). ${ }^{52,53}$ The RAAS is involved in the mechanisms of the formation of inflammatory processes in the human body. ${ }^{54,55}$ The virus COVID-19 uses ACE2 receptors of the RAAS to enter into human cells and launches neurodegenerative processes by RAAS dysfunction. ${ }^{56}$ Understanding the molecular mechanisms of pathogenesis prevents oxidative stress, inflammatory and neurodegenerative processes by correcting the gut microbiome. Probiotic bacteria with antioxidants include lacto- and bifidobacteria, as well as some species of propionic acid bacteria and enterobacteria, ${ }^{57-59}$ antimutagenic, immunomodulatory, and antitumor properties, can be used for the correction of the gut microbiome in modern methods of therapy. ${ }^{60-63}$ In modern therapy, not only do probiotics play an important role, but also postbiotics their metabolites and components. Lately, pharmabiotics have become popular in medical practice. Pharmabiotics are preparations based on probiotics and their metabolites with a known composition of active substances, deciphered mechanisms of their action, and proven efficacy and safety. ${ }^{64-66}$ 


\section{Oxidative Stress and Inflammation Oxidative Stress Characteristics}

Oxidative stress is an event caused by an imbalance between the production and accumulation of oxygen reactive species in cells and tissues and the ability of a biological system to detoxify reactive intermediates or repair damages. ${ }^{32}$ In order to maintain proper cellular homeostasis, a balance must be struck between the production and consumption of reactive oxygen. ${ }^{32}$ Oxidative stress is caused by the main reactive oxygen species: superoxide radicals, hydroxyl radicals $\mathrm{HO}^{-}$, lipid peroxide radicals, and hydrogen peroxide $\mathrm{H}_{2} \mathrm{O}_{2}{ }^{32}$

There are endogenous (product of metabolism and oxidative phosphorylation in mitochondria) and exogenous (negative external factors, as environmental pollution, radiation, drugs, bacterial infection, excessive iron intake, imbalance of the intestinal microbiome) reactive oxygen species. ${ }^{32,67-71}$ The damage of mitochondrial membranes can be because of increasing amounts of reactive oxygen species. ${ }^{32}$ Some enzymes capable of producing superoxide radicals are redox flavoproteins, xanthine oxidase, NADPH oxidase, and cytochrome P450. ${ }^{67,72}$

Reactive oxygen species can endanger cell viability by causing DNA hydroxylations, protein denaturation, lipid peroxidation, and apoptosis. ${ }^{32,73}$ Some oxygen reactive species act as cellular messengers in the transmission of redox signals and can disrupt normal cellular signaling mechanisms. ${ }^{32,68,70,71}$ Oxidative stress is a common pathogenetic mechanism of tissue damage that is accompanied by various inflammatory processes and has been linked to a number of diseases including atherosclerosis, cancer, emphysema, liver cirrhosis, arthritis, and diseases with chronic conditions such as cardiovascular, respiratory, and neurodegenerative diseases. ${ }^{32,37,71,74}$ Oxidative stress triggers neurodegenerative brain diseases, Parkinson's disease, amyotrophic lateral sclerosis, and depression. ${ }^{32,75-79}$ Neurodegenerative disorders are associated with the gut microbiome, which is involved in bidirectional communication as part of the gut-brain axis. ${ }^{32,80}$

To neutralize reactive oxygen species, the human body synthesizes antioxidant enzymes and molecules that form a natural biological antioxidant barrier. ${ }^{32}$ Antioxidants interact with reactive oxygen species and prevent the disruption of cellular functions. ${ }^{32}$ The most studied cellular antioxidants are the enzymes superoxide dismutase, catalase, and glutathione peroxidase. Less studied, but no less important, antioxidant enzymes are peroxiredoxins, sulfiredoxin, paraoxonase, glutathione S-transferase, and aldehyde dehydrogenase. ${ }^{32}$

However, reactive oxygen species are not always harmful and can be beneficial as they are used by the immune system as a way to attack and kill pathogens. ${ }^{81}$ Short-term oxidative stress may also be important in the prevention of aging by induction of a process named mitohormesis. ${ }^{82}$ Also, reactive oxygen species play an important role in cell signaling, a process called redox signaling. ${ }^{32}$

\section{Inflammatory Processes Caused by Viral Infections}

Although viruses can replicate in several cell types, the pathological outcome only appears in one or a few tissuespecific cells. ${ }^{83}$ The primary encounter with the virus occurs in mononuclear phagocytic cells such as monocytes, macrophages, and dendritic cells. ${ }^{83}$ The stimulation of the innate and adaptive immune system in response to viral infections destroys infected cells, inducing inflammation that may lead to severe pathological consequences for the host. The damage of cells caused by the immune system with a viral infection is known as virus-induced inflammation. ${ }^{83-85}$

In the earliest stages of viral infection, cytokines are produced when the innate immune defense is activated. ${ }^{83,86,87}$ Neutrophils are among the earliest types of phagocytic cells entering the site of infection and are classic markers of the inflammation process. ${ }^{83,86,87}$ The rapid release of cytokines at the site of infection initiates new reactions with far-reaching consequences, including inflammation. ${ }^{83,86,87}$ One of the first cytokines to be produced is tumor necrosis factor alpha TNF$\alpha$, which is synthesized by activated monocytes and macrophages. ${ }^{83,86,87}$ Inflammation is a very noticeable response to TNF- $\alpha{ }^{83,86,87}$ Inflammation is caused by the excessive release of antibodies, interferons, and proinflammatory cytokines, activation of the complement system, or hyperactivity of cytotoxic $\mathrm{T}$ cells.

In severe cases of certain viral infections, as in avian influenza $\mathrm{H} 5 \mathrm{~N} 1$ and coronavirus SARS-CoV-2, aberrant induction of the host immune response can elicit a flaring release of cytokines known as a cytokine storm. ${ }^{83,88}$ There is evidence for the development of progressive multifocal leukoencephalopathy, a fatal human demyelinating disease caused by the John Cunningham virus (JCV), in patients treated with Natalizumab monoclonal antibodies. ${ }^{89}$ The JCV virus is detected in $70-90 \%$ of the world's population, which can cause progressive multifocal 
leukoencephalopathy in people with weakened immune systems. ${ }^{90,91}$ About $50 \%$ of patients with viral multifocal leukoencephalopathy die within a few months after diagnosis. Several studies indicate the association of the Epstein-Barr virus (EBV) with the development of multiple sclerosis. ${ }^{89,92}$ The high incidence of multiple sclerosis in people who have undergone EBV infection may serve as evidence of the primacy of inflammatory processes in the remitting and progressive course of multiple sclerosis. ${ }^{93}$ Another virus associated with the development of multiple sclerosis is the Human Herpesvirus type 6 (HHV-6), which is involved in triggering autoimmune reactions. ${ }^{94-96}$ An inverse relationship has been found between the age of HHV-6 infection and the risk of developing multiple sclerosis in the future. The MS-associated retrovirus (MSRV) may be transactivated by external risk factors for multiple sclerosis such as HHV-6 and EBV viruses. Thus, various infectious agents (JCV, MSRV, HHV-6, EBV, and SARS-CoV-2), provoking inflammation, can be triggers of progressive neurodegenerative diseases such as Parkinson's disease, Alzheimer's disease, and multiple sclerosis. ${ }^{89,97}$

\section{Oxidative Stress and Inflammation in the Formation of Neurodegenerative \\ Diseases}

Oxidative stress and the inflammatory process it causes are able to form neurodegenerative diseases, including Parkinson's disease and multiple sclerosis. ${ }^{98}$ Chronic inflammation in the small intestine as a result of infection can lead to the activation of glial cells of the enteric nervous system, mainly nerve fibers of the autonomic nervous system, and a violation of the conformational properties of proteins, namely, $\alpha$-synuclein. Subsequently, the molecules of pathological forms of $\alpha$-synuclein trans synaptically penetrate the central nervous system along the afferent fibers of the vagus nerve and begin to exhibit prion-like properties affecting the dorsal nucleus and neurons of the caudal trunk. ${ }^{99,100}$ Disturbances in the composition of the gut microbiome are closely associated with delayed colonic transit, olfactory dysfunction, emotionalaffective disorders, and depression. ${ }^{41,101,102}$

Multiple sclerosis is a chronic autoimmune neurodegenerative disease in which the myelin sheath of nerve fibers in the brain and spinal cord is affected. ${ }^{103}$ At certain stages, the mechanisms of neurodegeneration in multiple sclerosis and Alzheimer's disease may have common features. The progression of Alzheimer's disease is associated with the accumulation of the pathological protein $\beta$-amyloid and neurofilaments and amyloid plaques formed from it in the brain. In multiple sclerosis, accumulation of the $\beta$-amyloid precursor in axons around amyloid plaques was also found, the concentration of which positively correlates with the stage of the disease $^{93}$ The neurodegenerative process and inflammation in multiple sclerosis can be enhanced in the case of mitochondrial dysfunction and oxidative injury of neurons. The $\alpha$ synuclein protein, which is responsible for the development of neurodegeneration, is also involved in the development of multiple sclerosis. The concentration of $\alpha$-synuclein increases with opticomyelitis and exacerbation of multiple sclerosis. ${ }^{104}$ There is evidence of acceleration of the neurodegenerative process under conditions of activation of systemic inflammation. ${ }^{105}$

\section{Cytokine Storm and Oxidative Stress Caused by COVID-I 9 ACE2 Receptors are the Gates for SARS-CoV-2}

Viral pandemic coronavirus infection COVID-19 (coronavirus disease 2019) caused by the Severe Acute Respiratory Syndrome-Related Coronavirus 2 (SARS-CoV-2), (https:// www.worldometers.info/coronavirus) leads to a wide range of functional consequences, ${ }^{106}$ capable of infecting most organs and systems in human, including the gut microbiome ${ }^{107-109}$ and central nervous system. ${ }^{110}$

Penetration into host cells is the first step in viral infection. The entrance gates for the coronavirus are the epithelium of the upper respiratory tract and the epithelial cells of the stomach and intestines. ${ }^{109,110}$ Dissemination of the COVID-19 virus from the systemic circulation or through the plate of ethmoid bone Lamina cribrosa can damage the brain. Changes in olfaction (hyposmia) at an early stage of the disease may indicate damage to the central nervous system and the mucous membrane of the nasopharynx as a result of the inflammatory process. ${ }^{110}$

The spike glycoprotein on the viral envelope of the coronavirus can bind to specific receptors on the membrane of host cells. Previous studies have shown that ACE2 is a specific functional receptor for SARS-CoV. ${ }^{111}$ It has been shown that SARS-CoV-2 can enter cells expressing ACE2 but not cells without ACE2 or cells expressing other coronavirus receptors such as aminopeptidase $\mathrm{N}$ and dipeptidyl peptidase 4, confirming that ACE2 is a cellular receptor for SARS-CoV-2., ${ }^{3,11}$ Further studies have shown that the 
binding affinity of the SARS-CoV-2 thorn glycoprotein with ACE2 is 10-20 times higher than that of SARS-CoV with ACE2. ${ }^{111,112}$ The probable mechanism of penetration of SARS-CoV-2 into host cells consists in binding the receptorbinding domain of the spike glycoprotein with the tip of the ACE2 subdomain. ${ }^{11-115}$ The fusion of the viral and host cell membranes is activated upon binding, and the viral RNA is subsequently released into the cytoplasm, causing infection. During SARS-CoV infection, intact ACE2 or its transmembrane domain is internalized together with the virus. ${ }^{111,116}$ The catalytically active site of ACE2 is not overlapped by the thorn glycoprotein, and the binding process does not depend on the peptidase activity of ACE2. ${ }^{111,114}$

\section{Pathogenesis of SARS-CoV-2}

Clinical manifestations of COVID-19 are variable, ranging from mild clinical manifestations to severe illness. ${ }^{117,118}$ Common clinical manifestations include headaches, loss of smell and taste, nasal congestion and runny nose, cough, muscle pain, sore throat, fever, diarrhea, and breathing difficulties. ${ }^{119,120}$ The SARS-CoV-2 virus can infect a wide variety of cells and body systems. COVID19 is best known for affecting the upper respiratory tract (sinuses, nose, and throat) and the lower respiratory tract (windpipe and lungs). ${ }^{121}$ The lungs are the organs most affected by COVID-19, as the virus gains access to host cells through the receptor for the angiotensin-converting enzyme 2 ACE2, which is most abundant on the surface of type II alveolar lung cells. ${ }^{122}$ The virus uses a special surface glycoprotein called a spike to bind to the ACE2 receptor and enter the host cell. ${ }^{123}$ COVID-19 leads to diffuse damage to the alveoli and inflammatory infiltrates containing lymphocytes in the lungs. ${ }^{124,125}$

It has been shown that multiple organs are damaged during infection with SARS-CoV-2. After the penetration of the virus, COVID-19 affects the ciliated epithelium of the nasopharynx and upper respiratory tract. ${ }^{126}$ Many people with COVID-19 are known to have neurological or mental health problems. The virus was found in cerebrospinal fluid upon dissection. The exact mechanism by which it enters the central nervous system remains unclear and may initially involve invasion of peripheral nerves, given the low levels of ACE2 in the brain. ${ }^{127-129}$ The virus can also enter the bloodstream from the lungs and cross the blood-brain barrier to gain access to the central nervous system, possibly in infected white blood cells. ${ }^{130}$ The SARS-CoV-2 virus infects the gastrointestinal tract because ACE2 is expressed in high levels in the glandular cells of the gastric, duodenal, and rectal epithelium, as well as endothelial cells and enterocytes of the small intestine. ${ }^{131}$

Although SARS-CoV-2 has a tropism for ACE2expressing airway epithelial cells, people with severe COVID-19 show symptoms of systemic hyperinflammation. The increased levels of IL-2, IL-7, IL-6, granulocytemacrophage colony-stimulating factor GM-CSF, interferongamma-induced protein 10 IP-10, chemoattractant protein of monocytes $1 \mathrm{MCP} 1$, inflammatory protein of macrophages 1 - alpha MIP-1 alpha, and tumor necrosis factor TNF-alpha, indicative of cytokine release syndrome, suggest an underlying immunopathology. ${ }^{132}$ Also, people with COVID-19 and acute respiratory distress syndrome have classic serum CRS biomarkers, including elevated levels of C-reactive protein CRP, lactate dehydrogenase $\mathrm{LDH}$, D-dimer, and ferritin. ${ }^{133}$ Systemic inflammation leads to vasodilation, which leads to inflammatory lymphocytic and monocytic infiltration of the lungs and heart. In particular, pathogenic T cells secreting GM-CSF have been shown to correlate with the recruitment of inflammatory monocytes secreting IL-6 and severe lung disease in people with COVID-19. ${ }^{125,134}$

\section{Cytokine Storm Caused by COVID-19}

The severity of the inflammation caused by COVID-19 can be attributed to the severity of the so-called cytokine storm. ${ }^{135}$ Levels of interleukin $1 \beta$, interferon gamma, interferon-induced protein 10 , and monocytic chemoattractant protein 1 were associated with the severity of COVID19 disease. Treatment has been proposed to combat the cytokine storm as it remains one of the leading causes of morbidity and mortality in COVID-19 disease. ${ }^{136}$

The cytokine storm occurs due to an acute hyperinflammatory reaction that causes clinical disease in a variety of diseases, but in COVID-19 this is associated with a worse prognosis and increased mortality. ${ }^{137}$ The hurricane causes acute respiratory distress syndrome, blood clotting phenomena such as strokes, myocardial infarction, encephalitis, acute kidney injury, and vasculitis. The production of IL-1, IL-2, IL-6, TNF-alpha, and interferon-gamma, all essential components of a normal immune response, inadvertently becomes the cause of the cytokine storm. Central nervous system cells, microglia, neurons, and astrocytes are also involved in the release of proinflammatory cytokines that affect the nervous system, and the effects of cytokine storms on the central nervous system are not uncommon. ${ }^{137,138}$ 


\section{Oxidative Stress and Systemic Inflammation in COVID-19}

Oxidative stress has recently been proposed as a key factor in COVID-19. ${ }^{139-141}$ The mechanism includes the activity of ACE2, which cleaves the octapeptide angiotensin II Ang II, which was previously generated by ACE. ${ }^{139}$ Since Ang II is a potent vasoconstrictor that plays a key role in raising blood pressure, its treatment with ACE2 induces vasodilation, enhanced by the formation of Ang 1-7, a peptide with potent vasodilating functions that are generated during this process. ${ }^{139}$ The binding of SARS-CoV-2 to ACE2 causes the virus to enter cells and, in turn, reduces the bioavailability of ACE2. ${ }^{139}$ Due to the protective function of ACE2, a decrease in its levels is associated with unfavorable clinical phenotypes, and its key role in the pathogenesis of SARSCov-2 has been described. ${ }^{139,142}$ Evidence has shown that Ang II regulates the activation of nicotinamide adenine dinucleotide phosphate NADPH oxidase ${ }^{143-146}$ and binds to angiotensin type 1 receptor AT1R. ${ }^{139,147}$ The activation of oxidase is one of the main factors in the formation of reactive oxygen species including the superoxide radical anion $\mathrm{O}^{2-}$ and hydrogen peroxide $\mathrm{H}_{2} \mathrm{O}_{2}{ }^{139}$ Therefore, the decreased bioavailability of ACE2 after SARS-CoV-2 binding allows Ang II to be available to interact with AT1R, which mediates signals for NADPH oxidase activation and induces oxidative stress and inflammatory responses that in turn contribute to the severity of COVID-19. ${ }^{139,148,149}$ It was shown, that NADPH oxidase-2 is overexpressed in hospitalized patients with COVID-19, causing increased oxidative stress. ${ }^{139,150}$

Inflammation and the immune response Coronavirus subtypes such as SARS-CoV and especially SARS-CoV -2 are capable of actively causing the so-called cytokine storm by mediating the increased production and release of proinflammatory cytokines, ${ }^{151}$ which confirms the high levels of inflammatory markers found in patients with COVID-19. ${ }^{132,139,152-155}$ Interestingly, one of the identified markers is the nonspecific C-reactive protein, a widely used biomarker for the diagnosis of sepsis. ${ }^{139}$ In addition, elevated levels of inflammatory cytokines and chemokines have been associated with the severity of COVID-19 and death. ${ }^{132,139,152-155}$ Elevated plasma concentrations of interleukins such as IL-1 $\beta$, IL-2, IL-6, IL-7, IL-8, IL-10 or IL-17, interferon $\gamma$, interferon $\gamma$-induced protein 10 , chemoattractant monocyte protein $1 \mathrm{MCP} 1$, granulocytemacrophage colony-stimulating factor, macrophage inflammatory protein $1 \alpha$ and tumor necrosis factor-alpha $\mathrm{TNF} \alpha$, among others, have been identified as inflammatory mediators in COVID-19. ${ }^{132,139,156-160}$ Importantly, macrophages and neutrophils also play a potential pathological role during SARS-CoV-2 infection ${ }^{161}$ by producing numerous reactive oxygen species including, but not limited to, $\mathrm{H}_{2} \mathrm{O}_{2}, \mathrm{O}^{2-}$, and hydroxyl radical $\mathrm{OH} .{ }^{139,162}$ Oxidative stress affects the immune system by altering immune cell function and inflammatory response. $^{139,163,164}$ The systemic cytokine profiles observed in patients with severe COVID-19 are similar to those seen in cytokine release syndromes such as sepsis, with increased production of cytokines such as IL-6, IL-8, $\mathrm{TNF} \alpha$, and other pro-inflammatory chemokines, including chemokine CC ligand 2 CCL2, CCL3 and chemokine CXC ligand 10 CXCL10. ${ }^{139}$

\section{Parkinson's Disease Accompanied by Inflammatory Processes of the Nervous System \\ Oxidative Stress and Inflammatory Processes in the Parkinson's Disease}

Parkinson's disease is a progressive nervous system disorder that affects human movement. The etiology of Parkinson's disease is still a matter of debate, ${ }^{165,166}$ while the number of clinical cases is growing steadily. ${ }^{167,168}$ Parkinson's disease is now recognized as a multisystem disease. The neurochemical and pathomorphological basis of Parkinson's disease is the death of neurons in the substantia nigra of the brain and the subsequent depletion of dopamine reserves in the striatum. ${ }^{168}$

One of the theories of the pathogenesis of Parkinson's disease suggests that, as a result of disruption of the functioning of the antioxidant system and increased formation of reactive oxygen species, oxidative stress leads to the rapid accumulation of abnormal conformations of the $\alpha$-synuclein protein in the affected neurons. The accumulation of the $\alpha$-synuclein protein in the neurons in amounts exceeding the capacity for its degradation by the proteolytic system leads to the formation of inclusion bodies in the cytoplasm, called Lewy bodies. The main component of Lewy bodies is $\alpha$-synuclein. ${ }^{168}$

The concept of conformational diseases suggests the role of the conformation of a single protein or several proteins in the initiation and progression of Parkinson's disease. ${ }^{169,170}$ Intracellular accumulation of not only $\alpha$ synuclein but also $\beta$-amyloid in the cerebral cortex was detected in patients with Parkinson's disease since stage III according to the Hoehn-Yahr scale. ${ }^{171}$ Thus, cortical 
accumulation of $\beta$-amyloid may be a determining factor in the development of the transition from early to late stages of Parkinson's disease. ${ }^{171}$

It has been shown that parasympathetic neurons of the intestinal submucosa and exogenous alimentary factors such as infectious and toxic are involved in the early stage of development of Parkinson's disease. ${ }^{99}$ There is evidence that a shift in the composition of the gut microbiome may play an important role in the initiation and progression of Parkinson's disease, as a result of the upward diffusion of $\alpha$ synuclein from the parasympathetic nervous system of the gut to the brain. ${ }^{172}$

\section{Modern Concepts of the Etiology of Parkinson's Disease}

Parkinson's disease is currently the second most common neurodegenerative disease, the incidence of which is expected to increase in the coming decades due to increased life expectancy. ${ }^{173,174}$ Although most cases of Parkinson's disease occur sporadically, a small subset of Parkinson's disease cases are hereditary and are attributed to mutations in genes associated with PARK loci including SNCA, Parkin, DJ-1, PINK1, NURR1, OMI/HTRA2, and LRRK2 associated with the disease. Many theories have been proposed for the etiology of idiopathic Parkinson's disease, ${ }^{174-177}$ but none of them provide a solid basis for explaining all symptoms. Indeed, some authors shrewdly view Parkinson's disease as a syndrome with various possible etiologies. ${ }^{174,178-180}$ While the exact cause of Parkinson's disease is currently unknown, scientists have come up with the following possible theories of this disease etiology: based on genetics, based on the environment, based on the presence of Lewy bodies, based on the presence of alpha-synuclein in Lewy bodies. According to genetics-based theory, there are certain genes that, when they become mutated, cause Parkinson's disease. However, these mutated genes are very rare, except in cases where Parkinson's runs in the family. There are also some gene variations that seem to slightly increase the risk of developing Parkinson's. ${ }^{174}$ According to environment-based theory, there are some environmental factors and toxins which may trigger Parkinson's disease, although they feel the increased risk is small. According to theory based on the presence of Lewy bodies, changes happening within the brain may also be a trigger for Parkinson's disease. Lewy bodies are proteins found in brain cells that are biomarkers of the disease and may hold the key to finding out the exact cause. ${ }^{174}$ According to theory based on the presence of alpha-synuclein in Lewy bodies, alpha-synuclein proteins form clumps in the cells which are thought to contribute to the disease. In the environmental toxin hypothesis, progressive neurodegeneration of Parkinson's disease may be caused by chronic exposure to a neurotoxin or limited exposure to initiate a self-replicating cascade of deleterious events. ${ }^{174,181}$ It is possible that the idiopathic manifestation of Parkinson's disease depends on several factors, such as individual nuclear/cytosolic protein variants, endosymbiont mitochondria, and microorganisms, which will synergistically contribute to the development of the disease. $^{174,177,182}$

Today, the theory of inflammatory processes initiated by the gut microbiome and the transmission of signals to the intestinal and central nervous systems mediating the vagus nerve is of the greatest interest. According to this theory, the gut microbiome can cause inflammation of the gut and brain, leading to immune-like Parkinson's disease. An imbalanced gut microbiome or a breakdown of the immune system can lead to gut dysbiosis, causing an inflammatory response with the partial movement of intestinal contents into the bloodstream and inevitably to distant parts of the body. ${ }^{174,183-185}$ The central nervous system is protected by the blood-brain barrier, a true barrier and an important mediator of central nervous system homeostasis, which separates the blood from the neuronal parenchyma and insulates the brain from harmful molecules. However, this blood-brain barrier can be disrupted in Parkinson's disease as a result of intestinal dysbiosis, creating a self-reinforcing loop leading to the activation and recruitment of peripheral immune cells and neurodegeneration. ${ }^{174,186-189}$

The gut microbiome associated with feces and mucous membranes also differs between people with Parkinson's disease and healthy people. ${ }^{174,190}$ In patients with Parkinson's disease, intestinal inflammation is observed, ${ }^{174,191}$ and it has been described that the infiltration of monocytes and T cells into the brain parenchyma is primarily caused by the microbiome associated with the intestinal mucosa. ${ }^{174,187,188}$ These cells appear to be required to control both local inflammatory responses in the brain and the activation of peripheral immune mechanisms. ${ }^{174,192}$ In addition, intestinal infection stimulates mitochondrial antigen presentation and autoimmune mechanisms that target cytotoxic mitochondria-specific $\mathrm{CD}^{+} \mathrm{T}$ cells to the periphery and to the brain. ${ }^{174,185}$ 
This once again indicates that mitochondria retain the ability to activate the innate immunity of neurons. ${ }^{174,182,185}$ There is also evidence that Parkinson's disease may result from the combined effects of inflammation and asynchronous vagal spread, ${ }^{174,177,187}$ being a common trigger of gut dysbiosis. ${ }^{174,177}$

Some bacteria contain immunoreactive motifs that are potent IgA inducers, as observed in multiple sclerosis and inflammatory bowel disease. ${ }^{174,193}$ This emphasizes the role of the gut microbiome as the main participant in the dynamic migration of plasma cells between the gut and the brain. ${ }^{174,194-196}$ However, it is interesting to ask why the immune-stimulating bacteria in the gut can lead to the recruitment of regulatory immune cells to the central nervous system. ${ }^{174,195,197}$ It can be explained that a breached intestinal barrier may allow gut microbiome-specific immune cells to act as systemic mediators able to penetrate the central nervous system during acute neuroinflammation. ${ }^{174,195,198}$ Recent reports show that gutderived IgA plasma cells are present in meningeal venous sinuses of slow blood flow whose fenestrations can potentially allow access of blood-borne pathogens into the brain. $^{174,194}$

\section{Role of the Raas System in the Pathogenesis of Parkinson's Disease and COVID-I 9}

\section{Involvement of the RAAS System in Systemic Inflammatory Processes}

The RAAS is a vital system of the human body, as it maintains plasma sodium concentration, blood pressure, vascular tone, and extracellular fluid volume, carries out tissue remodeling, and produces pro-inflammatory and pro-fibrotic effects. Renin and angiotensin are two of the most important constituents of RAAS. ${ }^{199}$ Renin, or angiotensinogenase, is secreted by the granular cells of the kidneys and is found in several isoforms containing 340 amino acids with antagonizing functions. ${ }^{200}$ Renin is also considered a hormone because it has a signaling function. The enzyme renin acts on its substrate to form angiotensin II, a universal effector peptide hormone. ${ }^{201}$

Angiotensin II is a versatile effector molecule with intracrine, autocrine, and paracrine roles which interacts with all body systems. ${ }^{202,203}$ Angiotensin II is one of the most powerful vasoconstrictors, regulates bronchial smooth muscle contraction, the proliferation of lung fibroblasts, and vascular permeability in the lung tissue, increases blood pressure and heart rate, stimulates plasminogen activator, inhibits the PAI-1 and PAI-2 proteins, increases the prothrombotic potential., affects the release of prostaglandins and vasoconstriction of the kidneys. ${ }^{204}$ Cyclooxygenase 1-Derived Prostaglandin E2 and its receptor have been identified as critical for angiotensindependent hypertension. Angiotensin II may promote lipogenesis, increase adipose tissue mass, and is associated with fatty inflammation, glucose intolerance, and insulin resistance. $^{201}$ In addition, angiotensin II stimulates the adrenal cortex to secrete aldosterone, a steroid hormone that maintains sodium-potassium homeostasis by stimulating the proximal renal tubules to increase sodium reabsorption and potassium release ${ }^{201}$ (Figure 1).

The most important components of the RAAS system are the angiotensin-converting enzymes ACE and ACE2, whose tasks are the maintenance of the homeostasis of the cardiovascular system, regulation of the systolic pressure, and osmotic and electrolyte balance. ${ }^{204}$ Despite the similarity of the $A C E$ and $A C E 2$ genes, the ACE and ACE2 enzymes perform different functions in the human body. Angiotensinogen is synthesized in the liver, after which it is converted by renin to angiotensin I, and then converted by an enzyme ACE into angiotensin II. Normally, ACE2 converts angiotensin II to angiotensin 1-7, which causes vasodilation, decreases blood pressure, and participates in

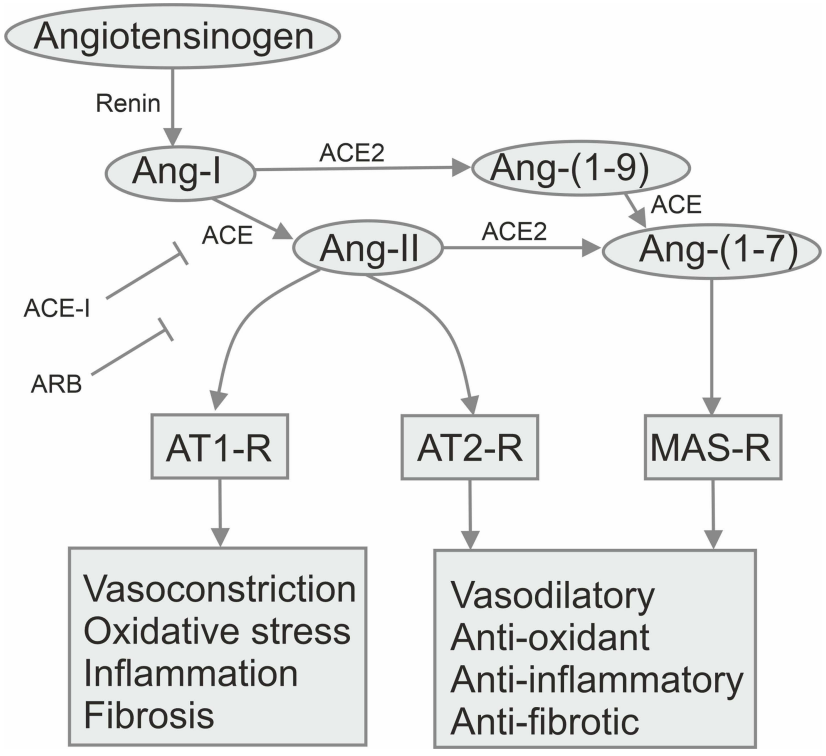

Figure I The scheme of the renin-angiotensin-aldosterone system. Abbreviations: ARB, angiotensin receptor blocker; ACE-I, ACE inhibitor; ATI-R, the angiotensin II type I receptor (ATI receptor); AT2-R, the angiotensin II type 2 receptor (AT2 receptor); Mas-R, mas receptor; Ang-(I-7), angiotensin-(I-7); Ang(I-9), angiotensin-(I-9); ACE, angiotensin-converting-enzyme; ACE2, angiotensinconverting enzyme 2; Ang-I, angiotensin I; Ang-II, angiotensin II. 
the absorption of neutrally charged amino acids in the gut. Moreover, ACE2 can interact with angiotensin I, converting it to angiotensin 1-9, which can be converted to angiotensin 1-7 under the action of ACE. ${ }^{204}$

Excessive activation of the tissue system of the RAAS is associated with cardiovascular disease, diabetes, kidney disease, preeclampsia, osteoporosis, and neurodegenerative diseases. ${ }^{53-55,205,206}$ All components of the RAAS have been identified in different areas of the brain at the level of the blood-brain barrier, and the RAAS of the brain is involved in additional brain functions and neurological disorders. $^{207,208}$

Angiotensin II through type 1 receptors activates the NADPH oxidase complex, which is involved in oxidative stress and inflammatory processes in the pathogenesis of major diseases associated with aging. In the basal ganglia and the nigrostriatal system, hyperactivation of the RAAS through the activation of the NADPH oxidase complex aggravates oxidative stress and the inflammatory response of microglia and promotes the progression of dopaminergic degeneration, which is inhibited by angiotensin receptor blockers and angiotensin-converting enzyme inhibitors. $^{209}$ An imbalance in renin and angiotensin II can lead to a wide range of chronic and acute diseases. Dopamine depletion leads to increased expression of angiotensin II, which stimulates the synthesis of dopamine, which is released via AT1 or AT2 receptors. In addition, AT1 receptors allosterically inhibit the activation of dopamine D1 receptors. Consequently, the RAAS can play an important modulating role in the flow of information from the cerebral cortex to the basal ganglia. High levels of angiotensin II may enhance neurodegeneration by activating the NADPH oxidase complex, which leads to increased production of reactive oxygen species. ${ }^{210}$ The manipulation of the RAAS, leading to an increase in the expression of ACE2, can affect endocrine functions, which can play an important role in pathological processes. ${ }^{201}$ In addition, ACE2 in the intestine functions as a partner for the amino acid transporter B0AT1. It is possible that the B0AT1/ACE2 complex in the intestinal epithelium regulates the composition and function of the gut microbiome and affects local and systemic antiviral immunity. ${ }^{211}$

Chronic activation of the RAAS leads to the onset and development of congestive heart failure syndromes, systemic hypertension, and chronic kidney disease. Excessive levels of circulating and tissue angiotensin II and aldosterone lead to a pro-fibrotic, inflammatory, and hypertrophic environment that causes remodeling and dysfunction in cardiovascular and renal tissues. ${ }^{212}$

\section{The Role of the RAAS System in the Pathogenesis of COVID-19}

Of particular interest is the interaction of SARS-CoV-2 and the RAAS via angiotensin-converting enzyme 2 ACE2, a receptor used by SARS-CoV-2 to gain access to cells. ${ }^{137}$ The RAAS system includes a carefully balanced and controlled hormone and receptor cascade involving multiple organ systems. ${ }^{137}$ The system is primarily responsible for blood pressure control, maintaining fluid and electrolyte balance, and maintaining systemic vascular resistance. $^{137,213}$

The RAAS is influenced by estrogen, cortisol, kallikrein-kinin system, Wnt/ $\beta$-catenin signaling pathways. It is assumed that the RAAS plays an important role in the pathogenesis of the coronavirus infection COVID-19. A wide range of functional consequences of COVID-19 forced us to pay closer attention to the RAAS. ${ }^{214,215}$ An imbalance in the work of the RAAS under the influence of COVID-19 can provoke an exacerbation of chronic diseases and a development of complications of the cardiovascular system. It has been shown that people with hypertension and an imbalance in ACE/ACE2 levels are likely to have a poor outcome with COVID-19 infection, even with antihypertensive drug treatment. ${ }^{216}$

To fully understand the pathophysiology of COVID19 , it is important to understand the expression and function of ACE2. ${ }^{137}$ It has been shown, COVID-19 has an affinity for the ACE2 cell membrane receptor of the RAAS. ${ }^{2,113,137,217-219}$ The receptor-binding S-protein of COVID-19 has a very high affinity for the ACE2 receptors, which it uses to penetrate human cells. ${ }^{56}$ Penetration of COVID-19 into target cells is a highly regulated multistep process, where binding to the ACE2 receptor is only the initial stage. ACE2 receptors are found on the cell membranes of the respiratory and gastrointestinal tracts, urinary, cardiovascular, and central nervous systems that are targets for penetration of COVID-19. ${ }^{2}$ However, the main and rapidly achievable target of COVID-19 is the alveolar cells of type II in the lungs, the defeat of which leads to pneumonia. ${ }^{2}$ It is assumed that the greater the number of ACE2 receptors, the more severe the COVID19 disease progresses. The identification of the membrane receptor ACE2 of the RAAS allows developing further strategies for the treatment of coronavirus infection and 
potential therapies to prevent virus penetration into target cells. $^{220,221}$

Now it is generally accepted that the ACE2 receptor protein is found on the endothelium in various human organs, including the skin, lymph nodes, thymus, bone marrow, spleen, liver, and kidneys, and the brain, as well as the mucous membranes of the mouth and nose, nasopharynx, lungs, stomach, small intestine, and colon, while ACE2 mRNA is found in almost every organ. ${ }^{137,217}$ The most notable finding is the surface expression of the ACE2 protein on alveolar epithelial cells of the lungs and enterocytes of the small intestine. ${ }^{137,217}$ This is especially important when considering the pathogenesis and clinical presentation of patients infected with COVID-19. ${ }^{137}$ Once the cell becomes infected with SARS-CoV-2, ACE2 is internalized and ACE2 expression is reduced. ${ }^{137}$ Therefore, the beneficial degradation of AngII to counterregulatory Ang (1-7) is reduced, leading to undeniable effects of AngII/AT1, ${ }^{222}$ a theory supported by the finding of elevated AngII levels in COVID-19 infected patients. $^{137,222,223}$

\section{Parkinson's Disease is Accompanied by a Violation of the RAAS System}

It is known that the RAAS system may also play a role in Parkinson's disease. ${ }^{224}$ Although the exact cause of this progressive neurodegenerative disorder of the basal ganglia remains unclear, it is assumed that inflammation and oxidative stress are key factors in the pathogenesis and progression of the disease. ${ }^{224}$ Since angiotensin II is a proinflammatory compound that can induce the production of reactive oxygen species due to the activation of the NADPH-dependent oxidase complex, this peptide can contribute to the death of dopaminergic cells. ${ }^{224}$ There are three different strategies for intervening in the pathogenesis or progression of Parkinson's disease. ${ }^{224}$ These include inhibition of the angiotensin-converting enzyme ACE, blockade of the angiotensin II type 1 receptor AT1, and stimulation of type 2 angiotensin II receptor AT2. ${ }^{224}$ Since angiotensin II is a pro-inflammatory compound ${ }^{225}$ that activates the NADPH-dependent oxidase complex, the main source of superoxide, ${ }^{226,227}$ it is possible to regulate the progression of Parkinson's disease by manipulating the RAAS system. $^{224}$

Allen et al (1992) were the first to suggest a potential link between brain RAAS and Parkinson's disease. ${ }^{228,229}$ These researchers measured a decrease in angiotensin receptor binding in the substantia nigra and striatum in the postmortem brains of patients with Parkinson's disease. ${ }^{229}$ Several studies confirm the important role of ACE in Parkinson's disease. ${ }^{229} \mathrm{ACE}$ is present in the striped pathway and basal ganglia structures. ${ }^{229-231}$ Patients with Parkinson's disease treated with perindopril, an ACE inhibitor, showed improved motor responses to the dopaminergic precursor 3,4-dihydroxy-1-phenylalanine. ${ }^{229,232} \mathrm{ACE}$ has been shown to metabolize bradykinin and thus modulate inflammation, a factor contributing to the development of Parkinson's disease. ${ }^{229,233}$ Activation of the AT1 receptor subtype by AngII promotes the development of nicotinamide adenine dinucleotide phosphate NADPH dependent oxidases, a significant source of reactive oxygen species. ${ }^{229,234,235}$ Treatment with ACE inhibitors has been shown to protect against loss of dopaminergic neurons in animal models of 1-methyl-4-phenyl-1,2,3,6-tetrahydropyridine (MPTP) and 6-hydroxydopamine (6-OHDA). ${ }^{229,236-238}$ The likely mechanism underlying this ACE inhibitor-induced protection is a decrease in the synthesis of AngII acting on the AT1 receptor subtype. ${ }^{224,229}$ It is known that the binding of AngII in the AT1 subtype activates the NADPH oxidase complex, thereby providing the main source of reactive oxygen species. ${ }^{229,239-241}$ In addition, activation of the AT1 receptor leads to stimulation of the NF-kB signaling pathway, facilitating the synthesis of chemokines, cytokines, and adhesion molecules, which are important for the migration of inflammatory cells in the area of tissue damage. ${ }^{229,242}$

The structures of the basal ganglia have a local RAAS, which indicates increased activity during dopaminergic degeneration. ${ }^{229,243-245}$ Villar-Cheda et al, ${ }^{229,246}$ reported that a decrease in dopaminergic activity caused by reserpine led to a significant increase in the expression of AT1 and AT2 receptors. ${ }^{229}$ A similar pattern was observed in 6-OH-dopaminergic dopaminergic denervation, in which a decrease in receptor expression was observed upon treatment with the dopamine precursor 1-DOPA. ${ }^{229}$ These results indicate a direct interaction between the RAAS and the dopaminergic system in the structures of the basal ganglia. ${ }^{229}$

\section{Common Elements of the RAAS System in COVID-19 and Parkinson's Disease}

The RAAS plays a key role in inflammatory processes that affect the microbiome, COVID-19 infection, and the development of Parkinson's disease. The universal role of the RAAS system in the formation of inflammatory 
processes leading to many chronic diseases accompanied by inflammatory processes requires further study and more detailed analysis in the post-COVID-19 time. Persistent dysbiosis after COVID-19 can be a factor in multisystem inflammatory syndrome with unpredictable consequences in recovered patients.

SARS-CoV-2 uses ACE2 as a receptor to infect human respiratory epithelial cells. ${ }^{247,248}$ The envelope of the SARS-CoV-2 virus contains the Spike protein with a receptor-binding region that directly binds to the extracellular domain of ACE2. ${ }^{248,249}$ The ACE2 enzyme and its ACE2 receptor are biotargets in the intestinal infection with SARS-CoV-2 and the development of Parkinson's disease. A recent study has demonstrated that the affinity of the S-protein SARS-CoV-2 for human ACE2 is even higher than that of SARS-CoV. ${ }^{112,248}$ Since SARS-CoV-2 must bind to the ACE2 receptor before entering host cells, the distribution and expression of ACE2 may be critical for the target organ of SARS-CoV-2 infection. ${ }^{247,248}$

Intestinal ACE2 is involved in the transport of amino acids, regulating the composition and function of the microbiome. It has been shown that widespread expression of ACE2 in human tissue may be associated with organ dysfunction, such as lung, kidney, and stomach, in patients with COVID-19. ${ }^{248}$ However, in Parkinson's disease, the pathogenesis of which is closely associated with old age, ACE2 plays a neurotrophic and protective role, activating the ACE2/Ang-(1-7)/Mas axis, thereby suppressing cognitive impairment. It has been shown that older people are more susceptible to COVID-19 and that older patients with COVID-19 have faster Parkinson's disease progression and higher mortality. Therefore, during the COVID-19 pandemic, it is extremely important to understand the role of ACE2 in Parkinson's disease. ${ }^{248}$

Several studies suggest that the binding of SARS-CoV -2 to the ACE2 receptor results in ACE2 depletion. This inhibits the ACE2/Ang-(1-7)/Mas receptor pathway and disrupts the balance of the RAAS system. The result is an exacerbation of severe acute pneumonia and cardiovascular complications such as myocardial injury, myocarditis, acute myocardial infarction, heart failure, and arrhythmia in patients with COVID-19. ${ }^{248,250,251}$ ACE2 plays a critical role in the evolution of COVID-19. This is not only a receptor, but it is also involved in postinfectious regulation, including the immune response, cytokine secretion, and viral genome replication. ${ }^{248,252}$ Consequently, target organs prone to developing complications from COVID-19 have some consistency in the distribution and expression levels of the ACE2 receptor $^{248}$ It is well known that ACE2 plays a key role in SARS-CoV-2 infection. ${ }^{248,253}$

Typical features of Parkinson's disease are the ubiquitous presence of alpha-synuclein-positive Lewy bodies, loss of dopamine neurons, and dystrophic Lewy neurites. ${ }^{248,254,255}$ RAAS also plays an irreplaceable role in brain function, and studies have shown that renin, ACE, Ang II, and Ang (1-7) are found in the central nervous system. They are involved in the regulation of blood pressure, water and food intake, maintenance of the bloodbrain barrier, and even in movement, learning, memory, and emotional control. ${ }^{248,256}$ Genetics, epidemiology, and clinical data indicate that overactivation of the RAAS system is one of the main elements of the pathogenesis of neurodegenerative diseases. ${ }^{248,256}$ Moreover, ACE2, including the ACE2/Ang-(1-7)/Mas axis, plays a regulatory role in neurodegenerative diseases. ${ }^{248,257}$ Dysregulation of RAAS is associated with the pathogenesis of Parkinson's disease, and drugs targeting RAAS can improve Parkinson's disease. ${ }^{248,258-260}$ The level of ACE was reduced in the cerebrospinal fluid of patients with Parkinson's disease and negatively correlated with the level of amyloid $A \beta{ }^{248,261,262}$ Moreover, electron microscopy has shown that ACE can delay fiber formation in a dose-dependent manner and reduce susceptibility to Parkinson's disease. ${ }^{248,263}$

ACE and ACE2 have also been found in the cerebrospinal fluid of patients with Parkinson's disease and multiple sclerosis. ${ }^{264}$ Zubenko et al found a decrease in the level of ACE in the cerebrospinal fluid in patients with Parkinson's disease, ${ }^{248,265}$ and Kawajiri et al revealed a decrease in ACE and ACE2 levels in the cerebrospinal fluid of patients with multiple sclerosis. ${ }^{248,266-268}$ However, there are few studies on the role of ACE2 in the pathological processes of Parkinson's disease and multiple sclerosis, and it is necessary to study the specific mechanism. ${ }^{248,269}$

\section{Lactobacillus-Based Probiotics for the Prevention of Inflammatory Processes Classification of Lactobacillus}

Lactobacillus is a genus of Gram-positive, aerotolerant anaerobes or microaerophilic, rod-shaped, non-sporeforming bacteria of the family Lactobacillaceae, order Lactobacillales, class Bacilli, division Firmicutes. Lactobacillus can grow at temperatures ranging from $2^{\circ}$ 
to $53^{\circ} \mathrm{C}$ and at $\mathrm{pH}$ levels ranging from 3 to 8 . The optimum temperature for lactobacteria is $30-40^{\circ} \mathrm{C}$, and $\mathrm{pH}$ 5.5-6.2. Lactobacillus is capable of breaking down carbohydrates, nitrates do not reduce, casein does not break down, gelatin does not liquefy, does not form indole and hydrogen sulfide. ${ }^{32}$

The Lactobacillaceae family is one of the most numerous in the bacterial world. ${ }^{270}$ The Lactobacillaceae family has high phenotypic, ecological, and phylogenetic diversity. ${ }^{271}$ Lactobacillus is divided into 26 phylogenetic groups and comprised over 260 phylogenetically, ecologically, and metabolically diverse species, the most famous of which are L. casei (L. casei, L. rhamnosus species), L. reuteri (L. reuteri, L. fermentum species), L. plantarum, L. acidophilus (L. acidophilus, L. helveticus), L. delbrueckii, L. brevis, L. salivarius. ${ }^{272,273}$

\section{Sources for Obtaining Lactobacteria}

Lactobacteria are found on plants, in various cavities of animals and humans, in dairy and fermented foods, and organic wastes. ${ }^{274}$ According to their lifestyle, lactobacteria are subdivided into free-living including ecological and plant isolates, host-adapted including invertebrate or vertebrate hosts, and nomadic species. ${ }^{275}$ Most of the species of lactobacteria found in the human intestine do not form stable populations and are classified as allochthonous, which are ingested with food. The species L. plantarum, L. casei, L. paracasei, and L. rhamnosus are not autochthonous in the classical sense but have an adaptation to the environment of the gastrointestinal tract and oral cavity that allows them to persist there for a long time. $^{276}$

The most common isolates from the gastric mucosa are Limosilactobacillus antri, Limosilactobacillus gastricus, Lactobacillus kalixensis, L. reuteri, and Lactobacillus ultunensis. The species L. crispatus, L. gasseri, Lactobacillus jensenii, Limosilactobacillus vaginalis, and Lactobacillus iners are frequently found in the vagina. ${ }^{32,277}$ A comprehensive study using whole-genome sequencing identified 86 Lactobacillus species from 52 non-human feces; 43 of these species were permanent residents in the intestines. $^{32,276}$

Lactobacteria have always been used by humans for food fermentation, are considered safe for humans, and have been classified as generally regarded as safe GRAS, which can be used as probiotics to maintain health. By releasing biologically active substances, lactobacteria can prevent pathological conditions such as decreased levels of neurotransmitters, chronic inflammation, oxidative stress, apoptosis, neurodegenerative diseases, ulcerative colitis, inflamed bowel syndrome, and allergies. ${ }^{278-282}$

\section{Anti-Inflammatory and Antioxidant Potential of Lactobacteria}

The ability of certain strains of probiotic bacteria to reduce oxidative stress is widely known and proven in vitro and in vivo. The antioxidant effect of probiotics is due to the production of antioxidant proteins and peptides (superoxide dismutase, thioredoxin, glutathione; proteins that chelate ions $\mathrm{Fe}^{2+}$ and $\mathrm{Cu}^{2+}$; vitamins (B1, B12, and others; short-chain fatty acids; refolding stress-damaged proteins; modulation of the species composition of the intestinal microbiome. $^{32,283}$ Examples of the antioxidant and antiinflammatory activity of lactobacteria (Table 1).

Due to the synthesis of biologically active compounds with antioxidant properties, lactobacteria can actively influence the general condition and antioxidant status of the organism. ${ }^{59,279,293-295}$ Some metabolites and components of lactobacteria, like exopolysaccharides and polyphenols, are signaling molecules that affect biochemical processes in the body, ${ }^{296-299}$ reduce the symptoms of dysbiosis and dysfunction of the gastrointestinal tract, ${ }^{300}$ protect the complex network of neuroglia in the nervous system $^{301-304}$ and have a positive effect on the axes of microbiome-gut-brain and microbiome-gut-lung. ${ }^{305,306}$

The antioxidant properties of lactobacteria are widely used in the manufacture of functional foods, dietary supplements, and medicines. The study of probiotic bacteria that can prevent the development of oxidative stress and its consequences is an extremely urgent task at present and is of particular importance in the context of the COVID-19 pandemic $^{307-311}$ (Figure 2).

During infection or oxidative stress in human tissues, inflammatory and autoimmune processes are activated with the participation of nuclear factor kappa B (NF-kB). The body's immune response to microbial products during infection with the participation of Toll-like receptor (TLR) leads to increased secretion of lipopolysaccharides, interleukin 1, and tumor necrosis factor-alpha (TNF $\alpha)$, which stimulate the body's antioxidant system by increasing the activity of the enzyme manganese superoxide dismutase (MnSOD), ${ }^{310,312,313}$ while chronically increased secretion 
Table I Examples of the Antioxidant and Anti-Inflammatory Activity of Lactobacteria

\begin{tabular}{|c|c|c|c|}
\hline Lactobacillus Species and Strains & Experimental Model & Benefits & Reference \\
\hline L. plantarum & Female BALB/c mice. & $\begin{array}{l}\text { Downregulation of pro-inflammatory } \\
\text { cytokines and an increase in anti-inflammatory } \\
\text { cytokines in human. }\end{array}$ & {$[277,284]$} \\
\hline L. rhamnosus CNCM I-3690 & HT-29 cells and dendritic cells. & $\begin{array}{l}\text { Clear anti-inflammatory profile and increase of } \\
\text { viability and average of worm lifespan. }\end{array}$ & {$[277,285]$} \\
\hline L. reuteri BM3630I & C57BL/6 mice. & $\begin{array}{l}\text { Anti-inflammatory role and maintaining healthy } \\
\text { conditions of mice as they aged. }\end{array}$ & {$[32,277,286]$} \\
\hline 81 lactobacteria strains of 6 different species & $\begin{array}{l}\text { E. coli MGI } 655 \text { strains carrying } \\
\text { plasmids encoding luminescent } \\
\text { biosensors pSoxS-luxand } \\
\text { pKatG-lux. }\end{array}$ & 5I strains demonstrated antioxidant activity. & {$[32,59]$} \\
\hline $\begin{array}{l}\text { L. acidophilus ATCC } 43 \text { I 2I, L. acidophilus ATCC } \\
\text { 4356, L. acidophilus 606, L. brevis ATCC } 8287 \text {, } \\
\text { L. casei YIT 9029, L. casei ATCC } 393 \text {, } \\
\text { L. rhamnosus GG }\end{array}$ & The human cancer cells. & $\begin{array}{l}\text { Heat-killed cell of L. acidophilus } 606 \text { and } L \text {. casei } \\
\text { ATCC } 393 \text { exhibited the most profound } \\
\text { inhibitory activity in the all of tested cell lines; } \\
\text { the soluble polysaccharides components of } \\
\text { L. acidophilus } 606 \text { evidenced the effective } \\
\text { anticancer activity. }\end{array}$ & {$[32,287]$} \\
\hline L. brevis MG000874 & $\begin{array}{l}\text { Albino mice exposed toD- } \\
\text { galactose-induced oxidative } \\
\text { stress. }\end{array}$ & $\begin{array}{l}\text { The treated animals displayed improvement in } \\
\text { superoxide dismutase, catalase, and } \\
\text { glutathione S-transferase in all tissues, as well } \\
\text { as glutathione in the liver and serum. }\end{array}$ & {$[32,288]$} \\
\hline L. fermentum U-2I & $\begin{array}{l}\text { C57/BL6 mice, } C \text {. elegans } \\
\text { exposed to paraquat-induced } \\
\text { oxidative stress. }\end{array}$ & $\begin{array}{l}\text { The lifespan of the } C \text {. elegans was extended by } \\
25 \% \text {. L. fermentum } U-2 \text { I ensured normal } \\
\text { coordination of movements and the safety of } \\
\text { dopaminergic neurons in the brain. }\end{array}$ & {$[32,289]$} \\
\hline Lactobacillus brevis $47 \mathrm{f}$ & $\begin{array}{l}\text { The Balb/c mice with } \\
5 \text {-fluorouracil induced } \\
\text { mucositis and oxidative stress. }\end{array}$ & $\begin{array}{l}\text { Protects the murine intestine from } \\
\text { enteropathy induced by } 5 \text {-fluorouracil and } \\
\text { prevent of lipid peroxidation in the gut tissues } \\
\text { and in the blood plasma. }\end{array}$ & [290] \\
\hline L. plantarum A7 (KC 355240, LA7) & $\begin{array}{l}24 \text { type } 2 \text { diabetic kidney } \\
\text { disease patients. }\end{array}$ & $\begin{array}{l}\text { Oxidized glutathione concentration was } \\
\text { significantly reduced; the levels of glutathione, } \\
\text { glutathione peroxidase, and glutathione } \\
\text { reductase were significantly increased; no } \\
\text { significant reduction in the 8-iso-prostaglandin } \\
\text { F2 } \alpha \text {, malon dialdehyde. }\end{array}$ & {$[32,291]$} \\
\hline L. acidophilus, L. casei & $\begin{array}{l}\text { Diabetic hemodialysis patients, } \\
28 \text { cases and } 27 \text { placebos. }\end{array}$ & $\begin{array}{l}\text { Patients who received probiotic supplements } \\
\text { showed significantly decreased plasma glucose, } \\
\text { serum insulin, assessment-estimated insulin } \\
\text { resistance and beta-cell function and HbAlc, } \\
\text { insulin sensitivity, serum C-reactive protein, } \\
\text { plasma malon dialdehyde, and total iron- } \\
\text { binding capacity. Patients showed an increase } \\
\text { in plasma total antioxidant capacity. }\end{array}$ & {$[32,292]$} \\
\hline
\end{tabular}




\section{MICROBIOME SOURCES}

\section{HUMAN DISEASES}

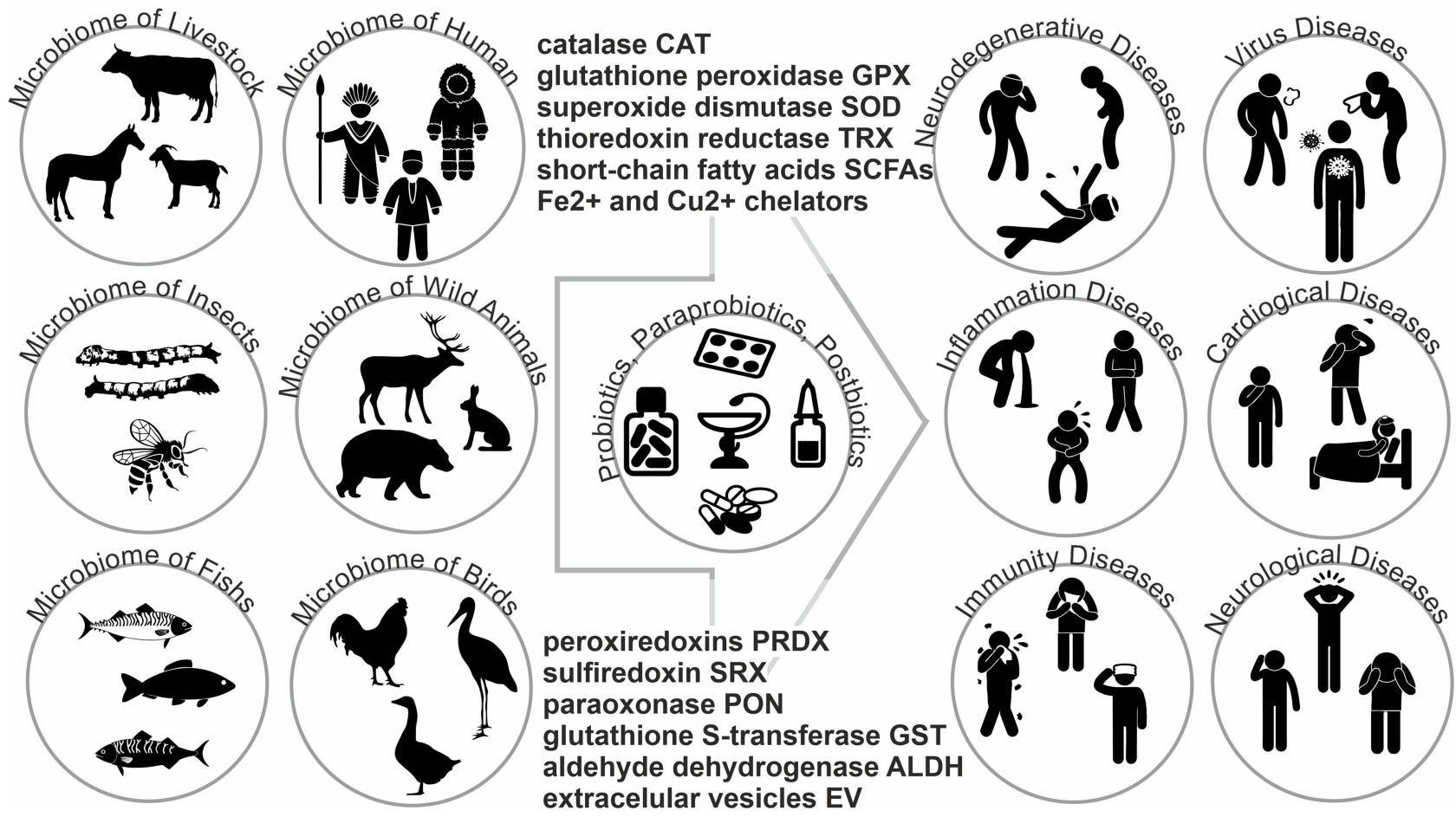

Figure 2 Lactobacteria from the different microbiome sources and the possibilities of their use as probiotics or pharmabiotics,and postbiotics in the prevention and therapy the human diseases.

of these compounds is triggered autoimmune and neurodegenerative processes in the body. ${ }^{314}$ It has been shown that lactobacteria in the gut microbiome can reduce inflammatory and autoimmune processes by activating the proliferation of regulatory T cells, decreasing the TLR activity and levels of TNF $\alpha$ and proinflammatory cytokines. ${ }^{315-318}$

Inflammation and oxidative stress in the intestine disrupt the function of the intestinal barrier, as a result of which the number of toxins and metabolites entering the bloodstream, causing inflammation and oxidative stress in organs and tissues, increases. ${ }^{319,320}$ Lactobacteria of the gut microbiome can prevent inflammation and oxidative stress in organs and tissues by reducing oxidative stress caused by hydrogen peroxide molecules, hydroxyl, and superoxide radicals in the intestine through the production of substances with antioxidant activity, such as thioredoxin reductase, superoxide dismutase, catalase, glutathione reductase, glutathione peroxidase, glutathione S-transferase, thiols (cysteine and glutathione), exopolysaccharides. ${ }^{59,278,279,321-325}$ Lactobacteria's ability to synthesize antioxidant enzymes, thiols, and exopolysaccharides varies by species and strain and determines their increased antioxidant potential. ${ }^{326-332}$
The knowledge accumulated in recent years about the antioxidant activity of lactobacteria makes it possible to formulate requirements for an ideal strain that reduces oxidative stress in the body. An ideal probiotic drug capable of reducing cytokine storms and oxidative stress in viral infections and COVID-19 should have the following characteristics. ${ }^{283,333-335}$ The probiotic strain should have direct antioxidant activity and have a complex effect on the innate immune and antioxidant systems of the human body. The probiotic strain must be a natural and complementary component of the human intestinal microbiome. The probiotic strain must have the ability to mildly mobilize the antioxidant potential of the target cells of the human body. ${ }^{334}$ The probiotic strain must be able to regulate the concentration of reactive oxygen species in the targeted organs of the body, for example, in the lungs. The probiotic strain must be capable of detoxifying the lipids, proteins, and other components damaged by reactive oxygen species in human cells. ${ }^{335}$ The probiotic strain should help restore the intestinal and blood-brain barriers that prevent the penetration of toxicants into the bloodstream and the brain. The probiotic strain should contribute to the restoration of the gut microbiome, which is an important 
organ that determines the immunomodulatory and antioxidant potential of a human. ${ }^{59,289,333-335}$ These properties are possessed by the probiotic strain of Lactobacillus fermentum U-21, which is capable of synthesizing a complex of antioxidants with proven high antioxidant activity against superoxide anion. Biologically active compounds obtained from the biomass and culture medium of the L. fermentum U-21 strain also have antioxidant activity against superoxide anion and can be used in pharmacology and medicine in the treatment of neurodegenerative diseases induced by oxidative stress, as well as in cosmetology with an increase in antioxidant status of skin. $^{59,289,290,333-335}$

\section{Microbiome Disruption in Parkinson's Disease and COVID-I 9 Altered Microbiome Composition in Parkinson's Disease}

Metagenomic studies show changes in the species composition of the gut microbiome of people with various diseases compared with healthy people. ${ }^{336-341}$ Changes in the structure of the gut microbiome can be observed in humans with diseases such as obesity and metabolic dysfunction, ${ }^{342}$ allergies, and autoimmune disorders, ${ }^{343-345}$ intestinal inflammation, irritable bowel syndrome, allergic gastroenteritis and necrotizing enterocolitis, ${ }^{346}$ type 1 and 2 diabetes, ${ }^{347}$ atherosclerosis, ${ }^{348}$ asthma $^{349}$ neurodegenerative diseases including Parkinson's disease. ${ }^{350}$ Experimental and clinical studies have revealed changes in the structure of the human gut microbiome as a result of degenerative diseases, ${ }^{281}$ depression, ${ }^{351,352}$ and autism, ${ }^{41,353}$ which are accompanied by inflammatory processes. $^{354-356}$

Currently, several studies are aimed at identifying differences in the microbiome of patients with Parkinson's disease compared to healthy control people. ${ }^{350}$ While most of them used fecal samples as a proxy for microbiome composition in the distal colon, some examined mucosal opportunistic pathogens or even saliva and nasal mucosa samples. ${ }^{350,357-359}$ The species of the Prevotellaceae family from the Bacteroidetes phylum have been implicated in the pathogenesis of inflammatory bowel disease ${ }^{193}$ and have dramatically decreased in the stool of patients with Parkinson's disease ${ }^{190,193,337,338,360-364}$ and in the sigmoid mucosa. ${ }^{350,357,365}$ It has been reported lower Bifidobacteriaceae levels in patients with Parkinson's disease. ${ }^{338,350}$ It was found a lower content of Bifidobacteriaceae both in the mucous membrane and in the feces ${ }^{350,357,366}$ and the saliva $a^{350,367}$ of patients with Parkinson's disease compared to controls, while others described the opposite. ${ }^{350,362,368,369}$ In a mouse model of Rotenone-induced Parkinson's disease, the number of Bifidobacteriaceae in the cecal and mucous membrane was reduced compared to control mice. ${ }^{350,370}$ It was found an increased content of Lactobacillaceae, ${ }^{350,362-364,366,367,369,371}$ and Erysipelotrichaceae, ${ }^{350,359,364,372}$ in the saliva and the stool of patients with Parkinson's disease compared to the control group whereas some other studies found decreased content of Lactobacillaceae $338,350,372$ and Erysipelotrichaceae $\mathrm{e}^{338,350,357,369}$ in the stool of patients with Parkinson's disease compared with healthy controls. The genera Roseburia, ${ }^{338,357,366}$ Blautia $^{338,357,366,369}$ and Faecalibacterium ${ }^{190,357,369}$ and Dorea $^{337,338,357}$ were less abundant in the stool of patients with Parkinson's disease. ${ }^{350}$ Genus Akkermansia was common in the stool of patients with Parkinson's disease. ${ }^{190,338,350,357,359,364,366,373}$ Akkermansia muciniphila can induce different $\mathrm{T}$ cell responses depending on other species present in a given microbiome. ${ }^{350,374}$ Also, it has been reported the increasing the viruses in the stool. Stool from patients with Parkinson's disease. ${ }^{338,350}$

\section{Altered Microbiome Composition in COVID-19}

It has been published that COVID-19 patients had an altered gut microbiome compared to the control group. $^{375-379}$ Using a shotgun for metagenomic sequencing of fecal samples it is described dysbiosis in the bacterial microbiome and mycobiome in patients with COVID-19 compared with healthy control patients. $^{375,376,379}$ Notably, COVID-19 patients generally had an increased number of opportunistic pathogens, a portion of the commensal microbiome that can become pathogenic in the event of a host disorder such as dysbiosis or a compromised immune system..$^{379,380}$ Opportunistic pathogens included Clostridium hathewayi, Actinomyces viscosus, and Bacteroides nordii at the time of hospitalization with SARS-CoV-2. ${ }^{379}$ It is shown that the number of specific opportunistic pathogens, Collinsella aerofaciens and Morganella morganii spp. was increased in fecal samples with a high level of active viral transcription and 
replication of SARS-CoV-2 compared to fecal samples from healthy patients. ${ }^{376,379}$ Conversely, fecal samples with low or no SARS-CoV-2 infectivity had elevated levels of bacteria belonging to Parabacteroides, Bacteroides, and Lachnospiraceae that produce shortchain fatty acids, especially butyric acid. ${ }^{379}$ Short-chain fatty acids are known to play an important role in enhancing host immunity. Thus, these data suggest that opportunistic pathogens pose a threat to both a decrease in host immunity and opportunistic infections in proportion to the burden of SARS-CoV-2. ${ }^{379}$ In another cohort, reduced bacterial diversity was described in fecal samples from patients with COVID-19 compared to healthy controls by analyzing the V3-V4 region of the 16S rRNA gene. ${ }^{377,379}$ The study also found an increase in opportunistic pathogens such as Streptococcus, Rothia, Veillonella, and Actinomyces among COVID-19 patients. ${ }^{379}$

One gut microbiome study based on 16S rRNA in COVID-19 patients showed that alpha diversity in these patients was lower than in healthy controls and the abundance of four genera: Streptococcus, Clostridium, Lactobacillus, and Bifidobacterium, tended to increase, but five other genera, Bacteroides, Roseburia, Faecalibacterium, Coprococcus, and Parabacteroides, showed lower numbers in COVID-19 patients than in controls. ${ }^{378,379}$ Dysbiosis with decreased levels of Lactobacillus and Bifidobacterium has been observed in some COVID-19 patients. ${ }^{378,379,381}$ It was shown that the composition of the fecal mycobiome in 30 hospitalized patients with COVID-19 was heterogeneous; however, some had been enriched with the fungal pathogens Candida and Aspergillus spp. compared to control. ${ }^{375,379}$

It has shown the potential importance of Firmicutes species in the severity of SARS-CoV-2 infection. It is assessed the association between the fecal microbiome and the severity of COVID-19 in seven patients. ${ }^{379,382}$ A total of 23 bacterial taxa were significantly associated with the severity of COVID-19, and the majority (15 of 23) was of the type Firmicutes. Of these, eight classes (Coprobacillus, Clostridium ramosum, and C. hathewayi) were positively correlated with the severity of the disease, and seven were negatively correlated. ${ }^{375,379,383}$

The feces of COVID-19 patients were enriched with opportunistic pathogens known to cause bacteremia, including Clostridium hathewayi, Actinomyces viscosus, and Bacteroides nordii ${ }^{375,376}$ due to the disturbed microbial ecology of the intestine and resistance to colonization. ${ }^{376,384,385}$ It showed a similar pattern of gut microbiome dysbiosis in patients with COVID-19. ${ }^{376,386}$ The number of butyrate-producing bacteria such as Faecalibacterium prausnitzii, Clostridium butyricum, Clostridium leptum, and Eubacterium rectale was significantly reduced in patients with COVID-19 compared with the control group. ${ }^{376,386}$ When patients with COVID-19 were compared to the control group, the number of common opportunistic microorganisms Enterobacteriaceae and Enterococcus was significantly higher. ${ }^{376,386}$ At the birth level, the genera of Streptococcus, Rothia, Veillonella, and Actinomyces (all opportunistic microorganisms) were enriched with feces from patients with COVID-19, while the deliveries of Romboutsia, Faecalibacterium, and Fusicatenibacter were enriched with feces from healthy people. ${ }^{376,377}$ The content of opportunistic bacteria Coprobacillus, Clostridium ramosum, and Clostridium hathewayi in the feces of patients during hospitalization was associated with COVID-19 disease, while the antiinflammatory bacterium Faecalibacterium prausnitzii showed a negative correlation, ${ }^{375}$ which suggests a baseline calibration of the intestinal microbe-host immunity, thereby influencing the disease response to SARSCoV-2 infection. ${ }^{376}$ Evidence is accumulating that a significant number of COVID-19 patients experienced systemic and organ-specific disease during follow-up after resolution of the disease, including fatigue, muscle weakness, sleep problems, anxiety, depression, diarrhea, and poor glycemic control. ${ }^{132,376,387-389}$ The long-term dysbiosis of the gut microbiome is also consistently observed in patients after COVID-19, ${ }^{375,390-392}$ which means that the gut microbiome is closely related to the health of the host. ${ }^{376}$

\section{The Role of Microbiome in the Prevention and Treatment of COVID-19 and Parkinson's Disease}

The microbiome and its specific components, including lactobacteria, determine the formation and maintenance of innate and acquired immunity, as well as antioxidant potential. Violation of the composition (signature) of the microbiome - dysbiosis, leads to increased sensitivity to infectious and neurological diseases. The immune status of different groups of the population has different indicators: first of all, patients with type II diabetes, autoimmune diseases, AIDS. ${ }^{32}$ Stressful conditions (social, physical, chemical, nutritional changes) always lead to dysbiosis of the microbiome and a decrease in immune homeostasis. 
Analysis of the state of the microbiome is an important biomarker of the state of the immune and nervous system and susceptibility to neurological and infectious diseases as COVID-19. ${ }^{32,393,394}$ The intestinal microbiome influences the host organism due to its ability to synthesize various biologically active compounds. The whole system functions as a single network. A breakdown in one link leads to the failure of the entire system $^{32,41,319,393,395}$ (Figure 3).

The gut microbiome is an organ that integrates the interaction of all body systems and protects against stress factors and infections, including virus infections like COVID-19. It has been shown the coronavirus infection COVID-19 leads to disruption of the gut microbiome and development of dysbiosis. ${ }^{396}$ Further, dysbiosis leads to inflammation and oxidative stress, which increases the rate and risk of developing chronic diseases.

The symbiotic gut microbiome is important for human health, physiology, and metabolism. ${ }^{343,397,398}$ The biodiversity of the microbiome of a healthy adult is counted in hundreds of different types of microorganisms. ${ }^{399,400}$ More than 600 different species of bacteria related to each other by symbiotic and antagonistic interactions can be found in the gut microbiome of an adult human. ${ }^{324,401}$ The composition of the gut microbiome differs between individuals, although Bacteroidetes, Firmicutes, Actinobacteria, Proteobacteria, Fusobacteria, and Verrucomicrobia are usually predominant in the human gut. ${ }^{402}$ The composition of the human gut microbiome can be influenced by factors such as food quality, smoking, age, body weight, health status, antibiotics, and habitat. ${ }^{403,404}$ The gut microbiome synthesizes many biologically active substances, such as amino acids, vitamins, neurotransmitters, hormones, and hormone-like substances that can affect the human body, penetrating the bloodstream through the intestinal barrier. $^{400,405-410}$ The gut microbiome functions as a "virtual endocrine organ" that regulates metabolic signaling pathways of the human body. ${ }^{398,410-412}$

Some probiotics and postbiotics, as a result of modulation and restoration of the gut microbiome, reduce dysbiosis, systemic inflammation, and oxidative stress in humans. ${ }^{413,414}$ There is evidence that probiotics and postbiotics have potential in the prevention and treatment of Parkinson's disease, as they support the composition of the gut microbiome, reduce oxidative stress and inflammation, and produce essential biologically active metabolites. ${ }^{47,49}$ As a result of reducing dysbiosis with the use of probiotics, the protective function of the intestine is restored, the systemic inflammatory process is decreased, and the concentrations of uremic toxin, p-cresol, urea, and phosphates in the blood are decreased, ${ }^{415-417}$ the lipid profile in the liver is normalized, ${ }^{11,418}$ the oxidative stress and inflammation in muscles are reduced by increasing the activity of antioxidant enzymes, ${ }^{419}$ the learning and memory are increased as a result of eliminating oxidative stress and neurodegenerative processes in the hippocampus, ${ }^{11,420-422}$ the oxidative stress in the heart and blood vessels is reduced by a decrease in the concentrations of NADPH oxidase 2 (Nox2) and $\mathrm{T}$ helper 17 cells (Th17), the polarization of regulatory $\mathrm{T}$ cells is increased, ${ }^{423}$ the basal glycemia and insulin resistance are decreased. ${ }^{424}$

Viruses that can infect both intestinal epithelial cells and symbiotic microorganisms have a significant effect on the composition of the intestinal microbiome. ${ }^{376,425,426}$ The gut microbiome is the primary antiviral barrier, which, using the CRISPR-Cas system, provides effective protection of symbiotic bacteria from various DNA and RNA viruses, phages, as well as COVID-19. ${ }^{425,427,428}$ One of the mechanisms of antiviral defense of the gut microbiome is a complex of exosomes of bacterial and human
Intestinal microbiome

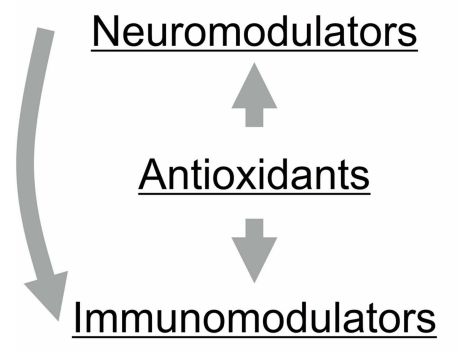

Host body

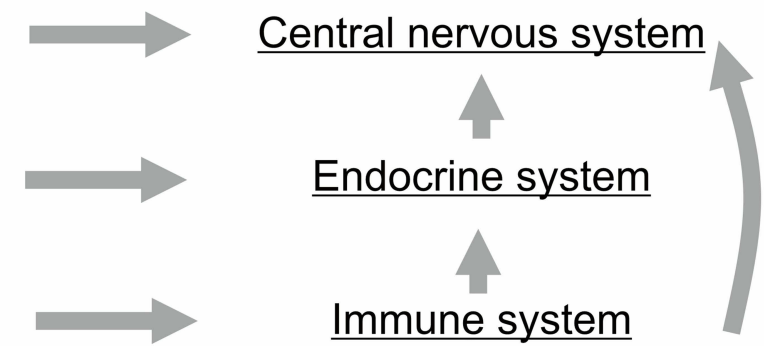

Figure 3 The intestinal microbiome influences the host organism due to its ability to synthesize various biologically active compounds. 
origin. Exosomes can capture viral particles, including COVID-19, and carry them into bacterial cells, where they are destroyed. ${ }^{429-432}$ Another mechanism of antiviral defense of the intestinal microbiome is the production of peptides and biologically active metabolites that can prevent viruses from entering cells. Microorganisms of the gut microbiome can synthesize peptides that are able to competitively bind to ACE2 cell receptors, block them from binding to COVID-19 and protect the intestinal epithelium from coronavirus infection and subsequent inflammatory processes. ${ }^{433}$ It has been shown that bifidobacteria, in particular Bifidobacterium longum GT-15, can reduce intestinal inflammatory processes by producing the type-III fibronectin domain-containing protein (FN3) that binds to a pro-inflammatory agent such as tumor necrosis factor $\alpha \mathrm{TNF} \alpha{ }^{434,435}$ The gut microbiome of people resistant to coronavirus infection is a promising source of Lactobacillus strains capable of producing peptides and other active metabolites that prevent the penetration of COVID-19 into human cells and decrease the severity and pathogenesis of this new coronavirus.

\section{Perspectives}

It is necessary to develop additional antioxidant and immunomodulatory pharmabiotics, postbiotics, and nextgeneration probiotic drugs for the prevention and treatment of COVID-19 infection. To create new generation pharmabiotics, and postbiotics, it is necessary to study the intestinal microbiome of stress-resistant people as a resource of biologically active compounds and strains of lactobacteria that ensure human resistance to coronavirus infection. After coronavirus infection and before vaccination, it is necessary to diagnose the state of the intestinal microbiome and normalize the disturbed state. To increase the effectiveness of protein vaccines against coronavirus infection, it is necessary to develop adjuvants based on lactobacteria and bifidobacteria capable of enhancing the cellular immune response. ${ }^{436}$

Recently, much attention has been paid to the search for new promising sources of lactobacteria with antioxidant properties from the gut microbiome of animals. Thus, the honey bee Apis mellifera, closely associated with human life, can be a promising source of beneficial strains of probiotic lactobacteria. Such prospects are related to the fact that bees can survive the winter without flying and empty their guts for 6 months due to their unique adaptation. ${ }^{437}$ The adaptation of bees to a long winter is provided by the combined antioxidant potential of the organism and the gut microbiome of bees, which slows down and prevents excessive oxidation of the substrate and protects the organism from oxidative stress. ${ }^{437}$

Lactobacteria species Lactobacillus Firm-4 and Firm-5, L. helveticus, L. kunkeei, L. helsingborgensis, L. kimbladii, L. mellis, L. mellifer, L. melliventris, L. apis, L. kullaberme, L. johnsonii, L. micheneri, L. timberlakei, L. quenuiae, and $L$. plantarum are represented in the gut of honey bees in the greatest diversity and are characterized by an enhanced antioxidant potential. ${ }^{158,438-440}$ The antioxidant potential of lactobacteria may be associated with the expression of antioxidant enzyme genes such as catalase, thioredoxin reductase, catalase, glutathione reductase superoxide dismutase, glutathione S-transferase, as well as other products with antioxidant properties, such as lipoteichoic acid. ${ }^{158,441}$

In the gut of wintering honey bees, the number of lactobacteria species with enhanced antioxidant potential, such as L. mellifer, L. apis, and L. melliventris, is increased. ${ }^{439,442}$ Ochratoxin A causes histopathological changes and liver and kidney dystrophy in rats. It was shown that rats fed with L. kunkeei probiotic bacteria from the honey bee gut microbiome have an increased protective potential against oxidative stress caused by ochratoxin A. ${ }^{436}$ Polystyrene microplastic exposure led to significant decreases in the $\alpha$-diversity of the honey bee gut microbiome, accompanied by changes to the core microbial population structure and oxidative stress. Lactobacillus spp. play a protective role against polystyrene microplastics exposure by stimulating the expression of antioxidative CAT, detoxification CYPQ1 and GSTS3, and immune system-related Domeless, Hopscotch, and Symplekin genes in the midgut. ${ }^{443}$ In the gut of honey bees, Lactobacillus species of L. plantarum (strains H28, H24, KX519413, KX519414, LP8, LP25, LP86, LP95, LP100) and L. kunkeei were characterized by an increased antioxidant potential that protects against different pesticides. ${ }^{436,440,444-446}$ All of these strains of lactobacteria from the gut of honey bees with an increased antioxidant potential can be selected as perspective strains for creating pharmabiotics. ${ }^{445}$

There are new prospects for the use of components of lactobacteria, rather than their use in living form cultures. Postbiotics are now defined as metabolites and cellular components that provide health benefits. ${ }^{32,447,448}$ Postbiotics are a promising area of research for future pharmaceuticals and functional foods with antioxidant properties for the treatment of depressive disorders. ${ }^{32,393}$ The potential of postbiotics can be used by packaging them into nanostructures, allowing them to be delivered to organs affected by inflammation. ${ }^{32,449}$ The use of extracellular vesicles of grampositive probiotic bacteria, which can freely enter the 
bloodstream, as well as tissues and organs of the human body, is another interesting area of research. ${ }^{32,450,451}$ As a modern method, metagenomics is widely used not only to study differences in the composition of the microbiome in disease states in comparison with healthy people, but also to study the functional genes of the intestinal microbiome. ${ }^{32}$ For this reason, it is desirable to use metagenomic analysis of sequenced whole genome bacterial DNA to study the antioxidant potential of the intestinal microbiome. This approach can yield significant results in the search for target genes that are included in the catalog of reference genes of the search tool. $^{32}$

\section{Conclusion}

Inflammatory processes of various organs and systems accompany many chronic and infectious human diseases. As a rule, they are accompanied by a violation of the composition and functions of the human intestinal microbiome, called dysbiosis of the intestinal tract. At the same time, inflammation and dysbiosis, having common indicators and mechanisms, are characterized by biomarkers characteristic of certain pathologies. The search for biomarkers of pathologies at the level of the microbiome and the human body is a step towards the practical diagnosis of the disease and the development of drugs. In the case of COVID-19 and Parkinson's disease, the RAAS system is the common system involved in the pathogenesis of diseases properties. ${ }^{32}$ Angiotensin-converting enzyme 2 ACE2 and its receptor are overlapping bio targets in SARS-CoV-2 and Parkinson's disease. The RAAS system was discovered and described over 100 years ago. It was demonstrated that the RAAS is involved in the formation of oxidative stress and inflammatory processes in viral and neurodegenerative diseases, and the intestinal microbiome performs a protective function of the body. The participation of the RAAS system in the inflammatory processes of all human organs and systems, caused by Parkinson's disease and COVID-19, has been shown. The involvement of the RAAS in complications after COVID-19 requires further research and detailed analysis. The apparent link between gut microbiome dysbiosis and COVID-19 and Parkinson's disease requires the targeted creation of pharmabiotics and postbiotics to correct the microbiome. Using the antioxidant potential of lactobacteria is undoubtedly the right approach in the prevention of inflammatory diseases. Lactobacteria are promising candidates for anti-inflammatory and antioxidant drugs. ${ }^{32,452,453}$ The term pharmabiotics, which was first published about 15 years ago, better describes probiotic-based medicines. ${ }^{454,455,456,457}$ The development of drugs aimed at eliminating the inflammation phenotype of the intestinal microbiome will be greatly facilitated if new methodological and conceptual approaches to the search for unique strains of probiotic bacteria are implemented; they include a comparative analysis of the genomes of lactobacteria, as well as metagenomes properties. ${ }^{32}$ Omics technologies have been used to study the intestinal microbiome of healthy people and patients with chronic inflammatory diseases. Characterization of the gut microbiome in health and disease is likely to become possible when the biomarkers of a dysfunctional microbiome are better understood. Efforts are being made to identify the genes responsible for the gut microbiome's neuromodulatory and immunomodulatory properties. ${ }^{32}$ The development of projects for the study of unique strains of lactobacteria from new promising sources using omics technologies is considered a necessary task of modern health care properties. $^{32}$

\section{Disclosure}

The authors report no conflicts of interest in this work.

\section{References}

1. Chaudhry ZL, Klenja D, Janjua N, Cami-Kobeci G, Ahmed BY. COVID-19 and Parkinson's disease: shared inflammatory pathways under oxidative stress. Brain Sciences. 2020;10(11):807. doi:10.3390/ brainsci10110807

2. Hoffmann M, Kleine-Weber H, Schroeder S, et al. SARS-CoV-2 cell entry depends on ACE2 and TMPRSS2 and is blocked by a clinically proven protease inhibitor. Cell. 2020;181(2):271-280. doi:10.1016/j. cell.2020.02.052

3. Zhou P, Yang XL, Wang XG, et al. A pneumonia outbreak associated with a new coronavirus of probable bat origin. Nature. 2020;579 (7798):270-273. doi:10.1038/s41586-020-2012-7

4. Benigni A, Cassis P, Remuzzi G. Angiotensin II revisited: new roles in inflammation, immunology and aging. EMBO Mol Med. 2010;2 (7):247-257. doi:10.1002/emmm.201000080

5. Hirano T, Murakami M. COVID-19: a new virus, but a familiar receptor and cytokine release syndrome. Immunity. 2020;52 (5):731-733. doi:10.1016/j.immuni.2020.04.003

6. Nile SH, Nile A, Qiu J, Li L, Jia X, Kai G. COVID-19: pathogenesis, cytokine storm and therapeutic potential of interferons. Cytokine Growth Factor Rev. 2020;53:66-70. doi:10.1016/j.cytogfr.2020.05.002

7. de Wit E, van Doremalen N, Falzarano D, Munster VJ. SARS and MERS: recent insights into emerging coronaviruses. Nat Rev Microbiol. 2016;14(8):523-534. doi:10.1038/nrmicro.2016.81

8. Niizuma K, Endo H, Chan PH. Oxidative stress and mitochondrial dysfunction as determinants of ischemic neuronal death and survival. $J$ Neurochem. 2009;109(Suppl 1):133-138. doi:10.1111/j.14714159.2009.05897.x

9. Hernansanz-Agustin P, Izquierdo-Alvarez A, Sanchez-Gomez FJ, et al. Acute hypoxia produces a superoxide burst in cells. Free Radic. Biol. Med. 2014;71:146-156. doi:10.1016/j.freeradbiomed.2014.03.011 
10. Gorlach A, Dimova EY, Petry A, et al. Reactive oxygen species, nutrition, hypoxia and diseases: problems solved? Redox Biol. 2015;6:372-385. doi:10.1016/j.redox.2015.08.016

11. Nicholls DG. Mitochondrial calcium function and dysfunction in the central nervous system. Biochimica et Biophysica Acta. 2009;1787(11):1416-1424. doi:10.1016/j.bbabio.2009.03.010

12. Niizuma K, Yoshioka H, Chen H, et al. Mitochondrial and apoptotic neuronal death signaling pathways in cerebral ischemia. Biochimica et Biophysica Acta. 2010;1802(1):92-99. doi:10.1016/j.bbadis.2009.09.002

13. Gazewood JD, Richards DR, Clebak K. Parkinson disease: an update. Am. Fam. Physician. 2013;87(4):267-273.

14. Deumens R, Blokland A, Prickaerts J. Modeling Parkinson's disease in rats: an evaluation of 6-OHDA lesions of the nigrostriatal pathway. Exp Neurol. 2002;175(2):303-317. doi:10.1006/ exnr.2002.7891

15. Prieto-Lloret J, Donnelly DF, Rico AJ, Moratalla R, Gonzalez C, Rigual RJ. Hypoxia transduction by carotid body chemoreceptors in mice lacking dopamine $\mathrm{D}(2)$ receptors. J Appl Physiol (1985). 2007;103(4):1269-1275. doi:10.1152/japplphysiol.00391.2007

16. Andrzejewski K, Jampolska M, Zaremba M, Joniec-Maciejak I, Boguszewski PM, Kaczynska K. Respiratory pattern and phrenic and hypoglossal nerve activity during normoxia and hypoxia in 6-OHDA-induced bilateral model of Parkinson's disease. J Physiol Sci. 2020;70(1):16. doi:10.1186/s12576-020-00743-4

17. Glinka YY, Youdim MBH. Inhibition of mitochondrial complexes I and IV by 6-hydroxydopamine. Eur J Pharmacol. 1995;292 (3):329-332. doi:10.1016/0926-6917(95)90040-3

18. Blum D, Torch S, Lambeng $\mathrm{N}$, et al. Molecular pathways involved in the neurotoxicity of 6-OHDA, dopamine and MPTP: contribution to the apoptotic theory in Parkinson's disease. Progress in Neurobiology. 2001;65(2):135-172. doi:10.1016/S0301-0082(01)00003-X

19. Tirmenstein MA, Hu CX, Scicchitano MS, et al. Effects of 6-hydroxydopamine on mitochondrial function and glutathione status in SH-SY5Y human neuroblastoma cells. Toxicology in Vitro. 2005;19(4):471-479. doi:10.1016/j.tiv.2005.01.006

20. Lalley PM. D1/D2-dopamine receptor agonist dihydrexidine stimulates inspiratory motor output and depresses medullary expiratory neurons. American Journal of Physiology Regulatory Integrative and Comparative Physiology. 2009;296(6):R18291836. doi:10.1152/ajpregu.00057.2009

21. Seccombe LM, Giddings HL, Rogers PG, et al. Abnormal ventilatory control in Parkinson's disease-further evidence for nonmotor dysfunction. Respiratory Physiology \& Neurobiology. 2011;179(2-3):300-304. doi:10.1016/j.resp.2011.09.012

22. Baille G, De Jesus AM, Perez T, et al. Ventilatory Dysfunction in Parkinson's Disease. J. Parkinsons Dis. 2016;6(3):463-471. doi:10.3233/JPD-160804

23. Blesa J, Trigo-Damas I, Quiroga-Varela A, Jackson-Lewis VR. Oxidative stress and Parkinson's disease. Front Neuroanat. 2015;9:91. doi:10.3389/fnana.2015.00091

24. Kim GH, Kim JE, Rhie SJ, Yoon S. The Role of oxidative stress in neurodegenerative diseases. Exp Neurobiol. 2015;24 (4):325-340. doi:10.5607/en.2015.24.4.325

25. Gong P, Deng F, Zhang W, et al. Tectorigenin attenuates the MPP (+)-induced SH-SY5Y cell damage, indicating a potential beneficial role in Parkinson's disease by oxidative stress inhibition. Exp. Ther. Med. 2017;14(5):4431-4437. doi:10.3892/etm.2017.5049

26. Cassarino DS, Halvorsen EM, Swerdlow RH, et al. Interaction among mitochondria, mitogen-activated protein kinases, and nuclear factor-kappaB in cellular models of Parkinson's disease. $J \quad$ Neurochem. 2000;74(4):1384-1392. doi:10.1046/j.14714159.2000.0741384.x
27. Chaudhry ZL, Ahmed BY. The role of caspases in Parkinson's Disease pathogenesis: a brief look at the mitochondrial pathway. Austin Alzheimer's and Parkinson's Disease. 2014;1(3):2-5.

28. Moon HE, Paek SH. Mitochondrial Dysfunction in Parkinson's Disease. Exp Neurobiol. 2015;24(2):103-116. doi:10.5607/ en.2015.24.2.103

29. Hunot S, Brugg B, Ricard D, et al. Nuclear translocation of NF-kappaB is increased in dopaminergic neurons of patients with Parkinson disease. Proceedings of the National Academy of Sciences of the United States of America. 1997;94 (14):7531-7536. doi:10.1073/pnas.94.14.7531

30. Erekat NS, Al-Jarrah MD. Association of Parkinson Disease Induction with Cardiac Upregulation of Apoptotic Mediators P53 and Active Caspase-3: an Immunohistochemistry Study. Medical Science Monitor Basic Research. 2018;24:120-126. doi:10.12659/MSMBR.910307

31. Wilkins LJ, Monga M, Miller AW. Defining Dysbiosis for a Cluster of Chronic Diseases. Sci Rep. 2019;9(1):12918. doi:10.1038/s41598-019-49452-y

32. Averina OV, Poluektova EU, Marsova MV, Danilenko VN. Biomarkers and utility of the antioxidant potential of probiotic Lactobacilli and Bifidobacteria as representatives of the human gut microbiota. Biomedicines. 2021;9(10):1340. doi:10.3390/ biomedicines 9101340

33. Wong CB, Sugahara H, Odamaki T, Xiao JZ. Different physiological properties of human-residential and non-human-residential bifidobacteria in human health. Benef Microbes. 2018;9 (1):111-122. doi:10.3920/BM2017.0031

34. Salvetti E, O'Toole PW. When regulation challenges innovation: the case of the genus. Lactobacillus. Trends Food Sci. Technol. 2017;66:187-194. doi:10.1016/j.tifs.2017.05.009

35. Arboleya S, Watkins C, Stanton C, Ross RP. Gut Bifidobacteria Populations in Human Health and Aging. Front Microbiol. 2016;7:1204. doi:10.3389/fmicb.2016.01204

36. Stavropoulou E, Bezirtzoglou E. Probiotics in Medicine: a Long Debate. Front Immunol. 2020;11:2192. doi:10.3389/ fimmu.2020.02192

37. Domej W, Oettl K, Renner W. Oxidative stress and free radicals in COPD-implications and relevance for treatment. Int. J. Chron. Obstruct. Pulmon. Dis. 2014;9:1207-1224. doi:10.2147/COPD. S5 1226

38. Calabrese V, Santoro A, Monti D, et al. Aging and Parkinson's Disease: inflammaging, neuroinflammation and biological remodeling as key factors in pathogenesis. Free Radic. Biol. Med. 2018;115:80-91. doi:10.1016/j.freeradbiomed.2017.10.379

39. Senoner T, Schindler S, Stattner S, Ofner D, Troppmair J, Primavesi F. Associations of Oxidative Stress and Postoperative Outcome in Liver Surgery with an Outlook to Future Potential Therapeutic Options. Oxid. Med. Cell. Longev. 2019;2019:3950818. doi:10.1155/2019/3950818

40. Kovtun AS, Averina OV, Zakharevich NV, Kasianov AS, Danilenko VN. In silico Identification of Metagenomic Signature Describing Neurometabolic Potential of Normal Human Gut Microbiota. Russian Journal of Genetics. 2018;54 (9):1101-1110. doi:10.1134/S1022795418090089

41. Averina OV, Kovtun AS, Polyakova SI, Savilova AM, Rebrikov DV, Danilenko VN. The bacterial neurometabolic signature of the gut microbiota of young children with autism spectrum disorders. J Med Microbiol. 2020a;69(4):558-571. doi:10.1099/jmm.0.001178

42. Benakis C, Martin-Gallausiaux C, Trezzi JP, Melton P, Liesz A, Wilmes P. The microbiome-gut-brain axis in acute and chronic brain diseases. Current Opinion in Neurobiology. 2020;61:1-9. doi:10.1016/j.conb.2019.11.009 
43. Bercik P, Collins SM, Verdu EF. Microbes and the gut-brain axis. Neurogastroenterol Motil. 2012;24(5):405-413. doi:10.1111/ j.1365-2982.2012.01906.x

44. Cryan JF, O'Riordan KJ, Cowan CSM, et al. The microbiota-gutbrain axis. Physiol Rev. 2019;99(4):1877-2013. doi:10.1152/ physrev.00018.2018

45. Hill JM, Bhattacharjee S, Pogue AI, Lukiw WJ. The gastrointestinal tract microbiome and potential link to Alzheimer's disease. Front. Neurol. 2014;5(4):43. doi:10.3389/fneur.2014.00043

46. Klingelhoefer L, Reichmann H. Pathogenesis of Parkinson disease - the gut-brain axis and environmental factors. Nature Reviews Neurology. 2015;11(11):625-636. doi:10.1038/ nrneurol.2015.197

47. Khan MS, Ikram M, Park JS, Park TJ, Kim MO. Gut microbiota, its role in induction of Alzheimer's disease pathology, and possible therapeutic interventions: special focus on anthocyanins. Cells. 2020;9(4):853. doi:10.3390/cells9040853

48. Caputi V, Giron M. Microbiome-gut-brain axis and toll-like receptors in Parkinson's disease. Int J Mol Sci. 2018;19(6):1689. doi:10.3390/ijms 19061689

49. Arora K, Green M, Prakash S. The microbiome and Alzheimer's disease: potential and limitations of prebiotic, synbiotic, and probiotic formulations. Frontiers in Bioengineering and Biotechnology. 2020;8:537847. doi:10.3389/Fbioe.2020.537847

50. Milyukhina IV, Karpenko MN, Timofeeva AA, Klimenko VM, Skoromec AA. The role of inflammation in the pathogenesis of Parkinson's disease. Neurological Journal. 2013;3(18):51-55.

51. Sampson TR, Debelius JW, Thron T, et al. Gut microbiota regulate motor deficits and neuroinflammation in a model of Parkinson's disease. Cell. 2016;167(6):1469-1480.e1412. doi:10.1016/j.cell.2016.11.018

52. Fountain JH, Lappin SL. Physiology, Renin Angiotensin System. StatPearls. Treasure Island (FL): StatPearls Publishing LLC; 2021:29261862.

53. Abiodun OA, Ola MS. Role of brain renin angiotensin system in neurodegeneration: an update. Saudi J. Biol. Sci. 2020;27 (3):905-912. doi:10.1016/j.sjbs.2020.01.026

54. Petrie JR, Guzik TJ, Touyz RM. Diabetes, hypertension, and cardiovascular disease: clinical insights and vascular mechanisms. Can J Cardiol. 2018;34(5):575-584. doi:10.1016/j. cjca.2017.12.005

55. Carbone LD, Vasan S, Prentice RL, et al. The renin-angiotensin aldosterone system and osteoporosis: findings from the women's health initiative. Osteoporos. Int. 2019;30(10):2039-2056. doi:10.1007/s00198-019-05041-3

56. Scialo F, Daniele A, Amato F, et al. ACE2: the major cell entry receptor for SARS-CoV-2. Lung. 2020;198(6):867-877. doi:10.1007/s00408-020-00408-4

57. Kullisaar T, Songisepp E, Zilmer M. Probiotics and oxidative stress. In: Lushchak V, editor. Oxidative Stress - Environmental Induction and Dietary Antioxidants. London, UK: IntechOpen; 2012:203-222.

58. Raimondi S, Amaretti A, Leonardi A, Quartieri A, Gozzoli C, Rossi M. Conjugated linoleic acid production by bifidobacteria: screening, kinetic, and composition. Biomed Res Int. 2016;2016:1-8. doi:10.1155/2016/8654317

59. Marsova M, Abilev S, Poluektova E, Danilenko V. A bioluminescent test system reveals valuable antioxidant properties of Lactobacillus strains from human microbiota. World J Microbiol Biotechnol. 2018;34(2):27. doi:10.1007/s11274-0182410-2

60. Eslami M, Yousefi B, Kokhaei P, et al. Importance of probiotics in the prevention and treatment of colorectal cancer. $J$ Cell Physiol. 2019;234(10):17127-17143. doi:10.1002/jcp.28473
61. Rinninella E, Raoul P, Cintoni M, et al. What is the healthy gut microbiota composition? A changing ecosystem across age, environment, diet, and diseases. Microorganisms. 2019;7(1):14. doi:10.3390/microorganisms 7010014

62. Kaźmierczak-Siedlecka K, Daca A, Fic M, van de Wetering T, Folwarski M, Makarewicz W. Therapeutic methods of gut microbiota modification in colorectal cancer management - fecal microbiota transplantation, prebiotics, probiotics, and synbiotics. Gut Microbes. 2020;11(6):1518-1530. doi:10.1080/ 19490976.2020.1764309

63. Garcia-Gonzalez N, Prete R, Perugini M, Merola C, Battista N, Corsetti A. Probiotic antigenotoxic activity as a DNA bioprotective tool: a minireview with focus on endocrine disruptors. FEMS Microbiol Lett. 2020;367(3):fnaa041. doi:10.1093/femsle/fnaa041

64. Żółkiewicz J, Marzec A, Ruszczyński M, Feleszko W. Postbiotics - A step beyond pre- and probiotics. Nutrients. 2020;12(8):2189. doi:10.3390/nu12082189

65. Rad AH, Aghebati-Maleki L, Kafil HS, Abbasi A. Molecular mechanisms of postbiotics in colorectal cancer prevention and treatment. Crit. Rev. Food Sci. Nutr. 2020;61(11):1787-1803. doi:10.1080/10408398.2020.1765310

66. Khaled JMA. Probiotics, prebiotics, and COVID-19 infection: a review article. Saudi J. Biol. Sci. 2021;28(1):865-869. doi:10.1016/j.sjbs.2020.11.025

67. Seaver LC, Imlay JA. Are respiratory enzymes the primary sources of intracellular hydrogen peroxide? J Biol Chem. 2004;279 (47):48742-48750. doi:10.1074/jbc.M408754200

68. Watson J. Oxidants, antioxidants and the current incurability of metastatic cancers. Open Biology. 2013;3(1):120144. doi:10.1098/rsob.120144

69. Davalli P, Marverti G, Lauriola A, D’Arca D. Targeting Oxidatively Induced DNA Damage Response in Cancer: opportunities for Novel Cancer Therapies. Oxid. Med. Cell. Longev. 2018;2018:2389523. doi:10.1155/2018/2389523

70. Sies H, Jones DP. Reactive oxygen species (ROS) as pleiotropic physiological signalling agents. Nat. Rev. Mol. Cell Biol. 2020;21 (7):363-383. doi:10.1038/s41580-020-0230-3

71. Vona R, Pallotta L, Cappelletti M, Severi C, Matarrese P. The Impact of Oxidative Stress in Human Pathology: focus on Gastrointestinal Disorders. Antioxidants. 2021;10(2):201. doi:10.3390/antiox10020201

72. Imlay JA. Pathways of oxidative damage. Annual Review of Microbiology. 2003;57:395-418. doi:10.1146/annurev. micro.57.030502.090938

73. Hardin SC, Larue CT, Oh MH, Jain V, Huber SC. Coupling oxidative signals to protein phosphorylation via methionine oxidation in Arabidopsis. Biochemical Journal. 2009;422 (2):305-312. doi:10.1042/BJ20090764

74. Zuo L, Prather ER, Stetskiv M, et al. Inflammaging and Oxidative Stress in Human Diseases: from Molecular Mechanisms to Novel Treatments. Int J Mol Sci. 2019;20(18):4472. doi:10.3390/ ijms20184472

75. Black CN, Bot M, Scheffer PG, Cuijpers P, Penninx BW. Is depression associated with increased oxidative stress? A systematic review and meta-analysis. Psychoneuroendocrinology. 2015;51:164-175. doi:10.1016/j.psyneuen.2014.09.025

76. Prasad KN. Oxidative Stress, Pro-Inflammatory Cytokines, and Antioxidants Regulate Expression Levels of MicroRNAs in Parkinson's Disease. Curr Aging Sci. 2017;10(3):177-184. doi:10.2174/1874609810666170102144233

77. Lindqvist D, Dhabhar FS, James SJ, et al. Oxidative stress, inflammation and treatment response in major depression. Psychoneuroendocrinology. 2017;76:197-205. doi:10.1016/j. psyneuen.2016.11.031 
78. Fedoce ADG, Ferreira F, Bota RG, Bonet-Costa V, Sun PY, Davies KJA. The role of oxidative stress in anxiety disorder: cause or consequence? Free Radic. Res. 2018;52(7):737-750. doi:10.1080/10715762.2018.1475733

79. Galecki P, Talarowska M. Inflammatory theory of depression. Psychiatr. Pol. 2018;52(3):437-447. doi:10.12740/PP/76863

80. Ma Q, Xing C, Long W, Wang HY, Liu Q, Wang RF. Impact of microbiota on central nervous system and neurological diseases: the gut-brain axis. $J$ Neuroinflammation. 2019;16(1):53. doi:10.1186/s12974-019-1434-3

81. Segal AW. How neutrophils kill microbes. Annu. Rev. Immunol. 2005;23:197-223. doi:10.1146/annurev.immunol.23.021704.115 653

82. Gems D, Partridge L. Stress-response hormesis and aging: "that which does not kill us makes us stronger". Cell Metab. 2008;7 (3):200-203. doi:10.1016/j.cmet.2008.01.001

83. Bhattacharyya S. Inflammation During Virus Infection: swings and Roundabouts. In: Bramhachari PV, editor. Dynamics of Immune Activation in Viral Diseases. Singapore: Springer Singapore; 2020:43-59.

84. Rouse BT. Virus-induced immunopathology. Adv. Virus Res. 1996;47:353-376. doi:10.1016/s0065-3527(08)60739-3

85. Rouse BT, Sehrawat S. Immunity and immunopathology to viruses: what decides the outcome? Nat. Rev. Immunol. 2010;10 (7):514-526. doi:10.1038/nri2802

86. Allen IC, Scull MA, Moore CB, et al. The NLRP3 inflammasome mediates in vivo innate immunity to influenza A virus through recognition of viral RNA. Immunity. 2009;30(4):556-565. doi:10.1016/j.immuni.2009.02.005

87. Thomas PG, Dash P, Aldridge JR, et al. The intracellular sensor NLRP3 mediates key innate and healing responses to influenza A virus via the regulation of caspase-1. Immunity. 2009;30 (4):566-575. doi:10.1016/j.immuni.2009.02.006

88. Tisoncik JR, Korth MJ, Simmons CP, Farrar J, Martin TR, Katze MG. Into the eye of the cytokine storm. Microbiology and Molecular Biology Reviews. 2012;76(1):16-32. doi:10.1128/ MMBR.05015-11

89. Tarlinton RE, Martynova E, Rizvanov AA, Khaiboullina S, Verma S. Role of viruses in the pathogenesis of multiple sclerosis. Viruses. 2020;12(6):643. doi:10.3390/v12060643

90. Paz SPC, Branco L, Pereira MA, Spessotto C, Fragoso YD. Systematic review of the published data on the worldwide prevalence of John Cunningham virus in patients with multiple sclerosis and neuromyelitis optica. Epidemiol Health. 2018;40: e2018001. doi:10.4178/epih.e2018001

91. Barzon L. Ongoing and emerging arbovirus threats in Europe. J. Clin. Virol. 2018;107:38-47. doi:10.1016/j.jcv.2018.08.007

92. Delbue S, Tadeo CS, Elia F, Ferrante P. JC virus replication at the first symptoms of multiple sclerosis: a case report. Intervirology. 2015;58(5):278-282. doi:10.1159/000441473

93. Mangiardi M, Crawford DK, Xia X, et al. An animal model of cortical and callosal pathology in multiple sclerosis. Brain Pathol. 2011;21(3):263-278. doi:10.1111/j.1750-3639.2010.00444.x

94. Leibovitch EC, Jacobson S. Evidence linking HHV-6 with multiple sclerosis: an update. Curr Opin Virol. 2014;9:127-133. doi:10.1016/j.coviro.2014.09.016

95. Pormohammad A, Azimi T, Falah F, Faghihloo E. Relationship of human herpes virus 6 and multiple sclerosis: a systematic review and meta-analysis. $J$ Cell Physiol. 2018;233(4):2850-2862. doi:10.1002/jcp. 26000

96. Akinsoji EO, Leibovitch E, Billioux BJ, et al. HHV-6 and hippocampal volume in patients with mesial temporal sclerosis. Ann Clin Transl Neur. 2020;7(9):1674-1680. doi:10.1002/acn3.51152
97. Bu X-L, Wang X, Xiang Y, et al. The association between infectious burden and Parkinson's disease: a case-control study. Parkinsonism Relat Disord. 2015;21(8):877-881. doi:10.1016/j. parkreldis.2015.05.015

98. Tan JSY, Chao YX, Rotzschke O, Tan EK. New Insights into Immune-Mediated Mechanisms in Parkinson's Disease. Int $J$ Mol Sci. 2020;21(23):9302. doi:10.3390/ijms21239302

99. Braak H, de Vos RAI, Bohl J, Del Tredici K. Gastric $\alpha$-synuclein immunoreactive inclusions in Meissner's and Auerbach's plexuses in cases staged for Parkinson's disease-related brain pathology. Neurosci Lett. 2006;396(1):67-72. doi:10.1016/j. neulet.2005.11.012

100. Svensson E, Horváth-Puhó E, Thomsen RW, et al. Vagotomy and subsequent risk of Parkinson's disease. Ann Neurol. 2015;78 (4):522-529. doi:10.1002/ana.24448

101. Alifirova VM, Zhukova NG, Zhukova IA, et al. Correlation between emotional-affective disorders and gut microbiota composition in patients with Parkinson's disease. Annals of the Russian Academy of Medical Sciences. 2016;71(6):427-435. doi:10.15690/vramn734

102. Mertsalmi TH, Aho VTE, Pereira PAB, et al. More than constipation - bowel symptoms in Parkinson's disease and their connection to gut microbiota. Eur. J. Neurol. 2017;24(11):1375-1383. doi:10.1111/ene. 13398

103. Lassmann H. Multiple sclerosis pathology. Cold Spring Harb. Perspect. Med. 2018;8(3):a028936. doi:10.1101/cshperspect. a028936

104. Wang $\mathrm{H}$, Wang $\mathrm{K}, \mathrm{Xu} \mathrm{W}$, et al. Cerebrospinal fluid $\alpha$-synuclein levels are elevated in multiple sclerosis and neuromyelitis optica patients during replase. $J$ Neurochem. 2012;122(1):19-23. doi:10.1111/j.1471-4159.2012.07749.x

105. Williams-Gray $\mathrm{CH}$, Wijeyekoon R, Yarnall AJ, et al. Serum immune markers and disease progression in an incident Parkinson's disease cohort (ICICLE-PD). Mov Disord. 2016;31 (7):995-1003. doi:10.1002/mds.26563

106. Wilen CB, Trypsteen W, Van Cleemput J, Snippenberg W, Gerlo S, Vandekerckhove L. On the whereabouts of SARS-CoV-2 in the human body: a systematic review. PLoS Path. 2020;16(10):e1009037. doi:10.1371/journal.ppat.1009037

107. Dhar D, Mohanty A. Gut microbiota and Covid-19- possible link and implications. Virus Res. 2020;285:198018. doi:10.1016/j. virusres.2020.198018

108. Azkur AK, Akdis M, Azkur D, et al. Immune response to SARS-CoV-2 and mechanisms of immunopathological changes in COVID-19. Allergy. 2020;75(7):1564-1581. doi:10.1111/all.14364

109. Khatiwada S, Subedi A. Lung microbiome and coronavirus disease 2019 (COVID-19): possible link and implications. Hum Microb J. 2020;17:100073. doi:10.1016/j.humic.2020.100073

110. Demyanovskaya EG, Kryzhanovsky SM, Vasiliev AS, Shmyrev VI. Neurological aspects of COVID-19. Patient management tactics by a neurologist, taking into account the epidemiological situation. Lechashchiy Vrach. 2021;1(2):54-60. doi:10.26295/os.2021.63.96.011

111. Ni Y, Yang X, Zheng L, et al. Lactobacillus and Bifidobacterium improves physiological function and cognitive ability in aged mice by the regulation of gut microbiota. Mol. Nutr. Food Res. 2019;63(22):1900603. doi:10.1002/mnfr.201900603

112. Wrapp D, Wang N, Corbett KS, et al. Cryo-EM structure of the 2019-nCoV spike in the prefusion conformation. Science. 2020;367(6483):1260-1263. doi:10.1126/science.abb2507

113. Li WH, Moore MJ, Vasilieva N, et al. Angiotensin-converting enzyme 2 is a functional receptor for the SARS coronavirus. Nature. 2003;426(6965):450-454. doi:10.1038/nature02145 
114. Li F, Li WH, Farzan M, Harrison SC. Structure of SARS coronavirus spike receptor-binding domain complexed with receptor. Science. 2005;309(5742):1864-1868. doi:10.1126/science.1116480

115. Song WF, Gui M, Wang XQ, Xiang Y. Cryo-EM structure of the SARS coronavirus spike glycoprotein in complex with its host cell receptor ACE2. PLoS Path. 2018;14(8):e1007236. doi:10.1371/journal.ppat.1007236

116. Kuba K, Imai Y, Ohto-Nakanishi T, Penninger JM. Trilogy of ACE2: a peptidase in the renin-angiotensin system, a SARS receptor, and a partner for amino acid transporters. Pharmacol Ther. 2010;128 (1):119-128. doi:10.1016/j.pharmthera.2010.06.003

117. Grant MC, Geoghegan L, Arbyn M, et al. The prevalence of symptoms in 24,410 adults infected by the novel coronavirus (SARS-CoV-2; COVID-19): a systematic review and meta-analysis of 148 studies from 9 countries. PLoS One. 2020;15(6):e0234765. doi:10.1371/journal.pone.0234765

118. Greenhalgh T, Jimenez JL, Prather KA, Tufekci Z, Fisman D, Schooley R. Ten scientific reasons in support of airborne transmission of SARS-CoV-2. Lancet. 2021;397(10285):1603-1605. doi:10.1016/S0140-6736(21)00869-2

119. Wang CC, Prather KA, Sznitman J, et al. Airborne transmission of respiratory viruses. Science. 2021;373(6558):eabd9149. doi:10.1126/science.abd9149

120. Tsai PH, Lai WY, Lin YY, et al. Clinical manifestation and disease progression in COVID-19 infection. J Chin Med Assoc. 2021;84(1):3-8. doi:10.1097/JCMA.0000000000000463

121. Harrison AG, Lin T, Wang P. Mechanisms of SARS-CoV-2 Transmission and Pathogenesis. Trends Immunol. 2020;41 (12):1100-1115. doi:10.1016/j.it.2020.10.004

122. Verdecchia P, Cavallini C, Spanevello A, Angeli F. The pivotal link between ACE2 deficiency and SARS-CoV-2 infection. Eur. J. Intern. Med. 2020;76:14-20. doi:10.1016/j.ejim.2020.04.037

123. Letko M, Marzi A, Munster V. Functional assessment of cell entry and receptor usage for SARS-CoV-2 and other lineage B betacoronaviruses. Nature Microbiology. 2020;5(4):562-569. doi:10.1038/s41564-020-0688-y

124. Eketunde AO, Mellacheruvu SP, Oreoluwa PA. Review of Postmortem Findings in Patients With COVID-19. Cureus. 2020;12(7):e9438. doi:10.7759/cureus.9438

125. da Rosa Mesquita R, Francelino Silva Junior LC, Santos Santana FM, et al. Clinical manifestations of COVID-19 in the general population: systematic review. Wien Klin Wochenschr. 2021;133(7-8):377-382. doi:10.1007/s00508-020-01760-4

126. Marik PE, Iglesias J, Varon J, Kory P. A scoping review of the pathophysiology of COVID-19. Int J Immunopathol Pharmacol. 2021;35:20587384211048026. doi:10.1177/20587384211048026

127. Li YC, Bai WZ, Hashikawa T. The neuroinvasive potential of SARS-CoV2 may play a role in the respiratory failure of COVID-19 patients. J Med Virol. 2020;92(6):552-555. doi:10.1002/jmv. 25728

128. Baig AM, Khaleeq A, Ali U, Syeda H. Evidence of the COVID-19 Virus Targeting the CNS: tissue Distribution, Host-Virus Interaction, and Proposed Neurotropic Mechanisms. ACS Chem Neurosci. 2020;11(7):995-998. doi:10.1021/ acschemneuro.0c00122

129. Yavarpour-Bali H, Ghasemi-Kasman M. Update on neurological manifestations of COVID-19. Life Sciences. 2020;257:118063. doi:10.1016/j.1fs.2020.118063

130. Pezzini A, Padovani A. Lifting the mask on neurological manifestations of COVID-19. Nat. Rev. Neurol. 2020;16(11):636-644. doi:10.1038/s41582-020-0398-3

131. Gu J, Han B, Wang J. COVID-19: gastrointestinal Manifestations and Potential Fecal-Oral Transmission. Gastroenterology. 2020;158(6):1518-1519. doi:10.1053/j.gastro.2020.02.054
132. Huang C, Wang Y, Li X, et al. Clinical features of patients infected with 2019 novel coronavirus in Wuhan, China. Lancet. 2020;395(10223):497-506. doi:10.1016/S0140-6736(20)30183-5

133. Zhang C, Wu Z, Li JW, Zhao H, Wang GQ. Cytokine release syndrome in severe COVID-19: interleukin-6 receptor antagonist tocilizumab may be the key to reduce mortality. Int. J. Antimicrob. Agents. 2020;55(5):105954. doi:10.1016/j. ijantimicag.2020.105954

134. Gomez-Rial J, Rivero-Calle I, Salas A, Martinon-Torres F. Role of Monocytes/Macrophages in Covid-19 Pathogenesis: implications for Therapy. Infect Drug Resist. 2020;13:2485-2493. doi:10.2147/IDR.S258639

135. Soy M, Keser G, Atagunduz P, Tabak F, Atagunduz I, Kayhan S. Cytokine storm in COVID-19: pathogenesis and overview of anti-inflammatory agents used in treatment. Clin. Rheumatol. 2020;39(7):2085-2094. doi:10.1007/s10067-020-05190-5

136. Quirch M, Lee J, Rehman S. Hazards of the Cytokine Storm and Cytokine-Targeted Therapy in Patients With COVID-19: review. J. Med. Internet Res. 2020;22(8):e20193. doi:10.2196/20193

137. Wiese OJ, Allwood BW, Zemlin AE. COVID-19 and the renin-angiotensin system (RAS): a spark that sets the forest alight? Med. Hypotheses. 2020;144:110231. doi:10.1016/j. mehy.2020.110231

138. Bhaskar S, Sinha A, Banach M, et al. Cytokine Storm in COVID-19-Immunopathological Mechanisms, Clinical Considerations, and Therapeutic Approaches: the REPROGRAM Consortium Position Paper. Front Immunol. 2020;11:1648. doi:10.3389/fimmu.2020.01648

139. Beltran-Garcia J, Osca-Verdegal R, Pallardo FV, et al. Oxidative Stress and Inflammation in COVID-19-Associated Sepsis: the Potential Role of Anti-Oxidant Therapy in Avoiding Disease Progression. Antioxidants. 2020;9(10):936. doi:10.3390/ antiox 9100936

140. Cecchini R, Cecchini AL. SARS-CoV-2 infection pathogenesis is related to oxidative stress as a response to aggression. Med. Hypotheses. 2020;143:110102. doi:10.1016/j.mehy.2020.110102

141. Delgado-Roche L, Mesta F. Oxidative Stress as Key Player in Severe Acute Respiratory Syndrome Coronavirus (SARS-CoV) Infection. Arch Med Res. 2020;51(5):384-387. doi:10.1016/j. arcmed.2020.04.019

142. Gan R, Rosoman NP, Henshaw DJE, Noble EP, Georgius P, Sommerfeld N. COVID-19 as a viral functional ACE2 deficiency disorder with ACE2 related multi-organ disease. Med. Hypotheses. 2020;144:110024. doi:10.1016/j.mehy.2020.110024

143. Wei Y, Sowers JR, Nistala R, et al. Angiotensin II-induced NADPH oxidase activation impairs insulin signaling in skeletal muscle cells. $J$ Biol Chem. 2006;281(46):35137-35146. doi:10.1074/jbc.M601320200

144. Zablocki D, Sadoshima J. Angiotensin II and oxidative stress in the failing heart. Antioxid Redox Signal. 2013;19(10):1095-1109. doi:10.1089/ars.2012.4588

145. Dikalov SI, Nazarewicz RR, Angiotensin I. I-induced production of mitochondrial reactive oxygen species: potential mechanisms and relevance for cardiovascular disease. Antioxid Redox Signal. 2013;19(10):1085-1094. doi:10.1089/ars.2012.4604

146. Rincon J, Correia D, Arcaya JL, et al. Role of Angiotensin II type 1 receptor on renal $\mathrm{NAD}(\mathrm{P}) \mathrm{H}$ oxidase, oxidative stress and inflammation in nitric oxide inhibition induced-hypertension. Life Sciences. 2015;124:81-90. doi:10.1016/j.lfs.2015.01.005

147. Valente AJ, Yoshida T, Murthy SN, et al. Angiotensin II enhances AT1-Nox1 binding and stimulates arterial smooth muscle cell migration and proliferation through AT1, Nox1, and interleukin-18. American Journal of Physiology Heart and Circulatory Physiology. 2012;303(3):H282-296. doi:10.1152/ ajpheart.00231.2012 
148. Oudit GY, Kassiri Z, Patel MP, et al. Angiotensin II-mediated oxidative stress and inflammation mediate the age-dependent cardiomyopathy in ACE2 null mice. Cardiovasc. Res. 2007;75 (1):29-39. doi:10.1016/j.cardiores.2007.04.007

149. Sawalha AH, Zhao M, Coit P, Lu Q. Epigenetic dysregulation of ACE2 and interferon-regulated genes might suggest increased COVID-19 susceptibility and severity in lupus patients. Clin Immunol. 2020;215:108410. doi:10.1016/j. clim.2020.108410

150. Violi F, Oliva A, Cangemi R, et al. Nox2 activation in Covid-19. Redox Biol. 2020;36:101655. doi:10.1016/j.redox.2020.101655

151. Barnes BJ, Adrover JM, Baxter-Stoltzfus A, et al. Targeting potential drivers of COVID-19: neutrophil extracellular traps. Journal of Experimental Medicine. 2020;217(6):e20200652. doi:10.1084/jem.20200652

152. Chen G, Wu D, Guo W, et al. Clinical and immunological features of severe and moderate coronavirus disease 2019. J. Clin. Invest. 2020;130(5):2620-2629. doi:10.1172/JCI137244

153. Gong J, Dong H, Xia Q, et al. Correlation Analysis Between Disease Severity and Inflammation-related Parameters in Patients with COVID-19 Pneumonia. medRxiv. 2020;1:202. doi:10.1101/2020.02.25.20025643

154. Qin C, Zhou L, Hu Z, et al. Dysregulation of Immune Response in Patients With Coronavirus 2019 (COVID-19) in Wuhan, China. Clin Infect Dis. 2020;71(15):762-768. doi:10.1093/cid/ciaa248

155. Yang Y, Shen C, Li J, et al. Exuberant elevation of IP-10, MCP-3 and IL-1ra during SARS-CoV-2 infection is associated with disease severity and fatal outcome. medRxiv. 2020;1:20029975. doi:10.1101/2020.03.02.20029975

156. Mehta P, McAuley DF, Brown M, Sanchez E, Tattersall RS, Manson JJ. COVID-19: consider cytokine storm syndromes and immunosuppression. The Lancet. 2020;395(10229):1033-1034. doi:10.1016/S0140-6736(20)30628-0

157. Ruan Q, Yang K, Wang W, Jiang L, Song J. Clinical predictors of mortality due to COVID-19 based on an analysis of data of 150 patients from Wuhan, China. Intensive Care Med. 2020;46 (5):846-848. doi:10.1007/s00134-020-05991-x

158. Wu C, Chen X, Cai Y, et al. Risk Factors Associated With Acute Respiratory Distress Syndrome and Death in Patients With Coronavirus Disease 2019 Pneumonia in Wuhan, China. JAMA Internal Medicine. 2020;180(7):934-943. doi:10.1001/ jamainternmed.2020.0994

159. Wu D, Yang XO. TH17 responses in cytokine storm of COVID-19: an emerging target of JAK2 inhibitor Fedratinib. J Microbiol Immunol Infect. 2020;53(3):368-370. doi:10.1016/j. jmii.2020.03.005

160. Zhang W, Zhao Y, Zhang F, et al. The use of anti-inflammatory drugs in the treatment of people with severe coronavirus disease 2019 (COVID-19): the Perspectives of clinical immunologists from China. Clin Immunol. 2020;214:108393. doi:10.1016/j. clim.2020.108393

161. Merad M, Martin JC. Pathological inflammation in patients with COVID-19: a key role for monocytes and macrophages. Nat. Rev. Immunol. 2020;20(6):355-362. doi:10.1038/s41577-020-0331-4

162. Wang JZ, Zhang RY, Bai J. An anti-oxidative therapy for ameliorating cardiac injuries of critically ill COVID-19-infected patients. Int $J$ Cardiol. 2020;312:137-138. doi:10.1016/j. ijcard.2020.04.009

163. Nagar H, Piao S, Kim C-S. Role of Mitochondrial Oxidative Stress in Sepsis. Acute Crit Care. 2018;33(2):65-72. doi:10.4266/acc.2018.00157

164. Galley HF. Oxidative stress and mitochondrial dysfunction in sepsis. Br J Anaesth. 2011;107(1):57-64. doi:10.1093/bja/aer093
165. Alexoudi A, Alexoudi I, Gatzonis S. Parkinson's disease pathogenesis, evolution and alternative pathways: a review. Rev. Neurol. $\quad$ (Paris). 2018;174(10):699-704. doi:10.1016/j. neurol.2017.12.003

166. Reich SG, Savitt JM. Parkinson's disease. Med. Clin. North Am. 2019;103(2):337-350. doi:10.1016/j.mcna.2018.10.014

167. Dorsey ER, Sherer T, Okun MS, et al. The emerging evidence of the Parkinson pandemic. J. Parkinsons Dis. 2018;8(1):3-8. doi:10.3233/jpd-181474

168. Feigin VL, Nichols E, Alam T, et al. Global, regional, and national burden of neurological disorders, 1990-2016: a systematic analysis for the global burden of disease study 2016. The Lancet Neurology. 2019;18(5):459-480. doi:10.1016/ s1474-4422(18)30499-x

169. Dugger BN, Dickson DW. Pathology of neurodegenerative diseases. Cold Spring Harb. Perspect. Biol. 2017;9(7):a028035. doi:10.1101/cshperspect.a028035

170. Illarioshkin SN, Klyushnikov SA, Vigont VA, Seliverstov YA, Kaznacheyeva EV. Molecular pathogenesis in Huntington's disease. Biochemistry. 2018;83(9):1030-1039. doi:10.1134/ s0006297918090043

171. Kotagal V, Bohnen NI, Müller MLTM, Frey KA, Albin RL. Cerebral amyloid burden and Hoehn and Yahr stage 3 scoring in Parkinson disease. J. Parkinsons Dis. 2017;7(1):143-147. doi:10.3233/jpd-160985

172. Lubomski M, Tan AH, Lim S-Y, Holmes AJ, Davis RL, Sue CM. Parkinson's disease and the gastrointestinal microbiome. J. Neurol. 2019;267(9):2507-2523. doi:10.1007/s00415-01909320-1

173. Kontis V, Bennett JE, Mathers CD, Li G, Foreman K, Ezzati M. Future life expectancy in 35 industrialised countries: projections with a Bayesian model ensemble. The Lancet. 2017;389 (10076):1323-1335. doi:10.1016/S0140-6736(16)32381-9

174. Munoz-Pinto MF, Empadinhas N, Cardoso SM. The neuromicrobiology of Parkinson's disease: a unifying theory. Ageing Research Reviews. 2021;70:101396. doi:10.1016/j. arr.2021.101396

175. Langston JW. Current theories on the cause of Parkinson's disease. J. Neurol. Neurosurg. Psychiatry. 1989;Suppl:13-17. doi:10.1136/jnnp.52.suppl.13

176. Kalia LV, Lang AE. Parkinson's disease. The Lancet. 2015;386 (9996):896-912. doi:10.1016/S0140-6736(14)61393-3

177. Johnson ME, Stecher B, Labrie V, Brundin L, Brundin P. Triggers, Facilitators, and Aggravators: redefining Parkinson's Disease Pathogenesis. Trends in Neurosciences. 2019;42 (1):4-13. doi:10.1016/j.tins.2018.09.007

178. Kempster PA, Hurwitz B, Lees AJ. James Parkinson's Chimera: syndrome or disease? J $R$ Coll Physicians Edinb. 2017;47 (2):190-195. doi:10.4997/JRCPE.2017.220

179. Obeso JA, Stamelou M, Goetz CG, et al. Past, present, and future of Parkinson's disease: a special essay on the 200th Anniversary of the Shaking Palsy. Mov Disord. 2017;32(9):1264-1310. doi: $10.1002 / \mathrm{mds} .27115$

180. Titova N, Padmakumar C, Lewis SJG, Chaudhuri KR. Parkinson's: a syndrome rather than a disease? J Neural Transm (Vienna). 2017;124(8):907-914. doi:10.1007/s00702-016-1667-6

181. Burke RE, Dauer WT, Vonsattel JP. A critical evaluation of the Braak staging scheme for Parkinson's disease. Ann Neurol. 2008;64(5):485-491. doi:10.1002/ana.21541

182. Cardoso SM, Empadinhas N. The Microbiome-Mitochondria Dance in Prodromal Parkinson's Disease. Front. Physiol. 2018;9:471. doi:10.3389/fphys.2018.00471 
183. Engen PA, Dodiya HB, Naqib A, et al. The Potential Role of Gut-Derived Inflammation in Multiple System Atrophy. J. Parkinsons Dis. 2017;7(2):331-346. doi:10.3233/JPD-160991

184. Houser MC, Tansey MG. The gut-brain axis: is intestinal inflammation a silent driver of Parkinson's disease pathogenesis? NPJ Parkinsons Dis. 2017;3:3. doi:10.1038/s41531-016-0002-0

185. Matheoud D, Cannon T, Voisin A, et al. Intestinal infection triggers Parkinson's disease-like symptoms in Pink1(-/-) mice. Nature. 2019;571(7766):565-569. doi:10.1038/s41586-019-1405-y

186. Gray MT, Woulfe JM. Striatal blood-brain barrier permeability in Parkinson's disease. J. Cereb. Blood Flow Metab. 2015;35 (5):747-750. doi:10.1038/jcbfm.2015.32

187. Campos-Acuna J, Elgueta D, Pacheco R. T-Cell-Driven Inflammation as a Mediator of the Gut-Brain Axis Involved in Parkinson's Disease. Front Immunol. 2019;10:239. doi:10.3389/ fimmu.2019.00239

188. Peralta Ramos JM, Iribarren P, Bousset L, Melki R, Baekelandt V. Peripheral Inflammation Regulates CNS Immune Surveillance Through the Recruitment of Inflammatory Monocytes Upon Systemic alpha-Synuclein Administration. Front Immunol. 2019;10:80. doi:10.3389/fimmu.2019.00080

189. Sweeney MD, Sagare AP, Zlokovic BV. Blood-brain barrier breakdown in Alzheimer disease and other neurodegenerative disorders. Nat. Rev. Neurol. 2018;14(3):133-150. doi:10.1038/ nrneurol.2017.188

190. Unger MM, Spiegel J, Dillmann KU, et al. Short chain fatty acids and gut microbiota differ between patients with Parkinson's disease and age-matched controls. Parkinsonism Relat Disord. 2016;32:66-72. doi:10.1016/j.parkreldis.2016.08.019

191. Devos D, Lebouvier T, Lardeux B, et al. Colonic inflammation in Parkinson's disease. Neurobiol Dis. 2013;50:42-48. doi:10.1016/ j.nbd.2012.09.007

192. Harms AS, Thome AD, Yan Z, et al. Peripheral monocyte entry is required for alpha-Synuclein induced inflammation and Neurodegeneration in a model of Parkinson disease. Exp Neurol. 2018;300:179-187. doi:10.1016/j.expneurol.2017.11.010

193. Palm NW, de Zoete MR, Cullen TW, et al. Immunoglobulin A coating identifies colitogenic bacteria in inflammatory bowel disease. Cell. 2014;158(5):1000-1010. doi:10.1016/j.cell.2014.08.006

194. Fitzpatrick Z, Frazer G, Ferro A, et al. Gut-educated IgA plasma cells defend the meningeal venous sinuses. Nature. 2020;587 (7834):472-476. doi:10.1038/s41586-020-2886-4

195. Probstel AK, Zhou X, Baumann R, et al. Gut microbiota-specific $\operatorname{IgA}(+)$ B cells traffic to the CNS in active multiple sclerosis. $S c i$ Immunol. 2020;5(53):eabc7191. doi:10.1126/sciimmunol.abc7191

196. Shalapour S, Lin XJ, Bastian IN, et al. Inflammation-induced IgA + cells dismantle anti-liver cancer immunity. Nature. 2017;551 (7680):340-345. doi:10.1038/nature24302

197. Rojas OL, Probstel AK, Porfilio EA, et al. Recirculating Intestinal IgA-Producing Cells Regulate Neuroinflammation via IL-10. Cell. 2019;176(3):610-624 e618. doi:10.1016/j.cell.2018.11.035

198. Buscarinu MC, Cerasoli B, Annibali V, et al. Altered intestinal permeability in patients with relapsing-remitting multiple sclerosis: a pilot study. Mult. Scler. 2017;23(3):442-446. doi:10.1177/ 1352458516652498

199. Mirabito Colafella KM, Bovée DM, Danser AHJ. The renin-angiotensin-aldosterone system and its therapeutic targets. Exp Eye Res. 2019;186:107680. doi:10.1016/j.exer.2019.05.020

200. Wanka H, Staar D, Lutze P, et al. Anti-necrotic and cardioprotective effects of a cytosolic renin isoform under ischemia-related conditions. J. Mol. Med. 2015;94(1):61-69. doi:10.1007/s00109-015-1321-z
201. Patel S, Rauf A, Khan H, Abu-Izneid T. Renin-angiotensinaldosterone (RAAS): the ubiquitous system for homeostasis and pathologies. Biomed. Pharmacother. 2017;94:317-325. doi:10.1016/j.biopha.2017.07.091

202. Peach MJ, Dostal DE. The angiotensin II receptor and the actions of angiotensin II. J. Cardiovasc. Pharmacol. 1990;16(4):25-30. doi:10.1097/00005344-199016004-00007

203. Durante A, Peretto G, Laricchia A, et al. Role of the renin-angiotensin-aldosterone system in the pathogenesis of atherosclerosis. Curr. Pharm. Des. 2012;18(7):981-1004. doi: $10.2174 / 138161212799436467$

204. Hamming I, Cooper ME, Haagmans BL, et al. The emerging role of ACE2 in physiology and disease. The Journal of Pathology. 2007;212(1):1-11. doi:10.1002/path.2162

205. Rodriguez-Perez AI, Garrido-Gil P, Pedrosa MA, et al. Angiotensin type 2 receptors: role in aging and neuroinflammation in the substantia nigra. Brain, Behav., Immun. 2020;87:256-271. doi:10.1016/j.bbi.2019.12.011

206. Gathiram P, Moodley J. The role of the renin-angiotensinaldosterone system in preeclampsia: a review. Curr. Hypertens. Rep. 2020;22(11):89. doi:10.1007/s11906-020-01098-2

207. Mascolo A, Sessa M, Scavone C, et al. New and old roles of the peripheral and brain renin-angiotensin-aldosterone system (RAAS): focus on cardiovascular and neurological diseases. Int J Cardiol. 2017;227:734-742. doi:10.1016/j.ijcard.2016.10.069

208. Panariello F, Cellini L, Speciani M, De Ronchi D, Atti AR. How does SARS-CoV-2 affect the central nervous system? A working hypothesis. Front Psychiatry. 2020;11:582345. doi:10.3389/ fpsyt. 2020.582345

209. Labandeira-García JL, Garrido-Gil P, Rodriguez-Pallares J, Valenzuela R, Borrajo A, Rodriguez-Perez AI. Brain renin-angiotensin system and dopaminergic cell vulnerability. Front Neuroanat. 2014;8(8):67. doi:10.3389/ fnana.2014.00067

210. Kobiec T, Otero-Losada M, Chevalier G, et al. The renin-angiotensin system modulates dopaminergic neurotransmission: a new player on the scene. Front. Synaptic Neurosci. 2021;13:16. doi:10.3389/fnsyn.2021.638519

211. Viana SD, Nunes S, Reis F. ACE2 imbalance as a key player for the poor outcomes in COVID-19 patients with age-related comorbidities - role of gut microbiota dysbiosis. Ageing Research Reviews. 2020;62:101123. doi:10.1016/j.arr.2020.101123

212. Ames MK, Atkins CE, Pitt B. The renin-angiotensin-aldosterone system and its suppression. J. Vet. Intern. Med. 2019;33 (2):363-382. doi:10.1111/jvim.15454

213. Yang T, Xu C. Physiology and Pathophysiology of the Intrarenal Renin-Angiotensin System: an Update. J Am Soc Nephrol. 2017;28(4):1040-1049. doi:10.1681/ASN.2016070734

214. Alexandre J, Cracowski J-L, Richard V, Bouhanick B. Reninangiotensin-aldosterone system and COVID-19 infection. Ann Endocrinol. 2020;81(2-3):63-67. doi:10.1016/j.ando.2020.04.005

215. Tseng YH, Yang RC, Lu TS. Two hits to the renin-angiotensin system may play a key role in severe COVID-19. Kaohsiung J. Med. Sci. 2020;36(6):389-392. doi:10.1002/kjm2.12237

216. Coto E, Avanzas P, Gómez J. The renin-angiotensin-aldosterone system and coronavirus disease 2019. European Cardiology Review. 2021;16:e07. doi:10.15420/ecr.2020.30

217. Oudit GY, Kassiri Z, Jiang C, et al. SARS-coronavirus modulation of myocardial ACE2 expression and inflammation in patients with SARS. Eur. J. Clin. Invest. 2009;39(7):618-625. doi:10.1111/j.1365-2362.2009.02153.x 
218. Shang J, Wan Y, Luo C, et al. Cell entry mechanisms of SARS-CoV-2. Proceedings of the National Academy of Sciences of the United States of America. 2020;117(21):11727-11734. doi:10.1073/pnas.2003138117

219. South AM, Diz DI, Chappell MC. COVID-19, ACE2, and the cardiovascular consequences. Am J Physiol-Heart C. 2020;318 (5):1084-1090. doi:10.1152/ajpheart.00217.2020

220. Datta PK, Liu F, Fischer T, Rappaport J, Qin X. SARS-CoV-2 pandemic and research gaps: understanding SARS-CoV-2 interaction with the ACE2 receptor and implications for therapy. Theranostics. 2020;10(16):7448-7464. doi:10.7150/thno.48 076

221. Kumar BK, Sekhar KV. Druggable targets of SARS-CoV-2 and treatment opportunities for COVID-19. Bioorg. Chem. 2020;104:104269. doi:10.1016/j.bioorg.2020.104269

222. Kuba K, Imai Y, Penninger JM. Angiotensin-converting enzyme 2 in lung diseases. Curr Opin Pharmacol. 2006;6(3):271-276. doi:10.1016/j.coph.2006.03.001

223. Arentz M, Yim E, Klaff L, et al. Characteristics and Outcomes of 21 Critically Ill Patients With COVID-19 in Washington State. JAMA-J Am Med Assoc. 2020;323(16):1612-1614. doi:10.1001/ jama.2020.4326

224. Mertens B, Vanderheyden P, Michotte Y, Sarre S. The role of the central renin-angiotensin system in Parkinson's disease. J. Renin Angiotensin Aldosterone Syst. 2010;11(1):49-56. doi:10.1177/ 1470320309347789

225. Suzuki Y, Ruiz-Ortega M, Lorenzo O, Ruperez M, Esteban V, Egido J. Inflammation and angiotensin II. International Journal of Biochemistry \& Cell Biology. 2003;35(6):881-900. doi:10.1016/s1357-2725(02)00271-6

226. Griendling KK, Ushio-Fukai M. Reactive oxygen species as mediators of angiotensin II signaling. Regul Pept. 2000;91(13):21-27. doi:10.1016/s0167-0115(00)00136-1

227. Griendling KK, Sorescu D, Ushio-Fukai M. NAD(P)H oxidase: role in cardiovascular biology and disease. Circ. Res. 2000;86 (5):494-501. doi:10.1161/01.res.86.5.494

228. Allen AM, MacGregor DP, Chai SY, et al. Angiotensin II receptor binding associated with nigrostriatal dopaminergic neurons in human basal ganglia. Ann Neurol. 1992;32(3):339-344. doi:10.1002/ana.410320306

229. Wright JW, Kawas LH, Harding JWA. Role for the Brain RAS in Alzheimer's and Parkinson's Diseases. Front. Endocrinol. (Lausanne). 2013;4:158. doi:10.3389/fendo.2013.00158

230. Strittmatter SM, Snyder SH. Angiotensin converting enzyme immunohistochemistry in rat brain and pituitary gland: correlation of isozyme type with cellular localization. Neuroscience. 1987;21 (2):407-420. doi:10.1016/0306-4522(87)90131-x

231. Chai SY, McKenzie JS, McKinley MJ, Mendelsohn FA. Angiotensin converting enzyme in the human basal forebrain and midbrain visualized by in vitro autoradiography. Journal of Comparative Neurology. 1990;291(2):179-194. doi:10.1002/cne.902910203

232. Reardon KA, Mendelsohn FA, Chai SY, Horne MK. The angiotensin converting enzyme (ACE) inhibitor, perindopril, modifies the clinical features of Parkinson's disease. Aust. N. Z. J. Med. 2000;30(1):48-53. doi:10.1111/j.1445-5994.2000.tb01054.x

233. Jenkins TA, Mendelsohn FA, Chai SY. Angiotensin-converting enzyme modulates dopamine turnover in the striatum. $J$ Neurochem. 1997;68(3):1304-1311. doi:10.1046/j.14714159.1997.68031304.x

234. Chabrashvili T, Kitiyakara C, Blau J, et al. Effects of ANG II type 1 and 2 receptors on oxidative stress, renal NADPH oxidase, and SOD expression. American Journal of Physiology Regulatory Integrative and Comparative Physiology. 2003;285(1):R117124. doi:10.1152/ajpregu.00476.2002
235. Rodriguez-Pallares J, Quiroz CR, Parga JA, Guerra MJ, Labandeira-Garcia JL. Angiotensin II increases differentiation of dopaminergic neurons from mesencephalic precursors via angiotensin type 2 receptors. European Journal of Neuroscience. 2004;20(6):1489-1498. doi:10.1111/j.14609568.2004.03621.x

236. Jenkins TA, Wong JY, Howells DW, Mendelsohn FA, Chai SY. Effect of chronic angiotensin-converting enzyme inhibition on striatal dopamine content in the MPTP-treated mouse. J Neurochem. 1999;73(1):214-219. doi:10.1046/j.1471-4159.1999.0730214.x

237. Lopez-Real A, Rey P, Soto-Otero R, Mendez-Alvarez E, Labandeira-Garcia JL. Angiotensin-converting enzyme inhibition reduces oxidative stress and protects dopaminergic neurons in a 6-hydroxydopamine rat model of Parkinsonism. J Neurosci Res. 2005;81(6):865-873. doi:10.1002/jnr.20598

238. Munoz A, Rey P, Guerra MJ, Mendez-Alvarez E, Soto-Otero R, Labandeira-Garcia JL. Reduction of dopaminergic degeneration and oxidative stress by inhibition of angiotensin converting enzyme in a MPTP model of parkinsonism. Neuropharmacology. 2006;51 (1):112-120. doi:10.1016/j.neuropharm.2006.03.004

239. Babior BM. NADPH oxidase. Curr. Opin. Immunol. 2004;16 (1):42-47. doi:10.1016/j.coi.2003.12.001

240. Rodriguez-Pallares J, Parga JA, Munoz A, Rey P, Guerra MJ, Labandeira-Garcia JL. Mechanism of 6-hydroxydopamine neurotoxicity: the role of NADPH oxidase and microglial activation in 6-hydroxydopamine-induced degeneration of dopaminergic neurons. $J$ Neurochem. 2007;103(1):145-156. doi:10.1111/ j.1471-4159.2007.04699.x

241. Joglar B, Rodriguez-Pallares J, Rodriguez-Perez AI, Rey P, Guerra MJ, Labandeira-Garcia JL. The inflammatory response in the MPTP model of Parkinson's disease is mediated by brain angiotensin: relevance to progression of the disease. $J$ Neurochem. 2009;109(2):656-669. doi:10.1111/j.1471-4159.2009.05999.x

242. Okamura A, Rakugi $H$, Ohishi $M$, et al. Upregulation of renin-angiotensin system during differentiation of monocytes to macrophages. J. Hypertens. 1999;17(4):537-545. doi:10.1097/ 00004872-199917040-00012

243. Labandeira-Garcia JL, Rodriguez-Pallares J, Villar-Cheda B, Rodriguez-Perez AI, Garrido-Gil P, Guerra MJ. Aging, Angiotensin system and dopaminergic degeneration in the substantia nigra. Aging Dis. 2011;2(3):257-274.

244. Rodriguez-Perez AI, Valenzuela R, Joglar B, Garrido-Gil P, Guerra MJ, Labandeira-Garcia JL. Renin angiotensin system and gender differences in dopaminergic degeneration. Mol. Neurodegener. 2011;6(1):58. doi:10.1186/1750-1326-6-58

245. Garrido-Gil P, Joglar B, Rodriguez-Perez AI, Guerra MJ, Labandeira-Garcia JL. Involvement of PPAR-gamma in the neuroprotective and anti-inflammatory effects of angiotensin type 1 receptor inhibition: effects of the receptor antagonist telmisartan and receptor deletion in a mouse MPTP model of Parkinson's disease. J Neuroinflammation. 2012;9:38. doi:10.1186/17422094-9-38

246. Villar-Cheda B, Rodriguez-Pallares J, Valenzuela R, et al. Nigral and striatal regulation of angiotensin receptor expression by dopamine and angiotensin in rodents: implications for progression of Parkinson's disease. European Journal of Neuroscience. 2010;32 (10):1695-1706. doi:10.1111/j.1460-9568.2010.07448.x

247. Lan J, Ge J, Yu J, et al. Structure of the SARS-CoV-2 spike receptor-binding domain bound to the ACE2 receptor. Nature. 2020;581(7807):215-220. doi:10.1038/s41586-020-2180-5

248. Li Z, Xu X, Yang M, Feng J, Liu C, Yang C. Role of angiotensin-converting enzyme 2 in neurodegenerative diseases during the COVID-19 pandemic. Aging (Albany N. Y. 2020;12 (23):24453-24461. doi:10.18632/aging.103993 
249. Liu Z, Xiao X, Wei X, et al. Composition and divergence of coronavirus spike proteins and host ACE2 receptors predict potential intermediate hosts of SARS-CoV-2. J Med Virol. 2020;92(6):595-601. doi:10.1002/jmv.25726

250. Hanff TC, Harhay MO, Brown TS, Cohen JB, Mohareb AM. Is There an Association Between COVID-19 Mortality and the Renin-Angiotensin System? A Call for Epidemiologic Investigations. Clin Infect Dis. 2020;71(15):870-874. doi:10.1093/cid/ciaa329

251. Long B, Brady WJ, Koyfman A, Gottlieb M. Cardiovascular complications in COVID-19. Am. J. Emerg. Med. 2020;38 (7):1504-1507. doi:10.1016/j.ajem.2020.04.048

252. Michaud V, Deodhar M, Arwood M, Al Rihani SB, Dow P, Turgeon J. ACE2 as a Therapeutic Target for COVID-19; its Role in Infectious Processes and Regulation by Modulators of the RAAS System. J Clin Med. 2020;9(7):2096. doi:10.3390/ jcm9072096

253. Gheblawi M, Wang K, Viveiros A, et al. Angiotensin-Converting Enzyme 2: SARS-CoV-2 Receptor and Regulator of the Renin-Angiotensin System: celebrating the 20th Anniversary of the Discovery of ACE2. Circ. Res. 2020;126(10):1456-1474. doi:10.1161/CIRCRESAHA.120.317015

254. Morrone CD, Bishay J, McLaurin J. Potential Role of Venular Amyloid in Alzheimer's Disease Pathogenesis. Int J Mol Sci. 2020;21(6):1985. doi:10.3390/ijms21061985

255. Leroy E, Boyer R, Auburger G, et al. The ubiquitin pathway in Parkinson's disease. Nature. 1998;395(6701):451-452. doi: $10.1038 / 26652$

256. Paul M, Poyan Mehr A, Kreutz R. Physiology of local renin-angiotensin systems. Physiol Rev. 2006;86(3):747-803. doi:10.1152/physrev.00036.2005

257. Kaur P, Muthuraman A, Kaur M. The implications of angiotensin-converting enzymes and their modulators in neurodegenerative disorders: current and future perspectives. ACS Chem Neurosci. 2015;6(4):508-521. doi:10.1021/cn500363g

258. Ohrui T, Tomita N, Sato-Nakagawa $T$, et al. Effects of brain-penetrating ACE inhibitors on Alzheimer disease progression. Neurology. 2004;63(7):1324-1325. doi:10.1212/01. wnl.0000140705.23869.e9

259. Li NC, Lee A, Whitmer RA, et al. Use of angiotensin receptor blockers and risk of dementia in a predominantly male population: prospective cohort analysis. BMJ. 2010;340:b5465. doi:10.1136/bmj.b5465

260. Ongali B, Nicolakakis N, Tong XK, et al. Angiotensin II type 1 receptor blocker losartan prevents and rescues cerebrovascular, neuropathological and cognitive deficits in an Alzheimer's disease model. Neurobiol Dis. 2014;68:126-136. doi:10.1016/j. nbd.2014.04.018

261. Jochemsen HM, Teunissen CE, Ashby EL, et al. The association of angiotensin-converting enzyme with biomarkers for Alzheimer's disease. Alzheimers Res. Ther. 2014;6(3):27. doi:10.1186/alzrt257

262. Rocha NP, Toledo A, Corgosinho LTS, et al. Cerebrospinal Fluid Levels of Angiotensin-Converting Enzyme Are Associated with Amyloid-beta42 Burden in Alzheimer's Disease. J Alzheimers Dis. 2018;64(4):1085-1090. doi:10.3233/JAD-180282

263. Hu J, Igarashi A, Kamata M, Nakagawa H. Angiotensinconverting enzyme degrades Alzheimer amyloid beta-peptide (A beta); retards A beta aggregation, deposition, fibril formation; and inhibits cytotoxicity. J Biol Chem. 2001;276(51):47863-47868. doi:10.1074/jbc.M104068200

264. Zou K, Liu J, Watanabe A, et al. Abeta43 is the earliest-depositing Abeta species in APP transgenic mouse brain and is converted to Abeta41 by two active domains of ACE. American Journal of Pathology. 2013;182(6):2322-2331. doi:10.1016/j.ajpath.2013.01.053
265. Zubenko GS, Volicer L, Direnfeld LK, Freeman M, Langlais PJ, Nixon RA. Cerebrospinal fluid levels of angiotensin-converting enzyme in Alzheimer's disease, Parkinson's disease and progressive supranuclear palsy. Brain Research. 1985;328(2):215-221. doi:10.1016/0006-8993(85)91032-7

266. Kawajiri M, Mogi M, Higaki N, et al. Angiotensin-converting enzyme (ACE) and ACE2 levels in the cerebrospinal fluid of patients with multiple sclerosis. Mult. Scler. 2009;15 (2):262-265. doi:10.1177/1352458508097923

267. Kehoe PG, Wong S, Al Mulhim N, Palmer LE, Miners JS. Angiotensin-converting enzyme 2 is reduced in Alzheimer's disease in association with increasing amyloid-beta and tau pathology. Alzheimers Res. Ther. 2016;8(1):50. doi:10.1186/s13195016-0217-7

268. Kamel AS, Abdelkader NF, Abd El-Rahman SS, Emara M, Zaki HF, Khattab MM. Stimulation of ACE2/ANG(1-7)/Mas Axis by Diminazene Ameliorates Alzheimer's Disease in the D-Galactose-Ovariectomized Rat Model: role of PI3K/Akt Pathway. Molecular Neurobiology. 2018;55(10):8188-8202. doi:10.1007/s12035-018-0966-3

269. Evans CE, Miners JS, Piva G, et al. ACE2 activation protects against cognitive decline and reduces amyloid pathology in the Tg2576 mouse model of Alzheimer's disease. Acta Neuropathologica. 2020;139(3):485-502. doi:10.1007/s00401019-02098-6

270. Zheng J, Wittouck S, Salvetti E, et al. A taxonomic note on the genus Lactobacillus: description of 23 novel genera, emended description of the genus Lactobacillus Beijerinck 1901, and union of Lactobacillaceae and Leuconostocaceae. Int J Syst Evol Microbiol. 2020;70(4):2782-2858. doi:10.1099/ijsem.0.004107

271. Salvetti E, Harris HMB, Felis GE, O'Toole PW, Björkroth J. Comparative genomics of the genus Lactobacillus reveals robust phylogroups that provide the basis for reclassification. Appl Environ Microbiol. 2018;84(17):e00993-00918. doi:10.1128/ aem.00993-18

272. Zheng J, Ruan L, Sun M, Gänzle M, Björkroth J. A genomic view of lactobacilli and pediococci demonstrates that phylogeny matches ecology and physiology. Appl Environ Microbiol. 2015;81(20):7233-7243. doi:10.1128/aem.02116-15

273. Sun Z, Harris HMB, McCann A, et al. Expanding the biotechnology potential of lactobacilli through comparative genomics of 213 strains and associated genera. Nature Communications. 2015;6 (1):8322. doi:10.1038/ncomms 9322

274. Duar RM, Lin XB, Zheng J, et al. Lifestyles in transition: evolution and natural history of the genus Lactobacillus. FEMS Microbiology Reviews. 2017;41(1):27-48. doi:10.1093/femsre/fux030

275. Martino ME, Bayjanov JR, Caffrey BE, et al. Nomadic lifestyle of Lactobacillus plantarum revealed by comparative genomics of 54 strains isolated from different habitats. Environmental Microbiology. 2016;18(12):4974-4989. doi:10.1111/14622920.13455

276. Rossi M, Martinez-Martinez D, Amaretti A, Ulrici A, Raimondi S, Moya A. Mining metagenomic whole genome sequences revealed subdominant but constant Lactobacillus population in the human gut microbiota. Environmental Microbiology Reports. 2016;8(3):399-406. doi:10.1111/1758-2229.12405

277. Zhang Z, Lv J, Pan L, Zhang Y. Roles and applications of probiotic Lactobacillus strains. Appl Microbiol Biotechnol. 2018;102(19):8135-8143. doi:10.1007/s00253-018-9217-9

278. Achuthan AA, Duary RK, Madathil A, et al. Antioxidative potential of lactobacilli isolated from the gut of Indian people. Mol Biol Rep. 2012;39(8):7887-7897. doi:10.1007/s11033-012-1633-9

279. Mishra V, Shah C, Mokashe N, Chavan R, Yadav H, Prajapati J. Probiotics as potential antioxidants: a systematic review. J. Agric. Food Chem. 2015;63(14):3615-3626. doi:10.1021/jf506326t 
280. Kleniewska P, Hoffmann A, Pniewska E, Pawliczak R. The influence of probiotic Lactobacillus casei in combination with prebiotic inulin on the antioxidant capacity of human plasma. Oxid. Med. Cell. Longev. 2016;2016:1-10. doi:10.1155/2016/1340903

281. Westfall S, Lomis N, Prakash S. Ferulic acid produced by Lactobacillus fermentum influences developmental growth through a dTOR-mediated mechanism. Mol Biotechnol. 2018;61 (1):1-11. doi:10.1007/s12033-018-0119-y

282. Fung TC. The microbiota-immune axis as a central mediator of gut-brain communication. Neurobiol Dis. 2020;136:104714. doi:10.1016/j.nbd.2019.104714

283. Danilenko VN, Marsova MV, Poluektova EU. The use of cells of the strain Lactobacillus fermentum U-21 and biologically active substances obtained from them. Patent No. RU2019141103A by 11.06.2021. 2021. 1-26.

284. Bhandari P, Rishi P, Prabha V. Positive effect of probiotic Lactobacillus plantarum in reversing LPS-induced infertility in a mouse model. J Med Microbiol. 2016;65(5):345-350. doi:10.1099/jmm.0.000230

285. Grompone G, Martorell P, Llopis S, et al. Anti-inflammatory Lactobacillus rhamnosus CNCM I-3690 strain protects against oxidative stress and increases lifespan in Caenorhabditis elegans. PLoS One. 2012;7(12):e52493. doi:10.1371/journal.pone.0052493

286. Lee J, Yang W, Hostetler A, et al. Characterization of the anti-inflammatory Lactobacillus reuteri BM36301 and its probiotic benefits on aged mice. BMC Microbiol. 2016;16:69. doi:10.1186/s12866-016-0686-7

287. Choi SS, Kim Y, Han KS, You S, Oh S, Kim SH. Effects of Lactobacillus strains on cancer cell proliferation and oxidative stress in vitro. Lett Appl Microbiol. 2006;42(5):452-458. doi:10.1111/j.1472-765X.2006.01913.x

288. Noureen S, Riaz A, Arshad M, Arshad N. In vitro selection and in vivo confirmation of the antioxidant ability of Lactobacillus brevis MG000874. J Appl Microbiol. 2019;126(4):1221-1232. doi:10.1111/jam.14189

289. Marsova M, Poluektova E, Odorskaya M, et al. Protective effects of Lactobacillus fermentum U-21 against paraquat-induced oxidative stress in Caenorhabditis elegans and mouse models. World J Microbiol Biotechnol. 2020a;36(7):104. doi:10.1007/s11274-02002879-2

290. Marsova M, Odorskaya M, Novichkova M, et al. The Lactobacillus brevis $47 \mathrm{f}$ Strain Protects the Murine Intestine from Enteropathy Induced by 5-Fluorouracil. Microorganisms. 2020b;8(6):876. doi:10.3390/microorganisms8060876

291. Miraghajani M, Zaghian N, Mirlohi M, Feizi A, Ghiasvand R. The Impact of Probiotic Soy Milk Consumption on Oxidative Stress Among Type 2 Diabetic Kidney Disease Patients: a Randomized Controlled Clinical Trial. J. Ren. Nutr. 2017;27 (5):317-324. doi:10.1053/j.jrn.2017.04.004

292. Soleimani A, Zarrati Mojarrad M, Bahmani F, et al. Probiotic supplementation in diabetic hemodialysis patients has beneficial metabolic effects. Kidney Int. 2017;91(2):435-442. doi:10.1016/j. kint.2016.09.040

293. Amaretti A, Nunzio M, Pompei A, Raimondi S, Rossi M, Bordoni A. Antioxidant properties of potentially probiotic bacteria: in vitro and in vivo activities. Appl Microbiol Biotechnol. 2012;97(2):809-817. doi:10.1007/s00253-012-4241-7

294. Ho L, Ono K, Tsuji M, Mazzola P, Singh R, Pasinetti GM. Protective roles of intestinal microbiota derived short chain fatty acids in Alzheimer's disease-type beta-amyloid neuropathological mechanisms. Expert Rev. Neurother. 2017;18(1):83-90. doi:10.1080/14737175.2018.1400909
295. Nowak A, Paliwoda A, Błasiak J. Anti-proliferative, pro-apoptotic and anti-oxidative activity of Lactobacillus and Bifidobacterium strains: a review of mechanisms and therapeutic perspectives. Crit. Rev. Food Sci. Nutr. 2018;59(21):3456-3467. doi:10.1080/10408398.2018.1494539

296. Attia HN, Maklad YA. Neuroprotective effects of coenzyme Q10 on paraquat-induced Parkinson's disease in experimental animals. Behav. Pharmacol. 2018;29(1):79-86. doi:10.1097/ fbp. 0000000000000342

297. Flanagan E, Müller M, Hornberger M, Vauzour D. Impact of flavonoids on cellular and molecular mechanisms underlying age-related cognitive decline and neurodegeneration. Curr Nutr Rep. 2018;7(2):49-57. doi:10.1007/s13668-018-0226-1

298. Haddadi R, Nayebi AM, Eyvari Brooshghalan S. Silymarin prevents apoptosis through inhibiting the Bax/caspase- 3 expression and suppresses toll like receptor-4 pathway in the $\mathrm{SNc}$ of 6-OHDA intoxicated rats. Biomed. Pharmacother. 2018;104:127-136. doi:10.1016/j.biopha.2018.05.020

299. Zhang L, Zhang L, Li L, Hölscher C. Neuroprotective effects of the novel GLP-1 long acting analogue semaglutide in the MPTP Parkinson's disease mouse model. Neuropeptides. 2018;71:70-80. doi:10.1016/j.npep.2018.07.003

300. Ganji-Arjenaki M, Rafieian-Kopaei M. Probiotics are a good choice in remission of inflammatory bowel diseases: a meta analysis and systematic review. $J$ Cell Physiol. 2018;233 (3):2091-2103. doi:10.1002/jcp.25911

301. Clemente JC, Ursell LK, Parfrey LW, Knight R. The impact of the gut microbiota on human health: an integrative view. Cell. 2012;148(6):1258-1270. doi:10.1016/j.cell.2012.01.035

302. Cryan JF, Dinan TG. Mind-altering microorganisms: the impact of the gut microbiota on brain and behaviour. Nature Reviews Neuroscience. 2012;13(10):701-712. doi:10.1038/nrn3346

303. Maslowski KM, Mackay CR. Diet, gut microbiota and immune responses. Nat. Immunol. 2010;12(1):5-9. doi:10.1038/ni0111-5

304. Perez-Pardo P, Kliest T, Dodiya HB, et al. The gut-brain axis in Parkinson's disease: possibilities for food-based therapies. Eur $J$ Pharmacol. 2017;817:86-95. doi:10.1016/j.ejphar.2017.05. 042

305. Marsland BJ, Trompette A, Gollwitzer ES. The gut-lung axis in respiratory disease. Ann Am Thorac Soc. 2015;12(2):150-156. doi:10.1513/AnnalsATS.201503-133AW

306. Dang AT, Marsland BJ. Microbes, metabolites, and the gut-lung axis. Mucosal Immunol. 2019;12(4):843-850. doi:10.1038/ s41385-019-0160-6

307. Dias V, Junn E, Mouradian MM. The role of oxidative stress in Parkinson's disease. J. Parkinsons Dis. 2013;3(4):461-491. doi:10.3233/jpd-130230

308. Rao M, Gershon MD. The bowel and beyond: the enteric nervous system in neurological disorders. Nat Rev Gastro Hepat. 2016;13 (9):517-528. doi:10.1038/nrgastro.2016.107

309. Wang N, Song G, Yang Y, Yuan W, Qi M. Inactivated Lactobacillus promotes protection against myocardial ischemiareperfusion injury through NF-кB pathway. Biosci Rep. 2017;37 (6):BSR20171025. doi:10.1042/bsr20171025

310. Sun M-F, Zhu Y-L, Zhou Z-L, et al. Neuroprotective effects of fecal microbiota transplantation on MPTP-induced Parkinson's disease mice: gut microbiota, glial reaction and TLR4/TNF- $\alpha$ signaling pathway. Brain, Behav., Immun. 2018;70:48-60. doi:10.1016/j.bbi.2018.02.005

311. Wanchao S, Chen M, Zhiguo S, Futang X, Mengmeng S. Protective effect and mechanism of Lactobacillus on cerebral ischemia reperfusion injury in rats. Braz J Med Biol Res. 2018;51(7):e7172. doi:10.1590/1414-431x20187172 
312. Fukai T, Ushio-Fukai M. Superoxide dismutases: role in redox signaling, vascular function, and diseases. Antioxid Redox Sign. 2011;15(6):1583-1606. doi:10.1089/ars.2011.3999

313. Miriyala S, Spasojevic I, Tovmasyan A, et al. Manganese superoxide dismutase, MnSOD and its mimics. Biochim Biophys Acta. 2012;1822(5):794-814. doi:10.1016/j.bbadis.2011.12.002

314. Calder PC, Albers R, Antoine JM, et al. Inflammatory disease processes and interactions with nutrition. Br J Nutr. 2009;101 (S1):1-45. doi:10.1017/s0007114509377867

315. Ramalho R, Rao M, Zhang $\mathrm{C}$, et al. Immunometabolism: new insights and lessons from antigen-directed cellular immune responses. Semin Immunopathol. 2020;42(3):279-313. doi:10.1007/s00281-020-00798-w

316. Xue J, Ajuwon KM, Fang R. Mechanistic insight into the gut microbiome and its interaction with host immunity and inflammation. Anim Nutr. 2020;6(4):421-428. doi:10.1016/j. aninu.2020.05.007

317. Schubert M-L, Rohrbach R, Schmitt M, Stein-Thoeringer CK. The potential role of the intestinal micromilieu and individual microbes in the immunobiology of chimeric antigen receptor T-cell therapy. Front Immunol. 2021;12:1836. doi:10.3389/ fimmu.2021.670286

318. Xing C, Wang M, Ajibade AA, et al. Microbiota regulate innate immune signaling and protective immunity against cancer. Cell Host Microbe. 2021;29(6):959-974. doi:10.1016/j.chom.2021.03.016

319. Averina OV, Danilenko VN. Human intestinal microbiota: role in development and functioning of the nervous system. Microbiology. 2017;86(1):1-18. doi:10.1134/S0026261717010040

320. Bhattarai Y. Microbiota-gut-brain axis: interaction of gut microbes and their metabolites with host epithelial barriers. Neurogastroenterol Motil. 2018;30(6):e13366. doi:10.1111/ nmo. 13366

321. Kerksick C, Willoughby D. The antioxidant role of glutathione and $\mathrm{N}$-acetyl-cysteine supplements and exercise-induced oxidative stress. J Int Soc Sports Nutr. 2005;2(2):38. doi:10.1186/15502783-2-2-38

322. Jung K-A, Kwak M-K. The Nrf2 system as a potential target for the development of indirect antioxidants. Molecules. 2010;15 (10):7266-7291. doi:10.3390/molecules15107266

323. Kullisaar T, Songisepp E, Aunapuu M, et al. Complete glutathione system in probiotic Lactobacillus fermentum ME-3. Appl Biochem Microbiol. 2010;46(5):527-531. doi:10.1134/ S0003683810050030

324. Falony G, Joossens M, Vieira-Silva S, et al. Population-level analysis of gut microbiome variation. Science. 2016;352 (6285):560-564. doi:10.1126/science.aad3503

325. Tang W, Xing Z, Li C, Wang J, Wang Y. Molecular mechanisms and in vitro antioxidant effects of Lactobacillus plantarum MA2. Food Chem. 2017;221:1642-1649. doi:10.1016/j.foodchem.2016.10.124

326. Main PAE, Angley MT, O'Doherty CE, Thomas P, Fenech M. The potential role of the antioxidant and detoxification properties of glutathione in autism spectrum disorders: a systematic review and meta-analysis. Nutr. Metab. (Lond. 2012;9(1):35. doi:10.1186/1743-7075-9-35

327. Pophaly SD, Singh R, Pophaly SD, Kaushik JK, Tomar SK. Current status and emerging role of glutathione in food grade lactic acid bacteria. Microb Cell Fact. 2012;11(1):114. doi:10.1186/1475-2859-11-114

328. Lin J, Zou Y, Cao K, Ma C, Chen Z. The impact of heterologous catalase expression and superoxide dismutase overexpression on enhancing the oxidative resistance in Lactobacillus casei. $J$ Ind Microbiol Biotechnol. 2016;43(5):703-711. doi:10.1007/s10295016-1752-8
329. García-Giménez JL, Ibañez-Cabellos JS, Seco-Cervera M, Pallardó F. S1-1 - glutathione and cellular redox control in epigenetic regulation. Free Radic. Biol. Med. 2014;75:3. doi:10.1016/j.freeradbiomed.2014.10.828

330. Laiño J, Villena J, Kanmani P, Kitazawa H. Immunoregulatory effects triggered by lactic acid bacteria exopolysaccharides: new insights into molecular interactions with host cells. Microorganisms. 2016;4(3):27. doi:10.3390/ microorganisms 4030027

331. Lyu C, Hu S, Huang J, et al. Contribution of the activated catalase to oxidative stress resistance and $\gamma$-aminobutyric acid production in Lactobacillus brevis. Int. J. Food Microbiol. 2016;238:302-310. doi:10.1016/j.ijfoodmicro.2016.09.023

332. Mahdhi A, Leban N, Chakroun I, et al. Extracellular polysaccharide derived from potential probiotic strain with antioxidant and antibacterial activities as a prebiotic agent to control pathogenic bacterial biofilm formation. Microb. Pathog. 2017;109:214-220. doi:10.1016/j.micpath.2017.05.046

333. Danilenko VN, Marsova MV, Poluektova EU, Odorskaya MV, Yunes RA. Lactobacillus fermentum U-21 strain, which produces complex of biologically active substances which neutralize superoxide anion induced by chemical agents. Patent No. 2705250 by 05.02.2018. 2018. 1-16.

334. Danilenko VN, Marsova MV, Poluektova EU. The use of cells of the Lactobacillus fermentum U-21 strain and biologically active substances obtained from them. Patent No. 2019141103/20 (080350) by 11.12.2019. 2019. 1-24.

335. Danilenko VN, Stavrovskaya AV, Voronkov D, et al. The use of a pharmabiotic based on the Lactobacillus fermentum U-21 strain to modulate the neurodegenerative process in an experimental model of Parkinson's disease. Annals of Clinical and Experimental Neurology. 2020;14:62-69. doi:10.25692/ ACEN.2020.1.7

336. Scheperjans F, Aho V, Pereira PAB, et al. Gut microbiota are related to Parkinson's disease and clinical phenotype. Mov Disord. 2014;30(3):350-358. doi:10.1002/mds.26069

337. Petrov VA, Saltykova IV, Zhukova IA, et al. Analysis of gut microbiota in patients with Parkinson's disease. Bull Exp Biol Med. 2017;162(6):734-737. doi:10.1007/s10517-017-3700-7

338. Bedarf JR, Hildebrand F, Coelho LP, et al. Functional implications of microbial and viral gut metagenome changes in early stage L-DOPA-naïve Parkinson's disease patients. Genome Med. 2017;9(1):39. doi:10.1186/s13073-017-0428-y

339. Antunes AEC, Vinderola G, Xavier-Santos D, Sivieri K. Potential contribution of beneficial microbes to face the COVID-19 pandemic. Food Res. Int. 2020;136:109577. doi:10.1016/j. foodres.2020.109577

340. Xiang Z, Koo H, Chen Q, Zhou X, Liu Y, Simon-Soro A. Potential implications of SARS-CoV-2 oral infection in the host microbiota. J. Oral Microbiol. 2020;13(1):1853451. doi:10.1080/ 20002297.2020.1853451

341. Follmer C. Viral infection-induced gut dysbiosis, neuroinflammation, and alpha-synuclein aggregation: updates and perspectives on COVID-19 and neurodegenerative disorders. ACS Chem Neurosci. 2020;11(24):4012-4016. doi:10.1021/ acschemneuro.0c00671

342. Boulangé CL, Neves AL, Chilloux J, Nicholson JK, Dumas M-E. Impact of the gut microbiota on inflammation, obesity, and metabolic disease. Genome Med. 2016;8(1):42. doi:10.1186/s13073016-0303-2

343. Wang Z, Zhao Y. Gut microbiota derived metabolites in cardiovascular health and disease. Protein Cell. 2018;9(5):416-431. doi:10.1007/s13238-018-0549-0 
344. De Luca F, Shoenfeld Y. The microbiome in autoimmune diseases. Clin Exp Immunol. 2019;195(1):74-85. doi:10.1111/ cei. 13158

345. Xu H, Liu M, Cao J, et al. The dynamic interplay between the gut microbiota and autoimmune diseases. Journal of Immunology Research. 2019;2019:1-14. doi:10.1155/2019/7546047

346. Goulet O. Potential role of the intestinal microbiota in programming health and disease: figure 1. Nutr Rev. 2015;73 ( (suppl 1)):32-40. doi:10.1093/nutrit/nuv039

347. Needell JC, Zipris D. The role of the intestinal microbiome in type 1 diabetes pathogenesis. Curr. Diab. Rep. 2016;16(10):89. doi:10.1007/s11892-016-0781-z

348. Biscetti F, Nardella E, Cecchini AL, Landolfi R, Flex A. The role of the microbiota in the diabetic peripheral artery disease. Mediators Inflamm. 2019;2019:1-16. doi:10.1155/2019/4128682

349. Huang YJ, Marsland BJ, Bunyavanich S, et al. The microbiome in allergic disease: current understanding and future opportunities. J. Allergy Clin. Immunol. 2017;139(4):1099-1110. doi:10.1016/j. jaci.2017.02.007

350. Haikal C, Chen QQ, Li JY. Microbiome changes: an indicator of Parkinson's disease? Transl Neurodegener. 2019;8:38. doi:10.1186/s40035-019-0175-7

351. Averina OV, Zorkina YA, Yunes RA, et al. Bacterial metabolites of human gut microbiota correlating with depression. Int $\mathrm{J} \mathrm{Mol}$ Sci. 2020b;21(23):9234. doi:10.3390/Ijms21239234

352. Du Y, Gao X-R, Peng L, Ge J-F. Crosstalk between the microbiota-gut-brain axis and depression. Heliyon. 2020;6(6): e04097. doi:10.1016/j.heliyon.2020.e04097

353. Ding HT, Taur Y, Walkup JT. Gut microbiota and autism: key concepts and findings. J. Autism Dev. Disord. 2016;47 (2):480-489. doi:10.1007/s10803-016-2960-9

354. Chen -W-W, Zhang XIA, Huang W-J. Role of neuroinflammation in neurodegenerative diseases (Review). Mol Med Report. 2016;13(4):3391-3396. doi:10.3892/mmr.2016.4948

355. Siniscalco D, Schultz S, Brigida A, Antonucci N. Inflammation and neuro-immune dysregulations in autism spectrum disorders. Pharmaceuticals. 2018;11(2):56. doi:10.3390/ph11020056

356. Prata J, Machado AS, von Doellinger O, et al. The contribution of inflammation to autism spectrum disorders: recent clinical evidence. Methods Mol Biol. 2019;2011:493-510. doi:10.1007/ 978-1-4939-9554-7 29

357. Keshavarzian A, Green SJ, Engen PA, et al. Colonic bacterial composition in Parkinson's disease. Mov Disord. 2015;30 (10):1351-1360. doi:10.1002/mds.26307

358. Pereira PAB, Aho VTE, Paulin L, Pekkonen E, Auvinen P, Scheperjans F. Oral and nasal microbiota in Parkinson's disease. Parkinsonism Relat Disord. 2017;38:61-67. doi:10.1016/j. parkreldis.2017.02.026

359. Heintz-Buschart A, Pandey U, Wicke T, et al. The nasal and gut microbiome in Parkinson's disease and idiopathic rapid eye movement sleep behavior disorder. Mov Disord. 2018;33 (1):88-98. doi:10.1002/mds.27105

360. Minato T, Maeda T, Fujisawa Y, et al. Progression of Parkinson's disease is associated with gut dysbiosis: two-year follow-up study. PLoS One. 2017;12(11):e0187307. doi:10.1371/journal. pone.0187307

361. Hasegawa $\mathrm{S}$, Goto $\mathrm{S}$, Tsuji $\mathrm{H}$, et al. Intestinal dysbiosis and lowered serum lipopolysaccharide-binding protein in Parkinson's disease. Mov Disord. 2016;31:S40-S40. doi:10.1371/journal. pone. 0142164

362. Hopfner F, Kunstner A, Muller SH, et al. Gut microbiota in Parkinson disease in a northern German cohort. Brain Res. 2017;1667:41-45. doi:10.1016/j.brainres.2017.04.019

363. Scheperjans F, Aho V, Pereira PAB, et al. Gut Microbiota Are Related to Parkinson's Disease and Clinical Phenotype. Mov Disord. 2015;30(3):350-358. doi:10.1002/mds.26069
364. Lin $\mathrm{CH}$, Chen $\mathrm{CC}$, Chiang HL, et al. Altered gut microbiota and inflammatory cytokine responses in patients with Parkinson's disease. J Neuroinflammation. 2019;16(1):129. doi:10.1186/ s12974-019-1528-y

365. Aho VTE, Pereira PAB, Voutilainen S, et al. Gut microbiota in Parkinson's disease: temporal stability and relations to disease progression. EBioMedicine. 2019;44:691-707. doi:10.1016/j. ebiom.2019.05.064

366. Hill-Burns EM, Debelius JW, Morton JT, et al. Parkinson's Disease and Parkinson's Disease Medications Have Distinct Signatures of the Gut Microbiome. Mov Disord. 2017;32 (5):739-749. doi:10.1002/mds.26942

367. Mihaila D, Donegan J, Barns S, et al. The oral microbiome of early stage Parkinson's disease and its relationship with functional measures of motor and non-motor function. PLoS One. 2019;14(6):e0218252. doi:10.1371/journal.pone.0218252

368. Lin AQ, Zheng WX, He Y, et al. Gut microbiota in patients with Parkinson's disease in southern China. Parkinsonism Relat Disord. 2018;53:82-88. doi:10.1016/j.parkreldis.2018.05.007

369. Li W, Wu XL, Hu X, et al. Structural changes of gut microbiota in Parkinson's disease and its correlation with clinical features. Science China-Life Sciences. 2017;60(11):1223-1233. doi:10.1007/s11427-016-9001-4

370. Perez-Pardo P, Dodiya HB, Engen PA, et al. Gut bacterial composition in a mouse model of Parkinson's disease. Benef Microbes. 2018;9(5):799-814. doi:10.3920/BM2017.0202

371. Pietrucci D, Cerroni R, Unida V, et al. Dysbiosis of gut microbiota in a selected population of Parkinson's patients. Parkinsonism Relat Disord. 2019;65:124-130. doi:10.1016/j. parkreldis.2019.06.003

372. Qian Y, Yang X, Xu S, et al. Alteration of the fecal microbiota in Chinese patients with Parkinson's disease. Brain. Behav. Immun. 2018;70:194-202. doi:10.1016/j.bbi.2018.02.016

373. Li F, Wang P, Chen Z, Sui X, Xie X, Zhang J. Alteration of the fecal microbiota in North-Eastern Han Chinese population with sporadic Parkinson's disease. Neuroscience Letters. 2019;707:134297. doi:10.1016/j.neulet.2019.134297

374. Ansaldo E, Slayden LC, Ching KL, et al. Akkermansia muciniphila induces intestinal adaptive immune responses during homeostasis. Science. 2019;364(6446):1179. doi:10.1126/ science.aaw 7479

375. Zuo T, Zhang F, Lui GCY, et al. Alterations in Gut Microbiota of Patients With COVID-19 During Time of Hospitalization. Gastroenterology. 2020;159(3):944-955 e948. doi:10.1053/j. gastro.2020.05.048

376. Zuo T, Liu Q, Zhang F, et al. Depicting SARS-CoV-2 faecal viral activity in association with gut microbiota composition in patients with COVID-19. Gut. 2021;70(2):276-284. doi:10.1136/gutjnl2020-322294

377. Gu S, Chen Y, Wu Z, et al. Alterations of the Gut Microbiota in Patients With Coronavirus Disease 2019 or H1N1 Influenza. Clin Infect Dis. 2020;71(10):2669-2678. doi:10.1093/cid/ciaa709

378. Tao W, Zhang G, Wang X, et al. Analysis of the intestinal microbiota in COVID-19 patients and its correlation with the inflammatory factor IL-18. Med Microecol. 2020;5:100023. doi:10.1016/j.medmic.2020.100023

379. Yamamoto S, Saito M, Tamura A, Prawisuda D, Mizutani T, Yotsuyanagi H. The human microbiome and COVID-19: a systematic review. PLoS One. 2021;16(6):e0253293. doi:10.1371/journal.pone.0253293

380. Brown SP, Cornforth DM, Mideo N. Evolution of virulence in opportunistic pathogens: generalism, plasticity, and control. Trends Microbiol. 2012;20(7):336-342. doi:10.1016/j.tim.2012.04.005

381. Xu K, Cai H, Shen Y, et al. Management of COVID-19: the Zhejiang experience. Journal of Zhejiang University. Medical Sciences. 2020;49(2):147-157. doi:10.3785/j.issn.1008-9292.2020.02.02 
382. Shen Z, Xiao Y, Kang L, et al. Genomic Diversity of Severe Acute Respiratory Syndrome-Coronavirus 2 in Patients With Coronavirus Disease 2019. Clin Infect Dis. 2020;71 (15):713-720. doi:10.1093/cid/ciaa203

383. De Maio F, Posteraro B, Ponziani FR, Cattani P, Gasbarrini A, Sanguinetti M. Nasopharyngeal Microbiota Profiling of SARS-CoV-2 Infected Patients. Biological Procedures Online. 2020;22:18. doi:10.1186/s12575-020-00131-7

384. Elsayed S, Zhang K. Human infection caused by Clostridium hathewayi. Emerg Infect Dis. 2004;10(11):1950-1952. doi:10.3201/eid1011.040006

385. Tamilselvi R, Dakshinamoorthy M, Venkatesh A, Arumugam K. A Literature Review on Dental Caries Vaccine-A Prevention Strategy. Indian Journal of Public Health Research and Development. 2019;10:3041.

386. Tang L, Gu S, Gong Y, et al. Clinical Significance of the Correlation between Changes in the Major Intestinal Bacteria Species and COVID-19 Severity. Engineering (Beijing, China) 2020;6(10):1178-1184. doi:10.1016/j.eng.2020.05.013

387. Montefusco L, Ben Nasr M, D'Addio F, et al. Acute and long-term disruption of glycometabolic control after SARS-CoV-2 infection. Nat Metab. 2021;3(6):774-785. doi:10.1038/s42255-021-00407-6

388. Al-Aly Z, Xie Y, Bowe B. High-dimensional characterization of post-acute sequelae of COVID-19. Nature. 2021;594 (7862):259-264. doi:10.1038/s41586-021-03553-9

389. Weng J, Li Y, Li J, et al. Gastrointestinal sequelae 90 days after discharge for COVID-19. Lancet Gastroenterol Hepatol. 2021;6 (5):344-346. doi:10.1016/S2468-1253(21)00076-5

390. Chen Y, Gu S, Chen Y, et al. Six-month follow-up of gut microbiota richness in patients with COVID-19. Gut. 2021;1:gutjnl2021-324090. doi:10.1136/gutjnl-2021-324090

391. Sokol H, Contreras V, Maisonnasse P, et al. SARS-CoV-2 infection in nonhuman primates alters the composition and functional activity of the gut microbiota. Gut Microbes. 2021;13(1):1-19. doi:10.1080/19490976.2021.1893113

392. Yeoh YK, Zuo T, Lui GC, et al. Gut microbiota composition reflects disease severity and dysfunctional immune responses in patients with COVID-19. Gut. 2021;70(4):698-706. doi:10.1136/ gutjnl-2020-323020

393. Poluektova E, Yunes R, Danilenko V. The putative antidepressant mechanisms of probiotic bacteria: relevant genes and proteins. Nutrients. 2021;13(5):1591. doi:10.3390/nu13051591

394. Nezametdinova VZ, Yunes RA, Dukhinova MS, Alekseeva MG, Danilenko VN. The role of the PFNA operon in the recognition of host's immune signals: prospects for the use of the FN3 protein in the treatment of COVID-19. Int J Mol Sci. 2021;22:9219. doi:10.3390/ijms22179219

395. Belkina TV, Averina OV, Savenkova EV, Danilenko VN. Human intestinal microbiome and the immune system: the role of probiotics in shaping an immune system unsusceptible to COVID-19 infection. Biology Bulletin Reviews. 2021;11(4):523-539. doi:10.1134/S2079086421040034

396. Suvarna V, Baviskar N. The clinical overview on natural immunopolysaccharides as an adjuvant therapy of cancer. Int J Pharm Sci Res. 2021;12(7):3521-3536. doi:10.13040/ijpsr.0975-8232

397. Gentile F, Doneddu PE, Riva N, Nobile-Orazio E, Quattrini A. Diet, microbiota and brain health: unraveling the network intersecting metabolism and neurodegeneration. Int $J$ Mol Sci. 2020;21(20):7471. doi:10.3390/ijms21207471

398. Fan Y, Pedersen O. Gut microbiota in human metabolic health and disease. Nature Reviews Microbiology. 2020;19(1):55-71. doi:10.1038/s41579-020-0433-9

399. Arumugam M, Raes J, Pelletier E, et al. Enterotypes of the human gut microbiome. Nature. 2011;473(7346):174-180. doi:10.1038/ nature09944
400. Lynch SV, Phimister EG, Pedersen O. The human intestinal microbiome in health and disease. N. Engl. J. Med. 2016;375 (24):2369-2379. doi:10.1056/NEJMra1600266

401. Almeida A, Mitchell AL, Boland M, et al. A new genomic blueprint of the human gut microbiota. Nature. 2019;568 (7753):499-504. doi:10.1038/s41586-019-0965-1

402. Hasan N, Yang H. Factors affecting the composition of the gut microbiota, and its modulation. PeerJ. 2019;7:e7502. doi:10.7717/ peerj. 7502

403. Tyakht AV, Kostryukova ES, Popenko AS, et al. Human gut microbiota community structures in urban and rural populations in Russia. Nature Communications. 2013;4(1):2469. doi:10.1038/ ncomms 3469

404. Wilson AS, Koller KR, Ramaboli MC, et al. Diet and the human gut microbiome: an international review. Dig Dis Sci. 2020;65 (3):723-740. doi:10.1007/s10620-020-06112-w

405. Aziz Q, Doré J, Emmanuel A, Guarner F, Quigley EMM. Gut microbiota and gastrointestinal health: current concepts and future directions. Neurogastroenterol Motil. 2013;25(1):4-15. doi:10.1111/ nmo. 12046

406. Jandhyala SM. Role of the normal gut microbiota. World J Gastroenterol. 2015;21(29):8787. doi:10.3748/wjg.v21.i29.8787

407. Krishnan S, Alden N, Lee K. Pathways and functions of gut microbiota metabolism impacting host physiology. Curr Opin Biotechnol. 2015;36:137-145. doi:10.1016/j.copbio.2015.08.015

408. Marchesi JR, Adams DH, Fava F, et al. The gut microbiota and host health: a new clinical frontier. Gut. 2016;65(2):330-339. doi:10.1136/gutjnl-2015-309990

409. Plaza-Diaz J, Ruiz-Ojeda FJ, Gil-Campos M, Gil A. Mechanisms of action of probiotics. Adv. Nutr. 2019;10(suppl_1):49-66. doi:10.1093/advances/nmy063

410. Blaak EE, Canfora EE, Theis S, et al. Short chain fatty acids in human gut and metabolic health. Benef Microbes. 2020;11 (5):411-455. doi:10.3920/bm2020.0057

411. Evans JM, Morris LS, Marchesi JR. The gut microbiome: the role of a virtual organ in the endocrinology of the host. $J$ Endocrinol. 2013;218(3):37-47. doi:10.1530/joe-13-0131

412. Clarke G, Stilling RM, Kennedy PJ, Stanton C, Cryan JF, Dinan TG. Minireview: gut microbiota: the neglected endocrine organ. Mol Endocrinol. 2014;28(8):1221-1238. doi:10.1210/me.2014-1108

413. Sharma L, Riva A. Intestinal barrier function in health and disease - any role of SARS-CoV-2? Microorganisms. 2020;8(11):1744. doi:10.3390/microorganisms 8111744

414. Yang Y, Huang W, Fan Y, Chen G-Q. Gastrointestinal microenvironment and the gut-lung axis in the immune responses of severe COVID-19. Front Mol Biosci. 2021;8:647508. doi:10.3389/fmolb.2021.647508

415. Lopes RCSO, Balbino KP, Jorge MP, Ribeiro AQ, Martino HSD, Alfenas RCG. Modulation of intestinal microbiota, control of nitrogen products and inflammation by pre/probiotics in chronic kidney disease: a systematic review. Nutr. Hosp. 2018;35 (3):722-730. doi:10.20960/nh.1642

416. Plata C, Cruz C, Cervantes LG, Ramírez V. The gut microbiota and its relationship with chronic kidney disease. Int. Urol. Nephrol. 2019;51(12):2209-2226. doi:10.1007/s11255-01902291-2

417. Tao S, Tao S, Cheng Y, Liu J, Ma L, Fu P. Effects of probiotic supplements on the progression of chronic kidney disease: a meta-analysis. Nephrology. 2019;24(11):1122-1130. doi:10.1111/nep.13549

418. Fontana L, Plaza-Diaz J, Robles-Bolivar P, et al. Bifidobacterium breve CNCM I-4035, Lactobacillus paracasei CNCM I-4034 and Lactobacillus rhamnosus CNCM I-4036 modulate macrophage gene expression and ameliorate damage markers in the liver of Zucker-Lepr(fa/ fa) rats. Nutrients. 2021;13(1):202. doi:10.3390/ Nu13010202 
419. Tunapong W, Apaijai N, Yasom S, et al. Chronic treatment with prebiotics, probiotics and synbiotics attenuated cardiac dysfunction by improving cardiac mitochondrial dysfunction in male obese insulin-resistant rats. Eur J Nutr. 2017;57(6):2091-2104. doi:10.1007/s00394-017-1482-3

420. Bermudez-Humaran LG, Salinas E, Ortiz GG, Ramirez-Jirano LJ, Morales JA, Bitzer-Quintero OK. From probiotics to psychobiotics: live beneficial bacteria which act on the brain-gut axis. Nutrients. 2019;11(4):890. doi:10.3390/Nu11040890

421. Lew L-C, Hor -Y-Y, Yusoff NAA, et al. Probiotic Lactobacillus plantarum $\mathrm{P} 8$ alleviated stress and anxiety while enhancing memory and cognition in stressed adults: a randomised, double-blind, placebo-controlled study. Clin. Nutr. 2019;38(5):2053-2064. doi:10.1016/j.clnu.2018.09.010

422. Ruiz-Gonzalez C, Roman P, Rueda-Ruzafa L, RodriguezArrastia M, Cardona D. Effects of probiotics supplementation on dementia and cognitive impairment: a systematic review and meta-analysis of preclinical and clinical studies. Prog. Neuropsychopharmacol. Biol. Psychiatry. 2021;108:110189. doi:10.1016/j.pnpbp.2020.110189

423. Toral M, Romero M, Rodríguez-Nogales A, et al. Lactobacillus fermentum improves tacrolimus-induced hypertension by restoring vascular redox state and improving eNOS coupling. Mol. Nutr. Food Res. 2018;62(14):1800033. doi:10.1002/ mnfr.201800033

424. Toral M, Gómez-Guzmán M, Jiménez R, et al. The probiotic Lactobacillus coryniformis CECT5711 reduces the vascular pro-oxidant and pro-inflammatory status in obese mice. Clin. Sci. 2014;127(1):33-45. doi:10.1042/cs20130339

425. Mogotsi MT, Mwangi PN, Bester PA, et al. Metagenomic analysis of the enteric RNA virome of infants from the Oukasie clinic, North West province, South Africa, reveals diverse eukaryotic viruses. Viruses. 2020;12(11):1260. doi:10.3390/v12111260

426. Gregory AC, Zablocki O, Zayed AA, Howell A, Bolduc B, Sullivan MB. The gut virome database reveals age-dependent patterns of virome diversity in the human gut. Cell Host Microbe. 2020;28(5):724-740. doi:10.1016/j.chom.2020.08.003

427. Hidalgo-Cantabrana C, Sanozky-Dawes R, Barrangou R. Insights into the human virome using CRISPR spacers from microbiomes. Viruses. 2018;10(9):479. doi:10.3390/v10090479

428. Burmistrz M, Krakowski K, Krawczyk-Balska A. RNA-targeting CRISPR-Cas systems and their applications. Int $J$ Mol Sci. 2020;21(3):1122. doi:10.3390/ijms21031122

429. Toyofuku M, Nomura N, Eberl L. Types and origins of bacterial membrane vesicles. Nature Reviews Microbiology. 2018;17 (1):13-24. doi:10.1038/s41579-018-0112-2

430. Kalluri R, LeBleu VS. The biology, function, and biomedical applications of exosomes. Science. 2020;367(6478):eaau6977. doi:10.1126/science.aau6977

431. Macia L, Nanan R, Hosseini-Beheshti E, Grau GE. Host- and microbiota-derived extracellular vesicles, immune function, and disease development. Int J Mol Sci. 2019;21(1):107. doi:10.3390/ ijms21010107

432. Zhang Y, Bi J, Huang J, Tang Y, Du S, Li P. Exosome: a review of its classification, isolation techniques, storage, diagnostic and targeted therapy applications. Int $J$ Nanomedicine. 2020;15:6917-6934. doi:10.2147/ijn.s264498

433. Taghinezhad SS, Mohseni AH, Bermudez-Humaran LG, et al. Probiotic-based vaccines may provide effective protection against COVID-19 acute respiratory disease. Vaccines (Basel). 2021;9 (5):466. doi:10.3390/vaccines 9050466

434. Dyakov IN, Mavletova DA, Chernyshova IN, et al. FN3 protein fragment containing two type III fibronectin domains from B. longum GT15 binds to human tumor necrosis factor alpha in vitro. Anaerobe. 2020;65:102247. doi:10.1016/j.anaerobe. 2020.102247
435. Veselovsky VA, Dyachkova MS, Menyaylo EA, et al. Gene networks underlying the resistance of Bifidobacterium longum to inflammatory factors. Front Immunol. 2020;11:595877. doi:10.3389/fimmu.2020.595877

436. Hmood KA, Habeeb AH, Al-Mhnna KI. Antioxidant role of Lactobacillus $\mathrm{sp}$ isolated from honey bee against histological effects of ochratoxin in vivo. Al-Kufa University Journal for Biology. 2019;11(2):67-80.

437. Kešnerová L, Emery O, Troilo M, Liberti J, Erkosar B, Engel P. Gut microbiota structure differs between honeybees in winter and summer. ISME J. 2020;14(3):801-814. doi:10.1038/s41396-0190568-8

438. Ignasiak K, Maxwell A. Antibiotic-resistant bacteria in the guts of insects feeding on plants: prospects for discovering plant-derived antibiotics. BMC Microbiol. 2017;17(1):223. doi:10.1186/s12866017-1133-0

439. Ellegaard KM, Engel P. Genomic diversity landscape of the honey bee gut microbiota. Nature Communications. 2019;10 (1):446. doi:10.1038/s41467-019-08303-0

440. Iorizzo M, Testa B, Ganassi S, et al. Probiotic properties and potentiality of Lactiplantibacillus plantarum strains for the biological control of chalkbrood disease. Journal of Fungi. 2021;7 (5):379. doi:10.3390/jof7050379

441. Pan D, Mei X. Antioxidant activity of an exopolysaccharide purified from Lactococcus lactis subsp. lactis 12. Carbohydr. Polym. 2010;80(3):908-914. doi:10.1016/j.carbpol.2010.01.005

442. D'Alvise P, Böhme F, Codrea MC, et al. The impact of winter feed type on intestinal microbiota and parasites in honey bees. Apidologie. 2017;49(2):252-264. doi:10.1007/s13592-017-0551-1

443. Wang X, Zhong Z, Chen X, et al. High-fat diets with differential fatty acids induce obesity and perturb gut microbiota in honey bee. Int J Mol Sci. 2021;22(2):834. doi:10.3390/ijms22020834

444. Honey Chandran C, Keerthi TR. Probiotic potency of Lactobacillus plantarum KX519413 and KX519414 isolated from honey bee gut. FEMS Microbiol Lett. 2018;4(365):1-8. doi:10.1093/femsle/fnx285

445. Kenfack HMC, Ngoufack ZF, Kaktcham MP, Wang RY, Zhu T, Yin L. Safety and antioxidant properties of five probiotic Lactobacillus plantarum strains isolated from the digestive tract of honey bees. American Journal of Microbiological Research. 2018;6(1):1-8. doi:10.12691/ajmr-6-1-1

446. Niode N, Salaki C, Rumokoy L, Tallei T Lactic acid bacteria from honey bees digestive tract and their potential as probiotics. In: Buchori D, ed. International Conference and the 10th Congress of the Entomological Society of Indonesia. Series Advances in Biological Sciences Research. 8. Indonesia: Atlantis Press SARL; 2020:236-241.

447. Todorov SD, Tagg JR, Ivanova IV. Could Probiotics and Postbiotics Function as "Silver Bullet" in the Post-COVID-19 Era? Probiotics and Antimicrobial Proteins. 2021;1:1-9. doi:10.1007/s12602-021-09833-0

448. Salminen S, Collado MC, Endo A, et al. The International Scientific Association of Probiotics and Prebiotics (ISAPP) consensus statement on the definition and scope of postbiotics. Nat. Rev. Gastroenterol. Hepatol. 2021;18(9):649-667. doi:10.1038/ s41575-021-00440-6

449. Xu C, Qiao L, Guo Y, Ma L, Cheng Y. Preparation, characteristics and antioxidant activity of polysaccharides and proteins-capped selenium nanoparticles synthesized by Lactobacillus casei ATCC 393. Carbohydr. Polym. 2018;195:576-585. doi:10.1016/j. carbpol.2018.04.110

450. Molina-Tijeras JA, Galvez J, Rodriguez-Cabezas ME. The Immunomodulatory Properties of Extracellular Vesicles Derived from Probiotics: a Novel Approach for the Management of Gastrointestinal Diseases. Nutrients. 2019;11(5):1038. doi:10.3390/nu11051038 
451. Nishiyama K, Takaki T, Sugiyama M, et al. Extracellular Vesicles Produced by Bifidobacterium longum Export Mucin-Binding Proteins. Appl Environ Microbiol. 2020;86(19):e01464-01420. doi:10.1128/AEM.01464-20

452. Dixit Y, Wagle A, Vakil B. Patents in the Field of Probiotics, Prebiotics, Synbiotics: a Review., 01(02). Journal of Food: Microbiology, Safety \& Hygiene. 2016;01(02):1000111. doi:10.4172/2476-2059.1000111

453. Rani A, Saini KC, Bast F, et al. Microorganisms: a Potential Source of Bioactive Molecules for Antioxidant Applications. Molecules. 2021;26(4):1142. doi:10.3390/molecules26041142

454. Sleator RD, Hill C. Engineered pharmabiotics with improved therapeutic potential. Human vaccines. 2008;4(4):271-274. doi:10.4161/hv.4.4.6315
455. Sleator RD, Hill C. Rational design of improved pharmabiotics. $J$ Biomed Biotechnol. 2009;2009:275287. doi:10.1155/2009/275287

456. Shanahan F, Collins SM. Pharmabiotic manipulation of the microbiota in gastrointestinal disorders, from rationale to reality. Gastroenterol Clin North Am. 2010;39(3):721-726. doi:10.1016/ j.gtc.2010.08.006

457. Maria Remes Troche J, Coss Adame E, Angel Valdovinos Diaz M, et al. Lactobacillus acidophilus LB: a useful pharmabiotic for the treatment of digestive disorders. Therap Adv Gastroenterol. 2020;13:1756284820971201. doi:10.1177/1756284820971201

\section{Publish your work in this journal}

The Journal of Inflammation Research is an international, peerreviewed open-access journal that welcomes laboratory and clinical findings on the molecular basis, cell biology and pharmacology of inflammation including original research, reviews, symposium reports, hypothesis formation and commentaries on: acute/chronic inflammation; mediators of inflammation; cellular processes; molecular mechanisms; pharmacology and novel anti-inflammatory drugs; clinical conditions involving inflammation. The manuscript management system is completely online and includes a very quick and fair peerreview system. Visit http://www.dovepress.com/testimonials.php to read real quotes from published authors.

Submit your manuscript here: https://www.dovepress.com/journal-of-inflammation-research-journal 